\title{
A Comparison of Modifications to MELCOR Versions 1.8.2 and 1.8.6 for ITER Safety Analysis
}

Brad J. Merrill

Paul W. Humrickhouse

Richard L. Moore

June 2010

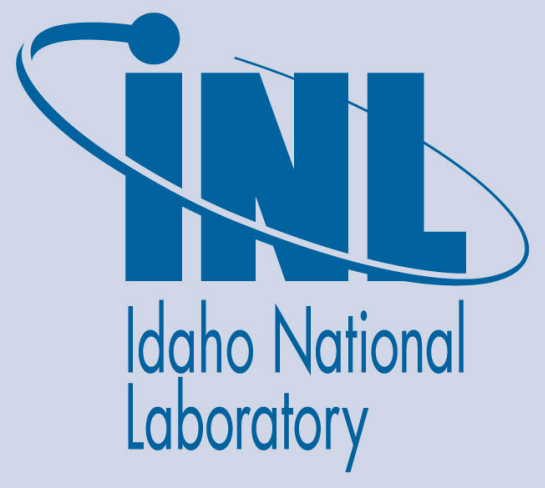

The INL is a U.S. Department of Energy National Laboratory operated by Battelle Energy Alliance 
INL/EXT-09-16715

\title{
A Comparison of Modifications to MELCOR Versions 1.8.2 and 1.8.6 for ITER Safety Analysis
}

\author{
Brad J. Merrill \\ Paul W. Humrickhouse \\ Richard L. Moore
}

June 2010

\begin{abstract}
Idaho National Laboratory
Fusion Safety Program

Thermal Sciences and Safety Analysis Department Idaho Falls, Idaho 83415

htto://www.inl.aov
\end{abstract}

Prepared for the

U.S. Department of Energy

Office of Science

Under DOE Idaho Operations Office

Contract DE-AC07-05ID14517 


\section{NOTICE}

This information was prepared as an account of work sponsored by an agency of the U.S. Government. Neither the U.S. Government nor any agency thereof, nor any of their employees, makes any warranty, express or implied, or assumes any legal liability or responsibility for any third party's use, or the results of such use, of any information, apparatus, product, or process disclosed herein, or represents that its use by such third party would not infringe privately owned rights. The views expressed herein are not necessarily those of the U.S. Nuclear Regulatory Commission. 


\begin{abstract}
The INL Fusion Safety Program (FSP) has previously made a number of additions and modifications to MELCOR 1.8.2 for use in fusion safety analyses. The standard version of MELCOR continues to be developed at Sandia National Laboratory (SNL), and many improvements were made between versions 1.8.2 and 1.8.6. The INL modifications have been introduced to MELCOR 1.8.6, and a comparison of this new version with the prior pedigreed version (1.8.2) is the subject of this report.

The codes are compared on the same problems used in the MELCOR 1.8.2 pedigree process. These first of these is a non-regression analysis which involves comparing the results from the modified version of MELCOR 1.8.6 against those predicted by the original, unmodified version of MELCOR 1.8.6. The modified MELCOR 1.8.6 is then compared with the pedigreed version of MELCOR 1.8.2 on a series of accident problems analyzed in the Generic Site Safety Report (GSSR), and a set of simple test problems designed specifically to test added and modified features. Satisfactory agreement is found between both versions of the code.
\end{abstract}




\title{
ACRONYMS
}

\author{
EOS Equation of State \\ FSP Fusion Safety Program \\ FW First Wall \\ GSSR Generic Site Safety Report \\ HTS Heat Transport System \\ INL Idaho National Laboratory \\ IO International Organization \\ IT International Team \\ ITER International Thermonuclear Experimental Reactor \\ FEAT Fusion Energy Advanced Tokamak \\ JCT Joint Central Team \\ NRC Nuclear Regulatory Commission \\ PFC Plasma Facing Component \\ PHTS Primary Heat Transport System \\ RPrS Rapport Preliminaire du Surete (Preliminary Safety Report) \\ SNL Sandia National Laboratory \\ SS Stainless Steel \\ TCWS Tokamak Cooling Water System \\ VV Vacuum Vessel
}




\section{CONTENTS}

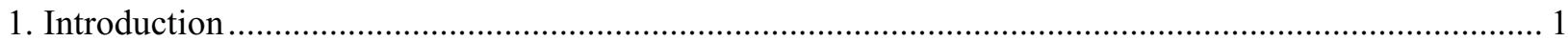

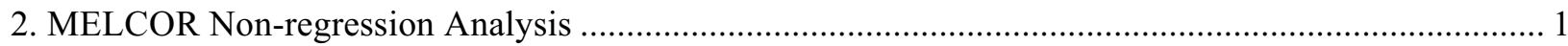

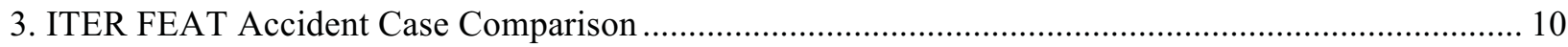

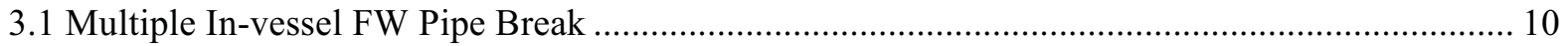

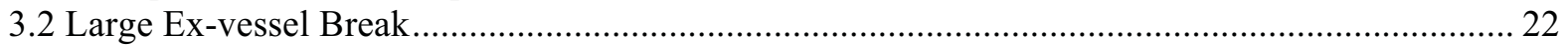

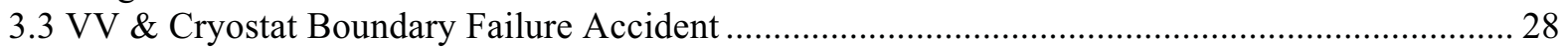

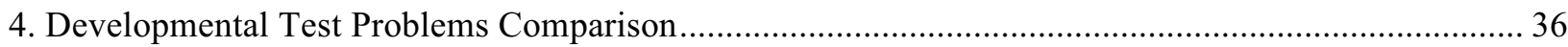

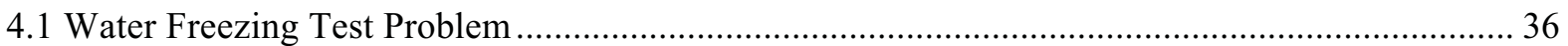

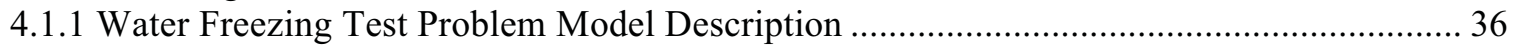

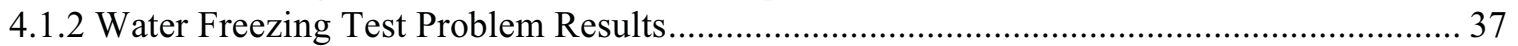

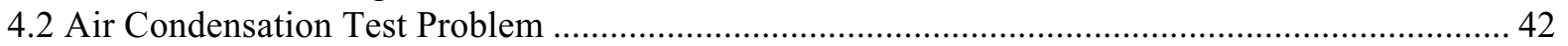

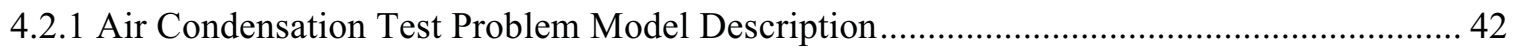

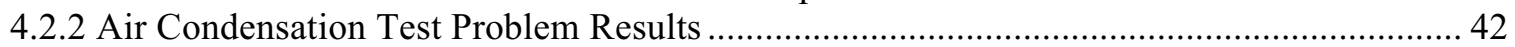

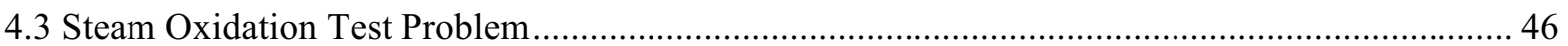

4.3.1 Steam Oxidation Test Problem Results for Beryllium .................................................... 47

4.3.2 Steam Oxidation Test Problem Results for Tungsten ........................................................ 49

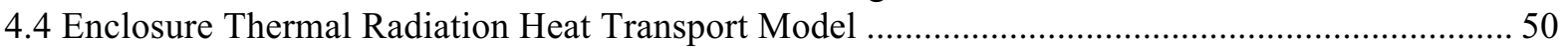

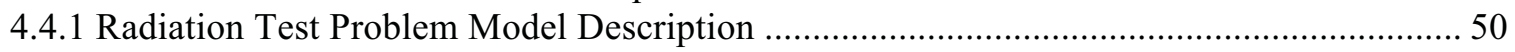

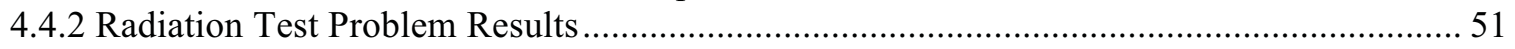

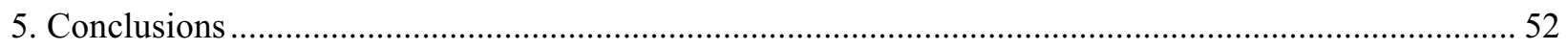

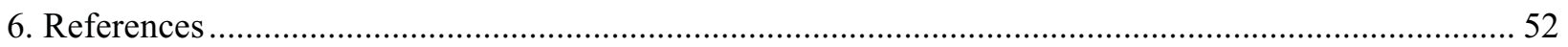




\section{A Comparison of Modifications to MELCOR Versions 1.8.2 and 1.8.6 for ITER Safety Analysis}

\section{Introduction}

During the Engineering Design Activity of the International Thermonuclear Experimental Reactor (ITER), the MELCOR 1.8.2 code was selected as one of several codes to be used to perform ITER safety analyses [1]. MELCOR was chosen because it has the capability of predicting coolant pressure, temperature, mass flow rate, and radionuclide and aerosol transport in nuclear facilities and reactor cooling systems. MELCOR can also predict structural temperatures (e.g. first wall, blanket, divertor, and vacuum vessel) resulting from energy produced by radioactive decay heat and/or chemical reactions (oxidation). The Idaho National Laboratory (INL) Fusion Safety Program (FSP) made fusion specific modifications to the MELCOR 1.8.2 code [2-6], including models for water freezing, air condensation, beryllium, carbon, and tungsten oxidation in steam and air environments, flow boiling in coolant loops, and radiative heat transfer in enclosures, that allowed MELCOR to assess the thermal hydraulic response of ITER cooling systems and the transport of radionuclides as aerosols during accident conditions. Recently, the ITER International Organization (IO) used a "pedigreed" version of MELCOR 1.8.2 $\left.{ }^{7}\right]$ to perform accident analyses for ITER's "Rapport Préliminaire de Sûreté" (Report Preliminary on Safety - RPrS).

The MELCOR thermal-hydraulics code [8] is currently under development at the Sandia National Laboratory (SNL) for the US Nuclear Regulatory Commission (NRC). MELCOR is used to model the progression of severe accidents in light water fission reactors.

Because MELCOR has undergone many improvements between version 1.8.2 and 1.8.6, the INL FSP decided to introduce fusion modifications into MELCOR 1.8.6, and thereby produce a version of MELCOR 1.8.6 with similar capabilities to the pedigreed version of MELCOR 1.8.2 used for the ITER RPrS. We have applied this version of MELCOR 1.8.6 to the same set of problems used in the MELCOR 1.8.2 pedigree analysis [7].

Section 2 describes a non-regression analysis that involves comparing the results from the modified version of MELCOR 1.8.6 against those predicted by the original, unmodified version of MELCOR 1.8.6. The purpose of this non-regression analysis is to demonstrate that the modifications made to the MELCOR 1.8.6 code do not drastically alter the intended functions of the MELCOR base code, and if they do to explain why the departure occurs and if the change is needed. The analysis was performed using the demonstration problem that came with the MELCOR 1.8.6 source distribution.

Section 3 makes a comparison between the pedigreed version of MELCOR 1.8.2 and the new modified version of MELCOR 1.8.6 on a set of accident problems used by the ITER Joint Central Team (JCT) in the Generic Site Safety Report (GSSR) [9].

Finally, in section 4 , the two versions of the code are compared on a series of developmental test problems described in the change documents $[2-4,6]$.

\section{MELCOR Non-regression Analysis}

A non-regression analysis was performed to ensure that the modifications made to MELCOR 1.8.6 for fusion do not significantly degrade the accuracy or performance of the MELCOR 1.8.6 code. The problem selected for this analysis was the demonstration problem that comes as part of the MELCOR 1.8.6 distribution files. 
This demonstration problem is designed to exercise all of the MELCOR physics packages in a single transient calculation. While this problem does not activate every single option available in MELCOR, it does activate each of the 16 physics packages available in the code that are used to simulate fluid flow, heat transfer, core disassembly, cavity debris formation, hydrogen burn, aerosol transport, and decay heat production, just to name a few. The sample problem is a simple model of a fission reactor plant. The accident being analyzed is a severe loss-of-flow accident. The model contains 8 fluid cells, 11 flow paths, and 12 heat structures, 30 core elements and one cavity region, which collectively represent a fission reactor and its containment building. As such, this model is not intended to represent any real fission reactor system nor is it recommended for that purpose by the MELCOR developers.

The MELCOR developers also note, by comments in this MELCOR input deck, that because of the lack of detail in this model, the results are both time-step size and convergence tolerance dependent. As a result, for this analysis the demonstration input deck was changed to give a maximum time-step of 0.1 seconds for the first $1 \times 10^{4} \mathrm{~s}$, after which time the maximum time-step size was increased to $1.0 \mathrm{~s}$. In addition, the convergence tolerances for fluid temperature, fluid pressure, and heat structure surface temperature, film mass, and boiling heat transfer were reduced to $1 \times 10^{-7}, 1 \times 10^{-6}, 5 \times 10^{-6}, 5 \times 10^{-4}$, and $1 \times 10^{-4}$ from the default values of $1 \times 10^{-6}, 2 \times 10^{-5}, 5 \times 10^{-4}, 1 \times 10^{-2}$, and $5 \times 10^{-2}$, respectively.

Figures 1 through 3 contain predicted surface temperatures of heat structures that represent the drywell concrete floor, a reactor shroud, and a reactor shroud ring. These figures contain predictions from both the original and modified versions of the MELCOR 1.8.6 code. As can be seen, the predicted temperature histories for these heat structures are in excellent agreement for the drywell floor and reactor shroud ring, with a slight deviation in the predicted reactor shroud temperature, resulting in a maximum temperature that is $\sim 100 \mathrm{~K}$ higher for the fusion version than the standard version of MELCOR. As mentioned in Reference [7], this deviation is primarily due to three modifications made to MELCOR 1.8.6 for the fusion version. These modifications are: the addition of a boiling heat transfer subroutine for internal flow, changes to the binary diffusion coefficient formulas used by subroutines HSDMTC and MPVIS [2], and changes to the aerosol transport subroutine RN1RN4 [3].

The internal flow boiling heat transfer subroutine provides a capability not previously available in MELCOR. This capability is required for a more accurate modeling of the heat transfer conditions of fusion reactor high heat flux components, such as the divertor, during normal operation or accident conditions. The diffusion coefficient evaluated in HSDMTC is used by MELCOR to estimate the rate of steam condensation on any given heat structure. This condensation model is based on the diffusion of the steam through a noncondensable gas boundary layer at the surface of the heat structure. The estimated mass transfer rate coefficient from this model is not only used to determine steam condensation, but is also used by MELCOR in the core physics package to predict the rate of heat structure surface oxidation, provided the surface is composed of a material for which oxidation equations are available in MELCOR. In the original version of the MELCOR code, the non-condensable boundary layer gas is always assumed to be air. In the modified version this assumption is removed, and the actual time-dependent gas composition next to the heat structure, as calculated by the code, is used to define the boundary layer composition. In subroutine MPVIS the original binary diffusion coefficient correlation was modified to give what some authors feel to be a more accurate formulation then the original correlation. The changes to RN1RN4 deal primarily with the aerosol deposition kernels, which where modified to reflect the actual time-dependent gas composition in a given volume, instead of assuming the aerosol are always settling through air, as in the original version of the code.

The impact these changes have on code predictions can be seen in Figure 4, which gives the reactor core vapor temperature predicted by the original, or standard, version of MELCOR 1.8.6 and the version modified by the INL for fusion applications. After $1 \times 10^{4}$ seconds, the prediction temperatures vary dramatically, with the modified version of MELCOR 1.8.6 predicting a temperature that reaches $\sim 3100 \mathrm{~K}$. With the use of an interactive debugger, it was discovered that this divergence is due to the timing of radioactive aerosol release from the reactor fuel into the core coolant volume. In the case of the original code this release appears to 
occur when the core still contains some liquid water, where as in the case of the modified code's prediction this release occurs when that water is primarily vapor.

To investigate which modifications have caused this divergence, code modifications were removed one at a time and the resulting temperature prediction compared to the original code's prediction. The results appear in Figures 5a through 5c. In each figure a different modification to the code was reversed. In Figure 5a, the aerosol modifications were reversed to the standard aerosol package of MELCOR 1.8.6. In Figure 5b, the binary diffusion coefficient correlation in MPVIS was restored to the original correlation in addition to the reversal of the aerosol modifications. In Figure 5c, the predicted core vapor temperature is given by the original boiling heat transfer subroutine, and the binary diffusion coefficient used for condensation is the original correlation for diffusion of steam in air, in addition to the two previous modification reversals. The surprising result is that the reversal of the first two modifications resulted in better agreement between the original and modified version than when the third modification reversal was made. In fact, when the boiling heat transfer subroutine was removed and the binary diffusion coefficient used in boundary layer mass transfer was reversed the maximum core vapor temperature reaches a new high of $\sim 4250 \mathrm{~K}$.

This result prompted the systematic removing and replacing of all of the remaining modifications, one at a time, and viewing the results with the aide of an interactive debugger until the appropriate modification was identified. It turned out to be seven lines of FORTRAN coding which had been commented out in subroutine CVTNEQ for the modified version of MELCOR. When this change was reversed, the results appear in Figure $5 \mathrm{~d}$, where there is now exact agreement between the original and modified versions of MELCOR 1.8.6. Subroutine CVTNEQ is used by MELCOR to calculate vapor and liquid temperatures in a given control volume for which the user has requested a non-equilibrium thermodynamic treatment of the water within that volume. In this case, separate vapor and liquid temperatures are determined iteratively based on the calculated vapor and liquid energies, masses, and an Equation of State (EOS) for water. This procedure iteratively adjusts the sub-volumes occupied by each phase (the sum of which equals the total volume for that cell) until the pressures returned from the EOS are equal for both phases. The section of coding commented out resides within this iteration process and artificially transfers energy between the vapor and liquid phases to prevent freezing of one of these phase during this iterative process.

Figure 6 contains a comparison between the original and modified versions of MELCOR 1.8.6 for the predicted core pressure. The agreement is very good. Figure 7 shows a similar comparison for the wetwell. While the initial trends are in good agreement prior to $\sim 7500 \mathrm{~s}$, in order to obtain complete agreement the four modifications mentioned above had to be reversed. The same could be said of the predicted reactor core steel mass and cavity debris that appear in Figures 8 and 9.

Figures 10 and 11 contain the predicted core hydrogen and aerosol release for this demonstration problem. Good agreement between the original and modified code versions was obtained even without reversing any of the fusion modifications. However, to obtain the same level of agreement for the aerosol mass release, the modifications to the aerosol package had to be reversed. This is as one would anticipate since the aerosol settling rate in steam would be faster than in air due to the lower viscosity. Settling rates are calculated with properties of air in the standard MELCOR aerosol package, even when settling through steam or other gases.

In summary, a non-regression analysis has been performed with the modified version of MELCOR 1.8.6 for fusion by using the demonstration problem that is included with the MELCOR 1.8.6 distribution. The modifications that most impact the predictions were identified and the influence of these modifications presented. While differences have been identified, in each case the modifications identified are required to address fusion specific requirements. This also includes the freezing of steam on cryogenic surfaces and the freezing of water droplets in high vacuums, both of which are experimentally observed phenomena [5]. At this time there is still an issue that needs to be resolved regarding the impact of the artificial energy transfer process in subroutine CVTNEQ on predicted temperatures of the MELCOR demonstration problem. 


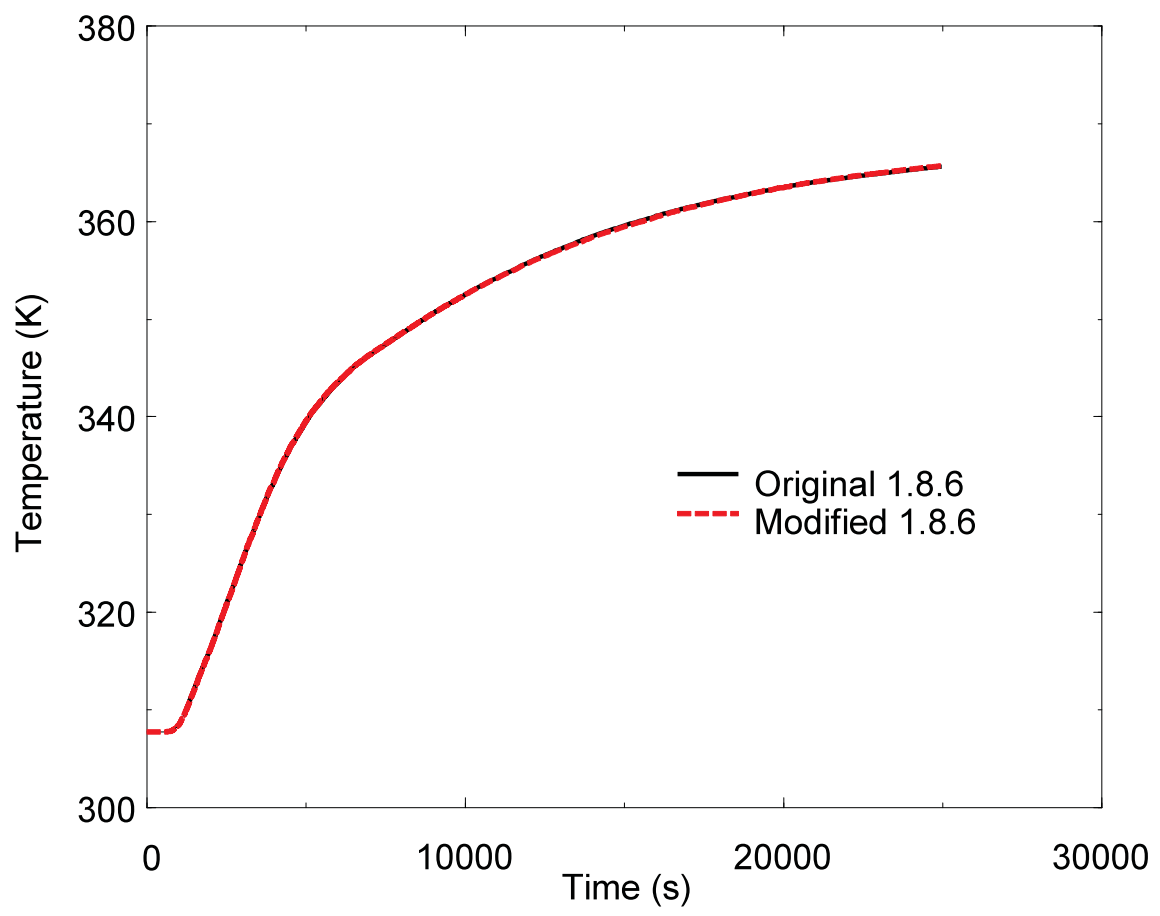

Figure 1. Drywell concrete floor surface temperature comparison for the demonstration problem sent with the MELCOR 1.8.6 source distribution.

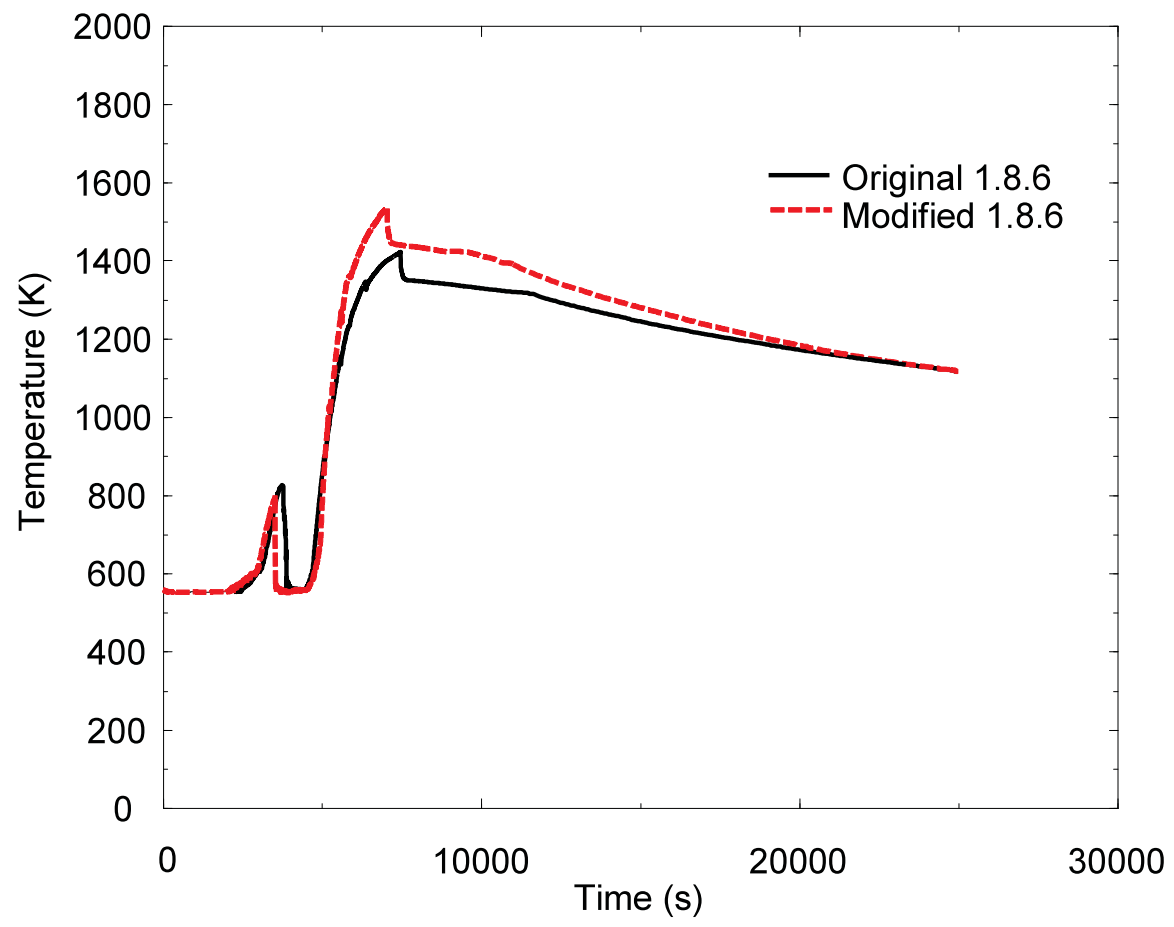

Figure 2. Reactor shroud surface temperature comparison for the demonstration problem sent with the MELCOR 1.8.6 source distribution. 


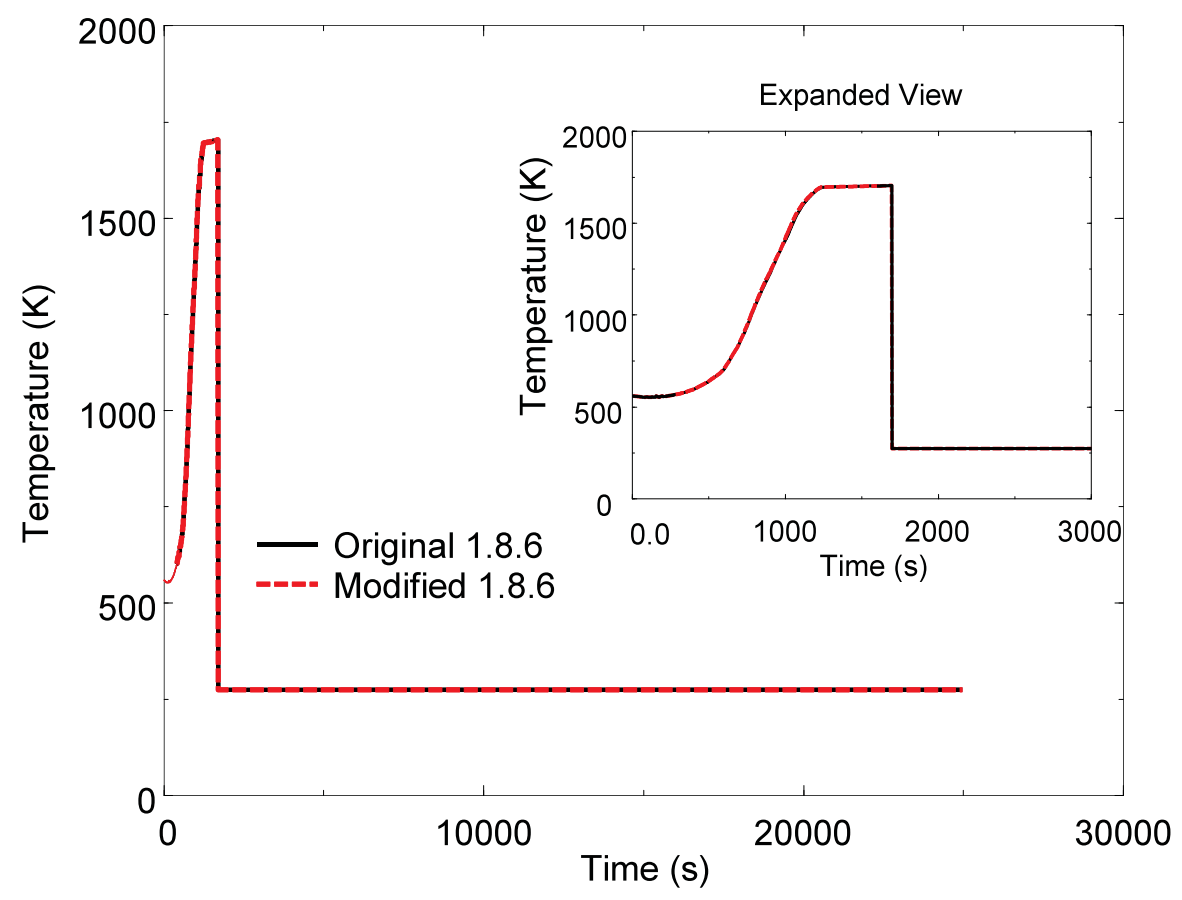

Figure 3. Shroud ring temperature comparison for the demonstration problem sent with the MELCOR 1.8.6 source distribution.

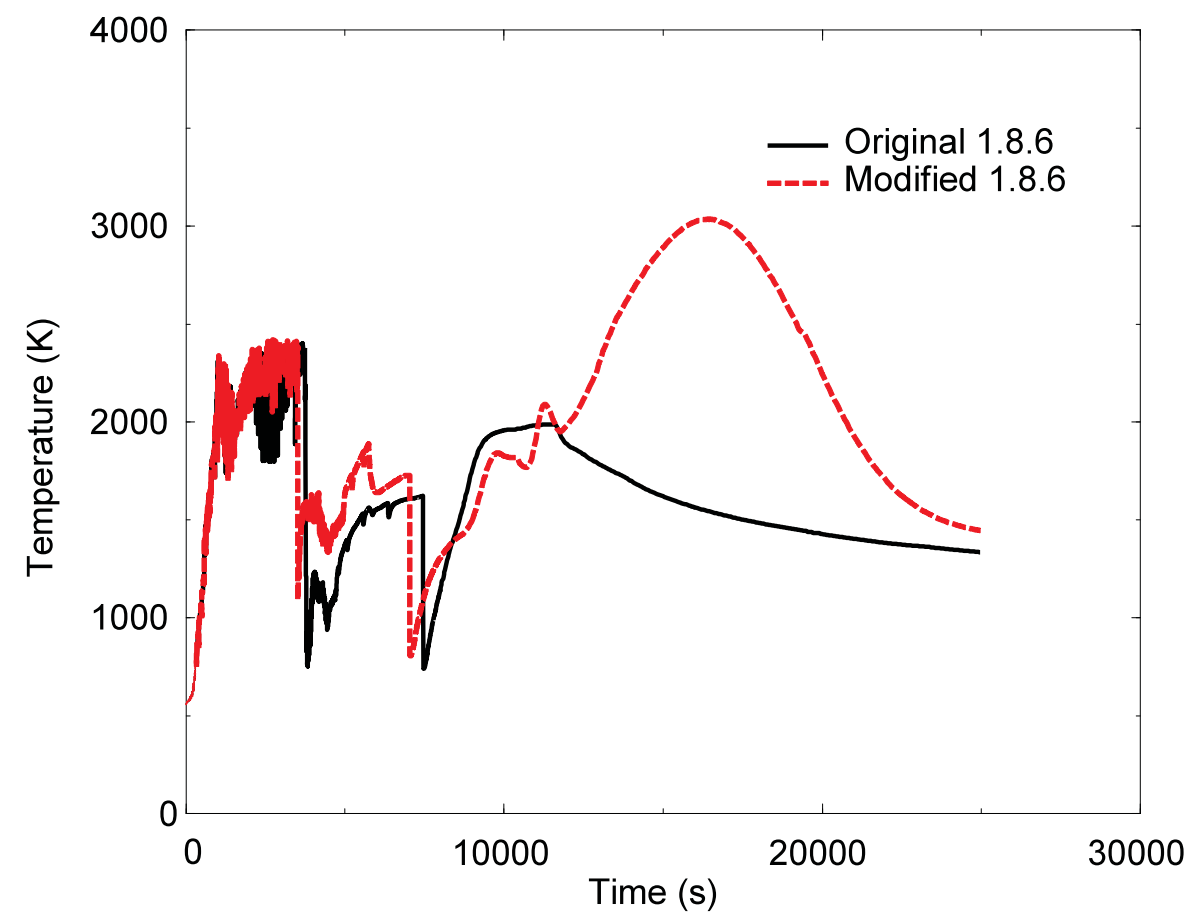

Figure 4. Reactor core vapor temperature comparison for the demonstration problem sent with the MELCOR 1.8.6 source distribution. 


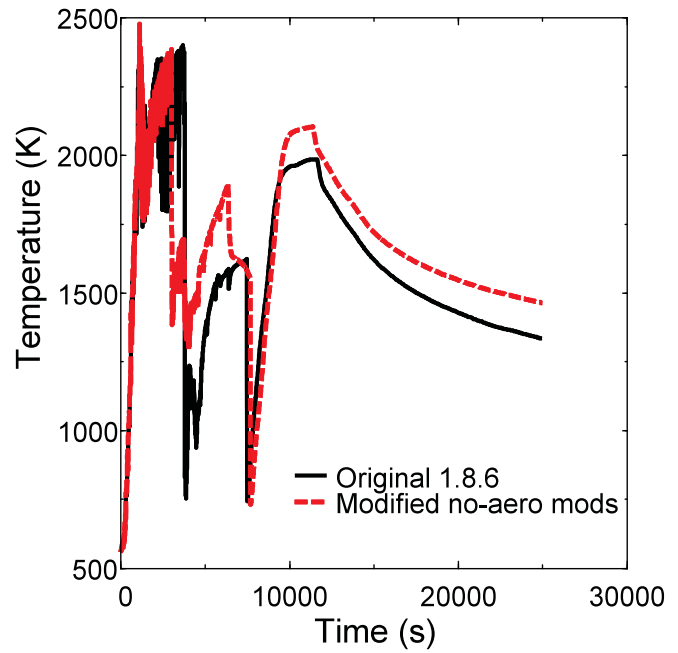

(a)

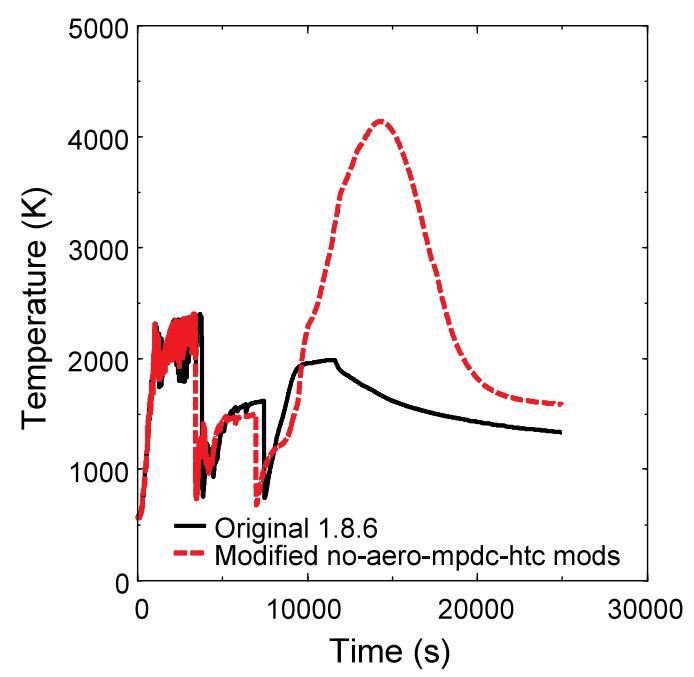

(c)

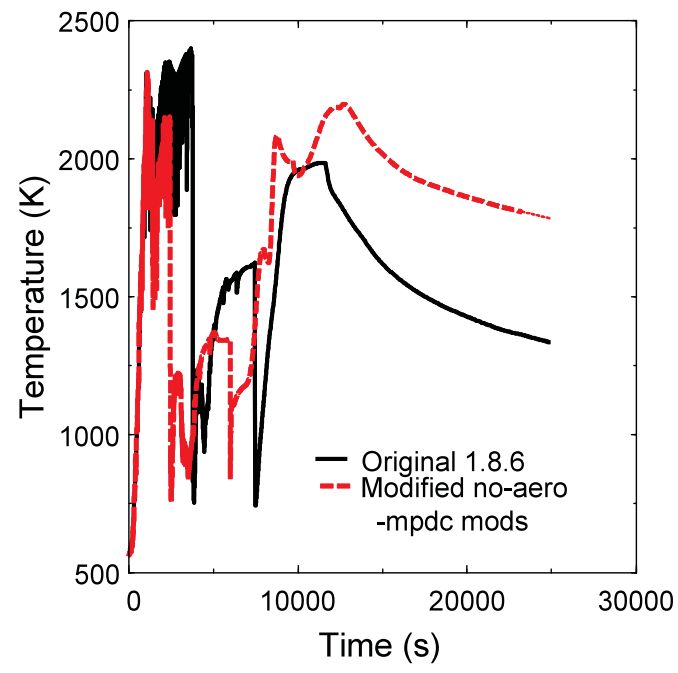

(b)

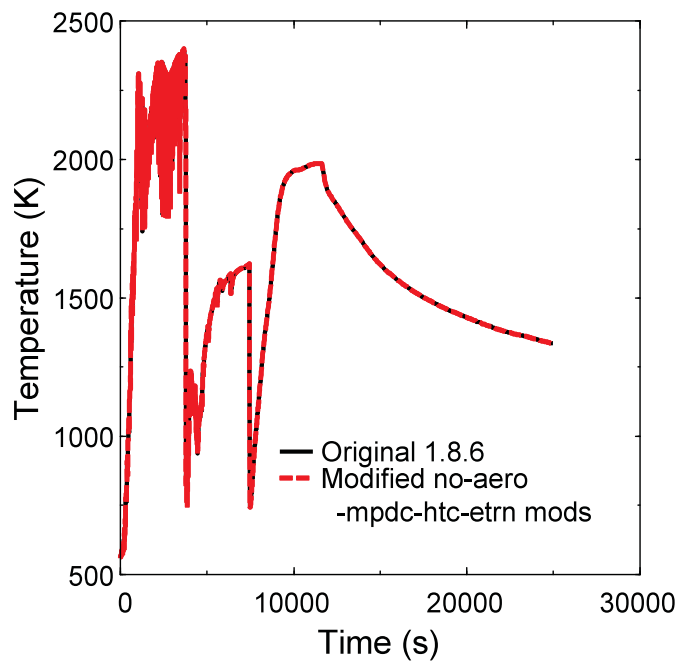

(d)

Figure 5. Impact on predicted reactor core vapor temperature of removing modifications in (a) aerosol package subroutine RN1RN4, (b) plus diffusion coefficient correlation in material properties package subroutine MPVIS, (c) plus boiling heat transfer correlation and diffusion coefficient in heat transfer package subroutine HSTRAN, and (d) plus artificial energy transfer in equation of state package subroutine CVTNEQ. 


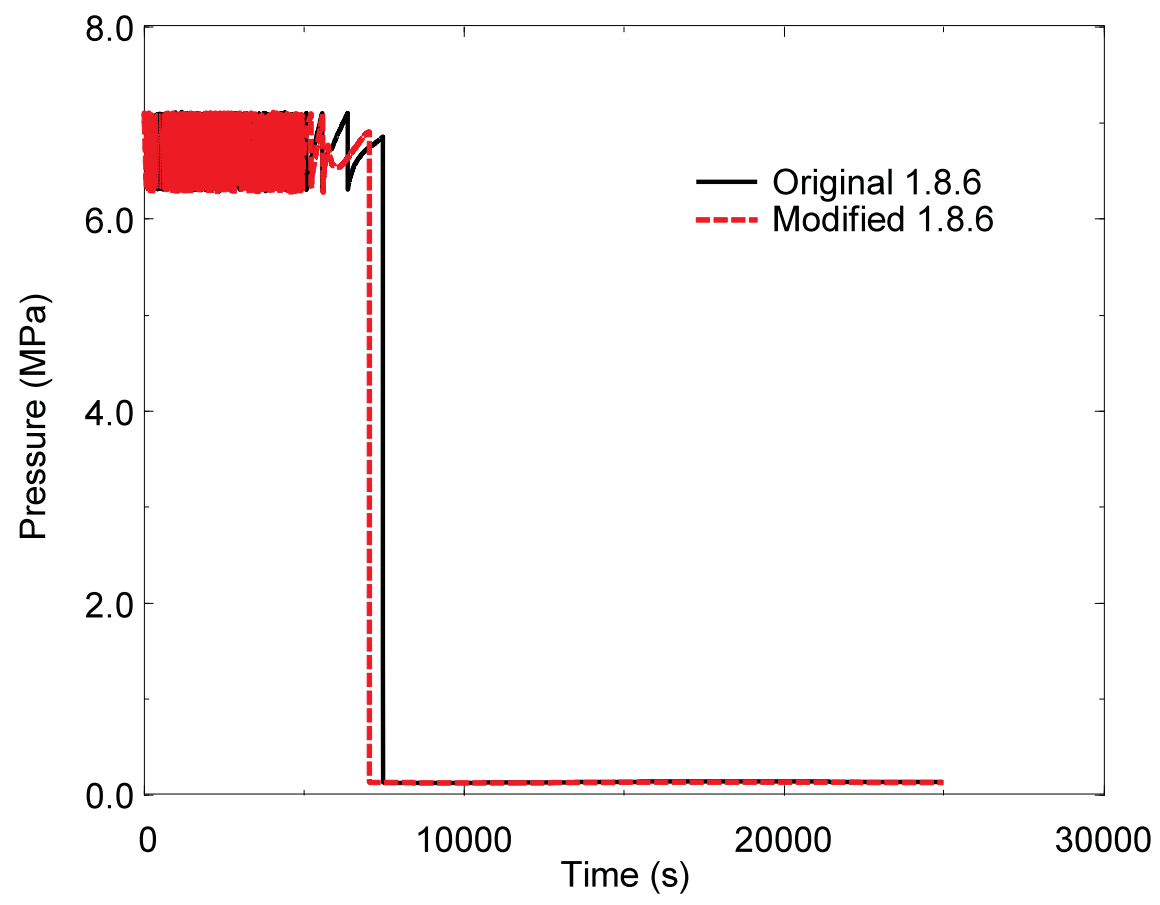

Figure 6. Reactor core pressure comparison for the demonstration problem sent with the MELCOR 1.8.6 source distribution.

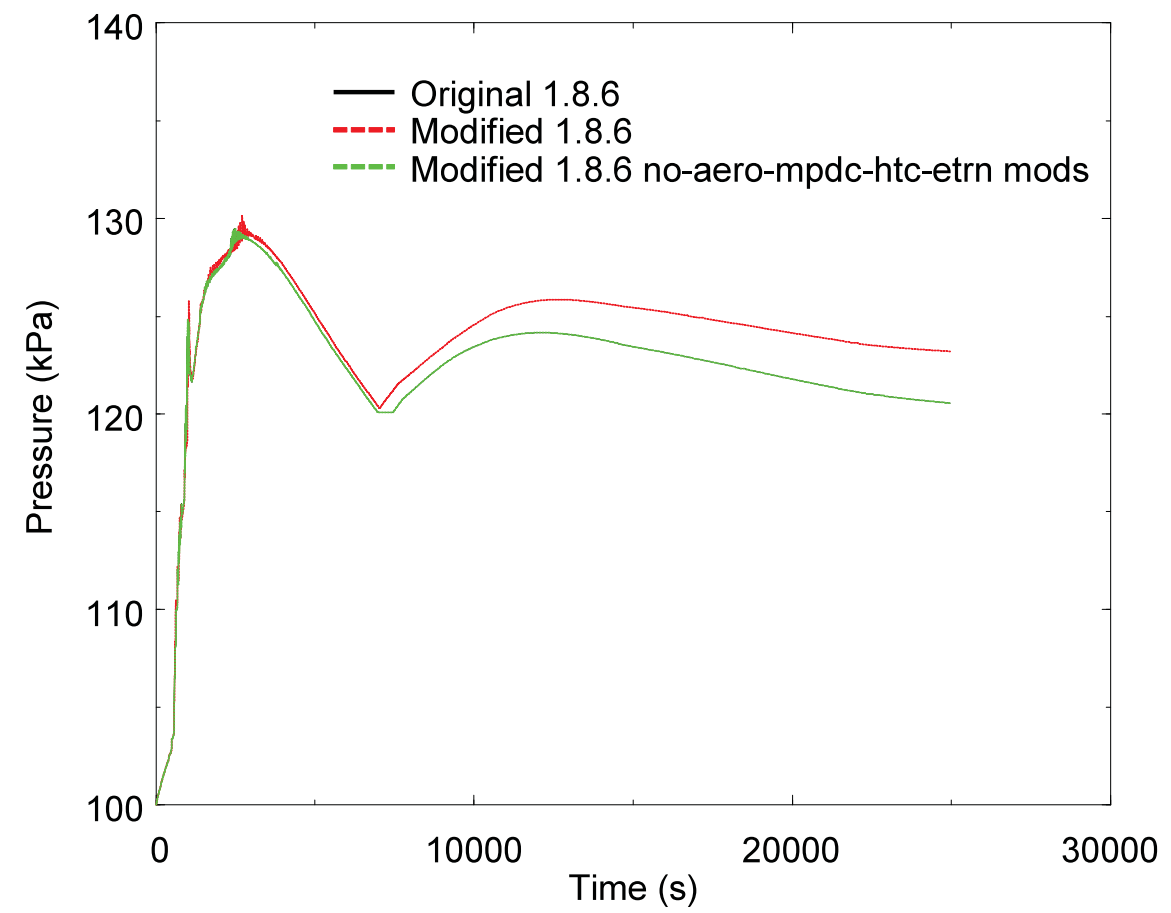

Figure 7. Wetwell pressure comparison for the demonstration problem sent with the MELCOR 1.8.6 source distribution. 


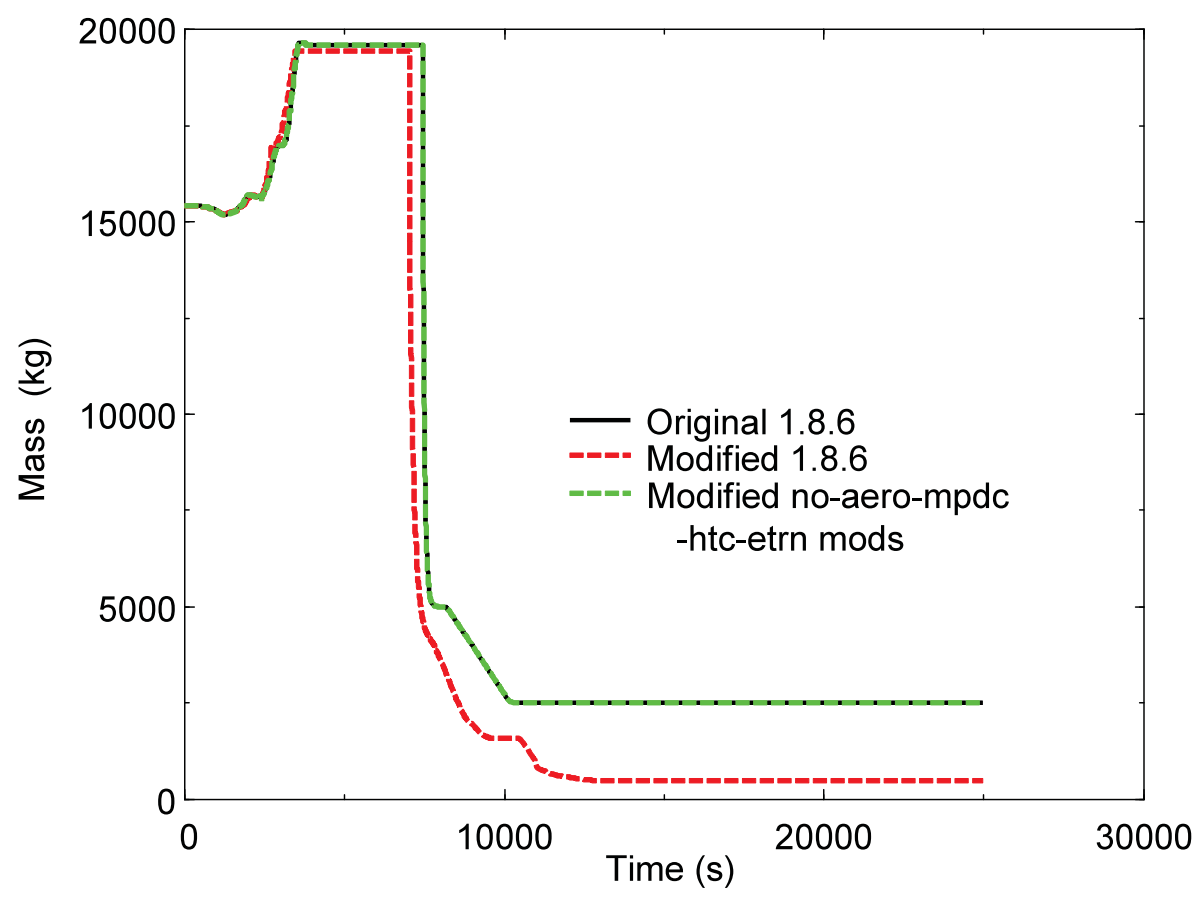

Figure 8. Reactor core steel mass comparison for the demonstration problem sent with the MELCOR 1.8.6 source distribution.

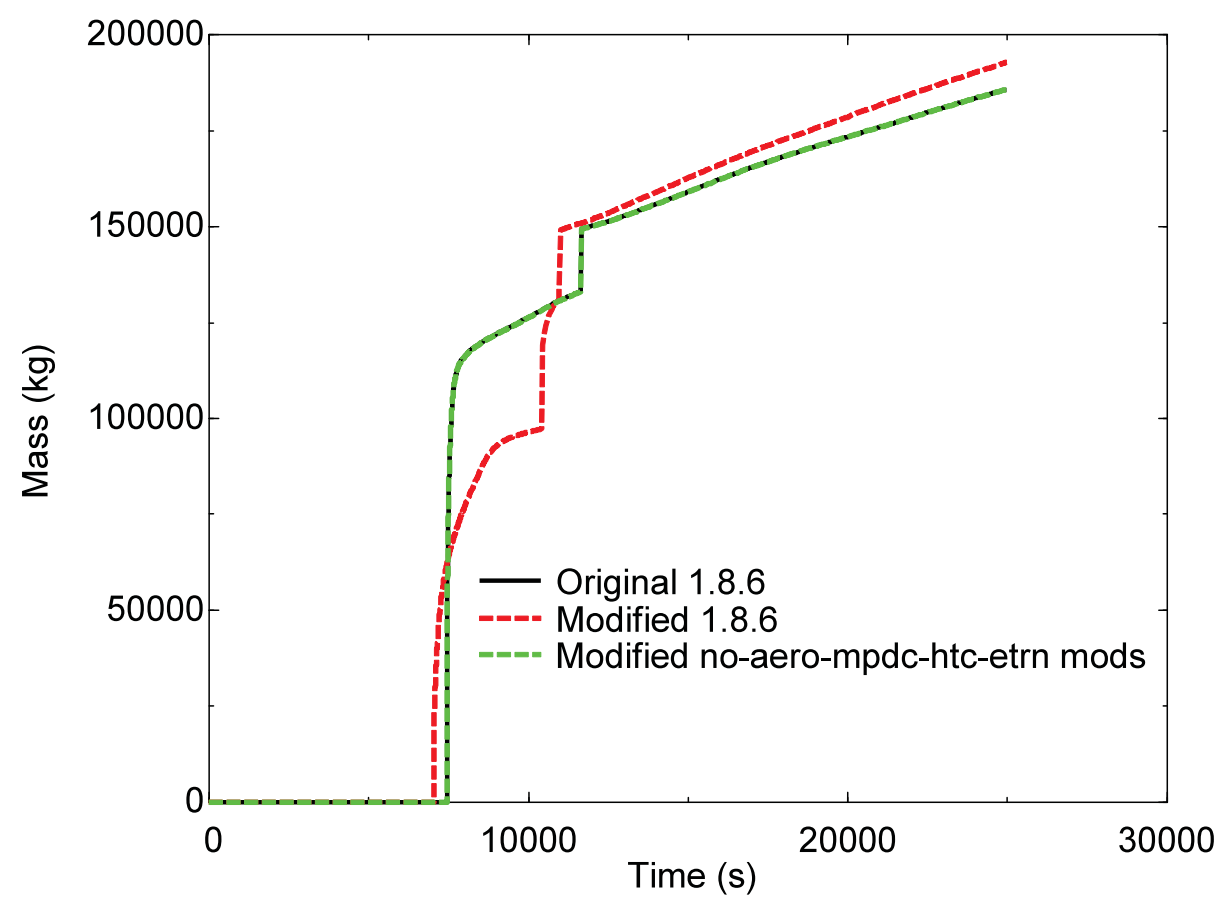

Figure 9. Cavity debris mass comparison for the demonstration problem sent with the MELCOR 1.8.6 source distribution. 


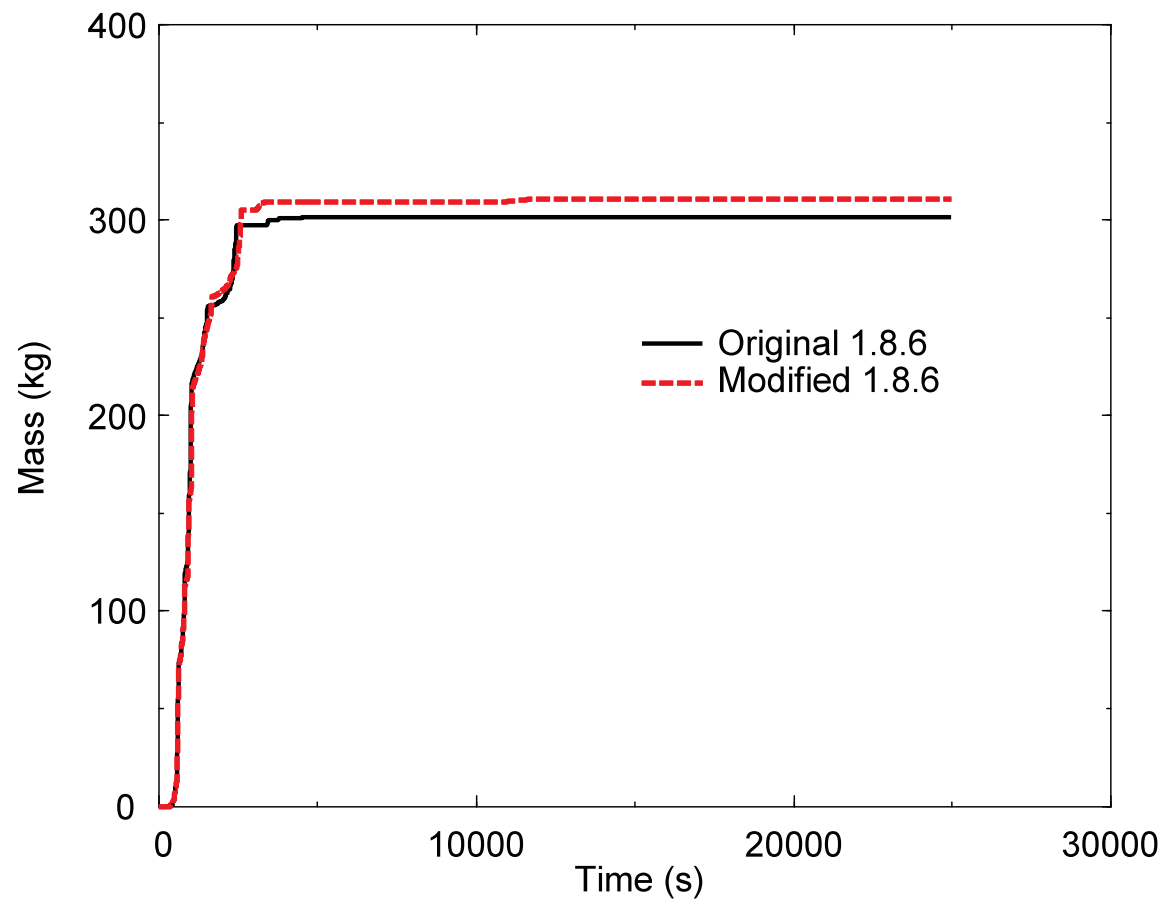

Figure 10. Reactor core hydrogen mass generation comparison for the demonstration problem sent with the MELCOR 1.8.6 source distribution

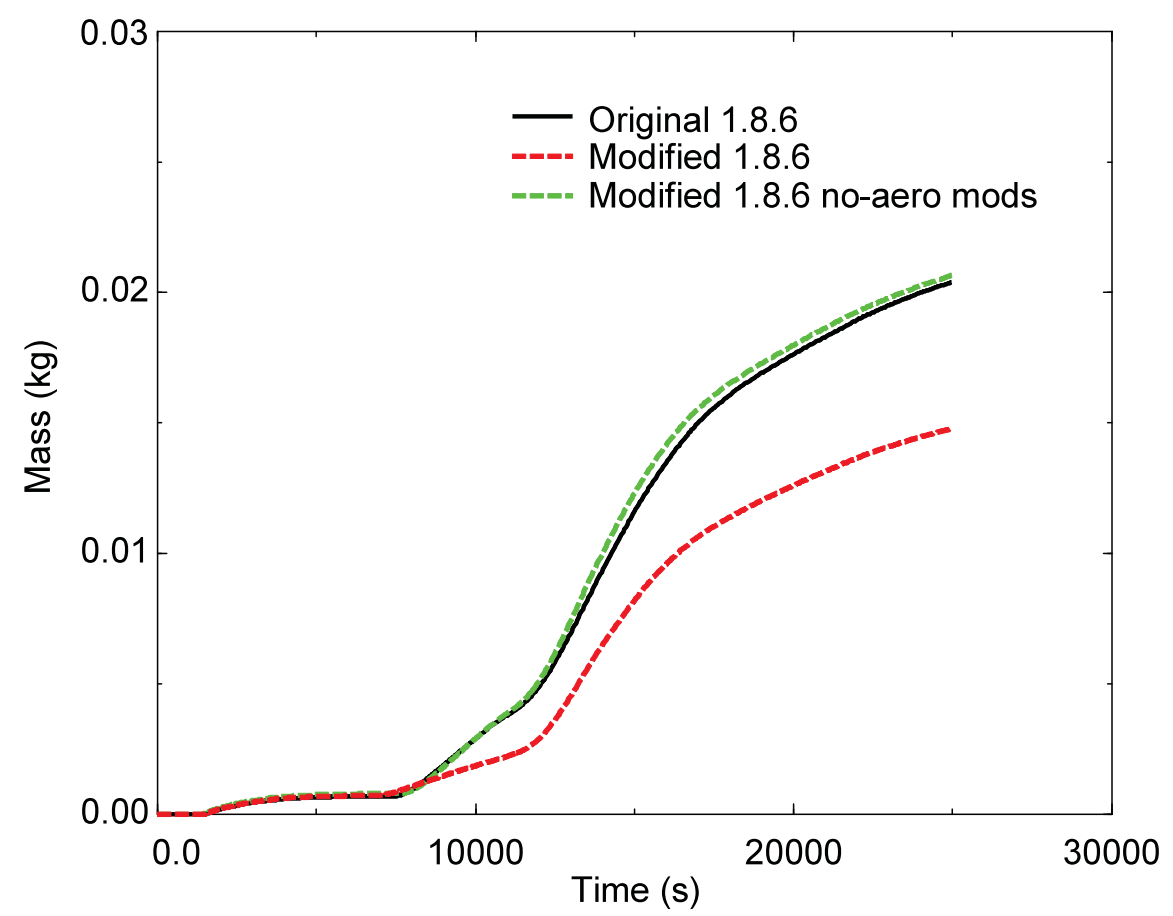

Figure 11. Aerosol mass release comparison for the demonstration problem sent with the MELCOR 1.8.6 source distribution. 


\section{ITER FEAT Accident Case Comparison}

In 2005 four relevant ITER FEAT accident cases were selected by the ITER International Team (IT) for a basis of comparison of the fusion version of the MELCOR 1.8.2 code against similar predictions obtained using the multi-fluids version of MELCOR 1.8.5. The results of that comparison were reported in [10], and the same problems were used in the pedigree process for MELCOR 1.8.2 described in [7]. Three of the four accident cases that were selected by the IT are examined in this report, which are: (1) a large ex-vessel pipe break, (2) multiple in-vessel first wall (FW) pipe breaks, and (3) vacuum vessel (VV) \& cryostat boundary failures. A detailed description of the accidents analyzed can be found in [9]. The fourth case, a divertor exvessel coolant pipe break, was not included in this report, although the agreement was good. An issue that arose in this problem in MELCOR 1.8.2 was a round-off error in the wall temperatures for the Heat Transport System (HTS) vault. This was an inherent problem in MELCOR 1.8.2, which was written in single precision FORTRAN. This issue is resolved in MELCOR 1.8.6, which is double precision.

\subsection{Multiple In-vessel FW Pipe Break}

This postulated event is the double-ended rupture of multiple 10-mm diameter first wall (FW) coolant pipes during a plasma burn. All $\mathrm{FW} /$ shield modules around the inboard and outboard toroidal circumference of the machine are postulated to be damaged by this event. The number of modules involved is estimated to be 54 . This bounds the worst possible damage to perfectly aligned $\mathrm{FW} /$ shield modules during a hypothetical plasma transient. Coolant will be discharged at a high flow rate directly into the VV from a total FW break area of 0.2 $\mathrm{m}^{2}$. The rapid coolant ingress will terminate the plasma by a disruption.

Figures 12 and 13 contain the mass flow rate and the integrated mass flow associated with the outboard break, respectively. Similarly, the mass flow rate and integrated mass flow from the inboard break are shown in Figures 14 and 15. As seen there is little difference in the break mass flow rates between MELCOR 1.8.2 and MELCOR 1.8.6.

Results for the water mass flow rate and the integrated mass flow through the drain line are shown in Figures 16 and 17. The vapor mass flow rate through relief lines 1 and 2 and their corresponding integrated mass flows are shown in Figures 18, 19, 20 and 21, respectively. As seen there is little difference in the results produced by each version of MELCOR.

A comparison of the plasma chamber vapor temperature and pressure is shown in Figures 22 and 23, respectively. The lower temperature observed initially in MELCOR 1.8.2 is due to the fact that heat transfer was turned off at pressures below $500 \mathrm{~Pa}$. In MELCOR 1.8.6, the vapor is allowed to reach thermal equilibrium with the walls. Following the pipe breaks, there is little difference in the results.

In Figures 24, 25, 26, 27, and 28 the pressure as a function of time is shown for different locations between the plasma chamber and the suppression tank. Differences in the results are on the order of a few percent or less for most of the transient.

The mass of water in the drain tank and the vacuum vessel are shown in Figures 29 and 30. Figures 31, 32, and 33 contain the corresponding volume of water in the drain tank, FW blanket and the vacuum vessel. Once again results from MELCOR 1.8.2 and MELCOR 1.8.6 match very well.

Overall the agreement between MELCOR 1.8.2 and MELCOR 1.8.6 for this accident is excellent. 


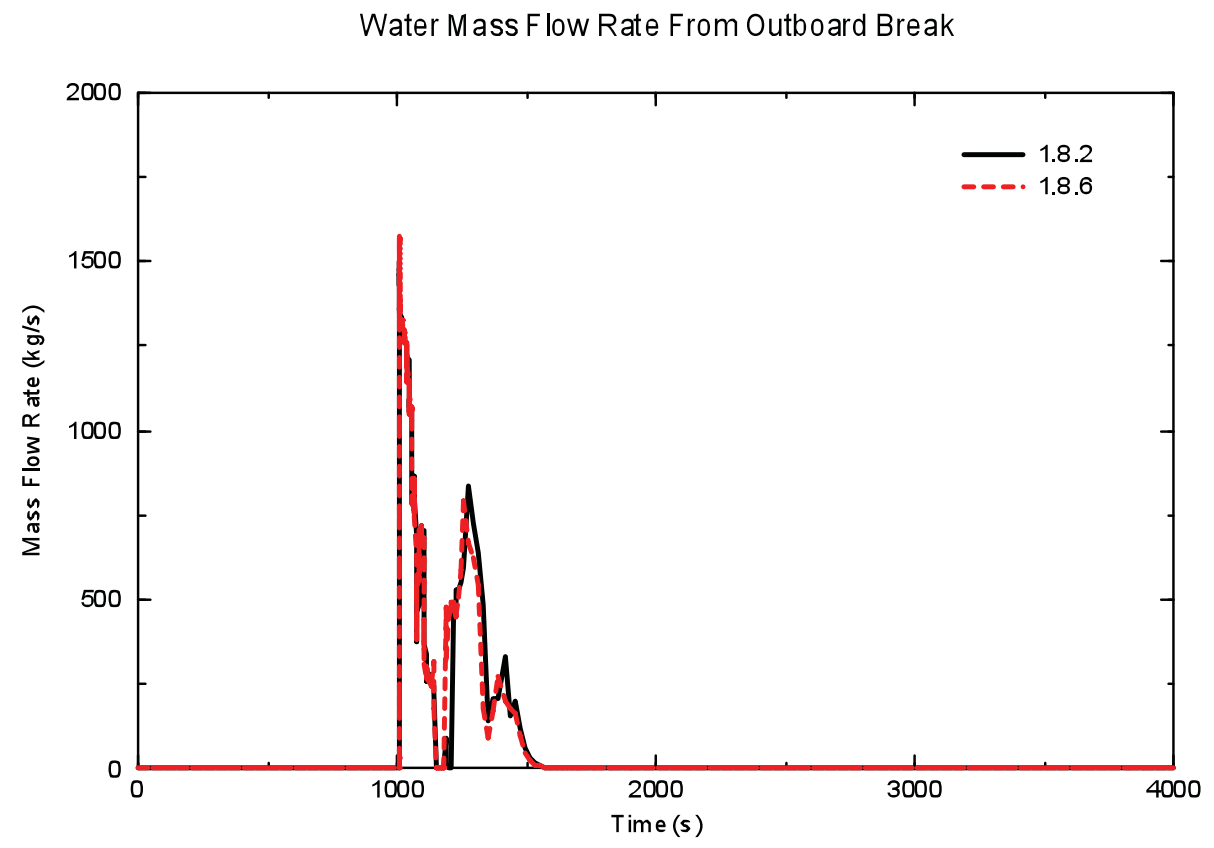

Figure 12. Water mass flow rate from outboard break.

Integrated Water Mass F low From O utboard Break

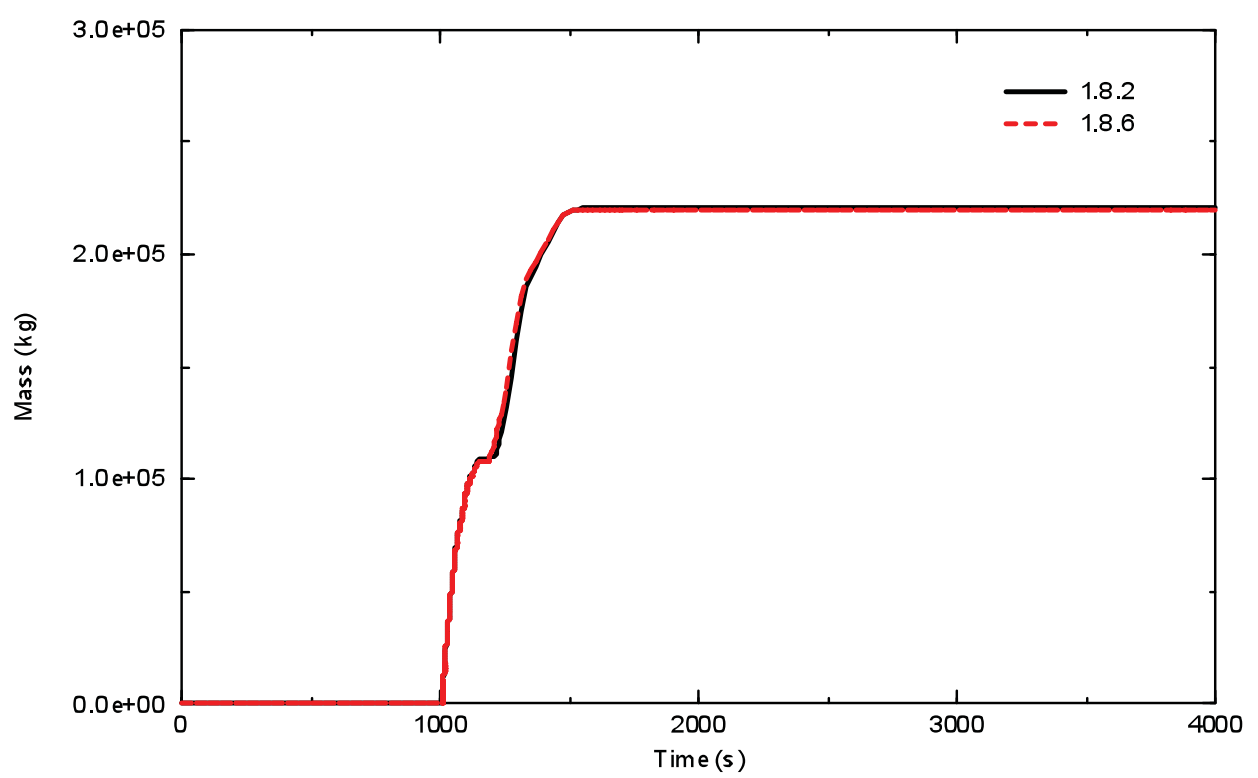

Figure 13. Integrated water mass flow from outboard break. 


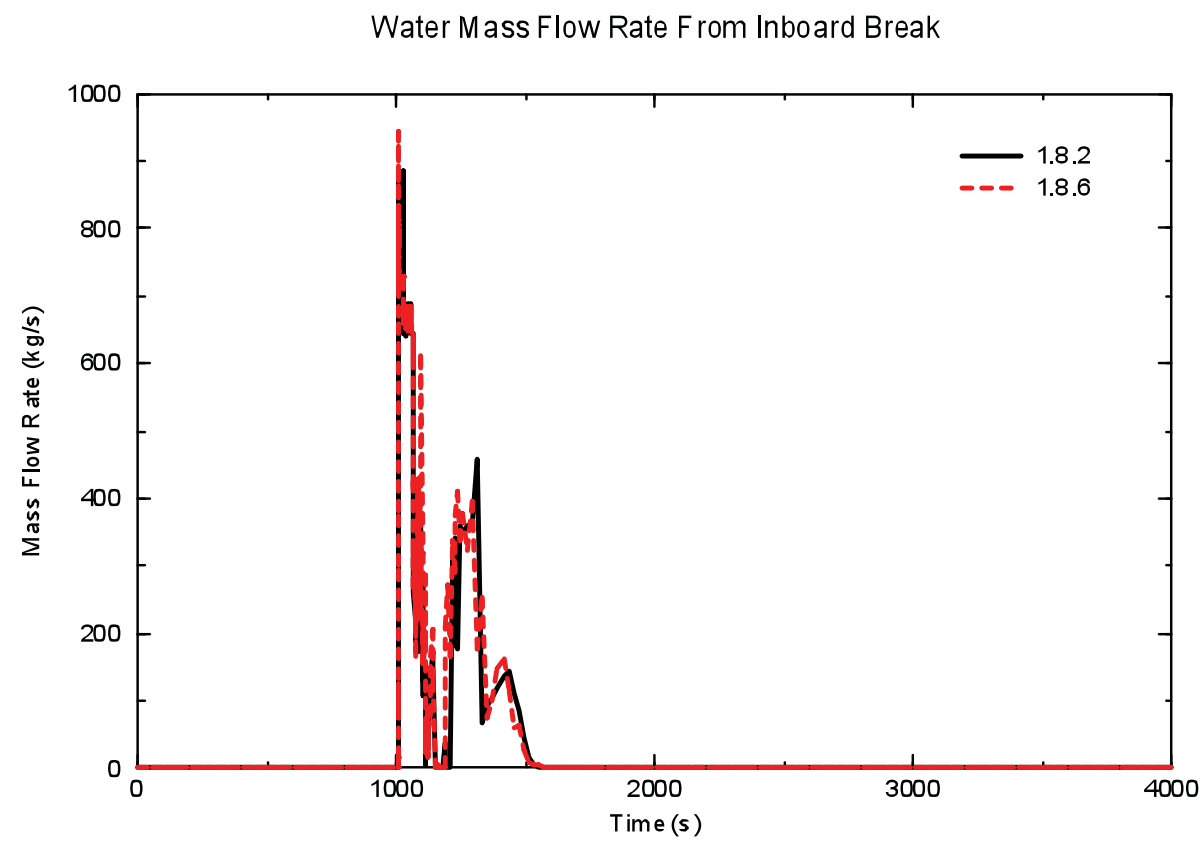

Figure 14. Water mass flow rate from inboard break.

Integrated Water Mass Flow From Inboard Break

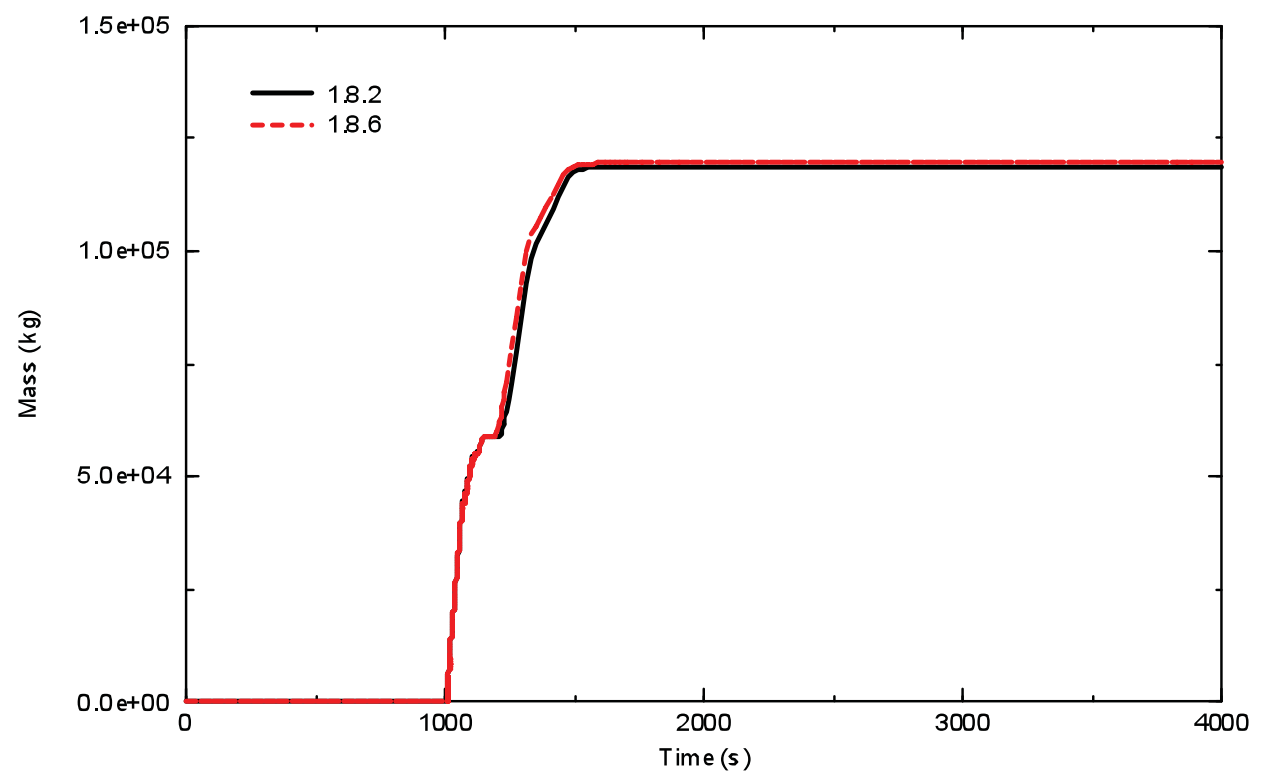

Figure 15. Integrated water mass flow from inboard break. 


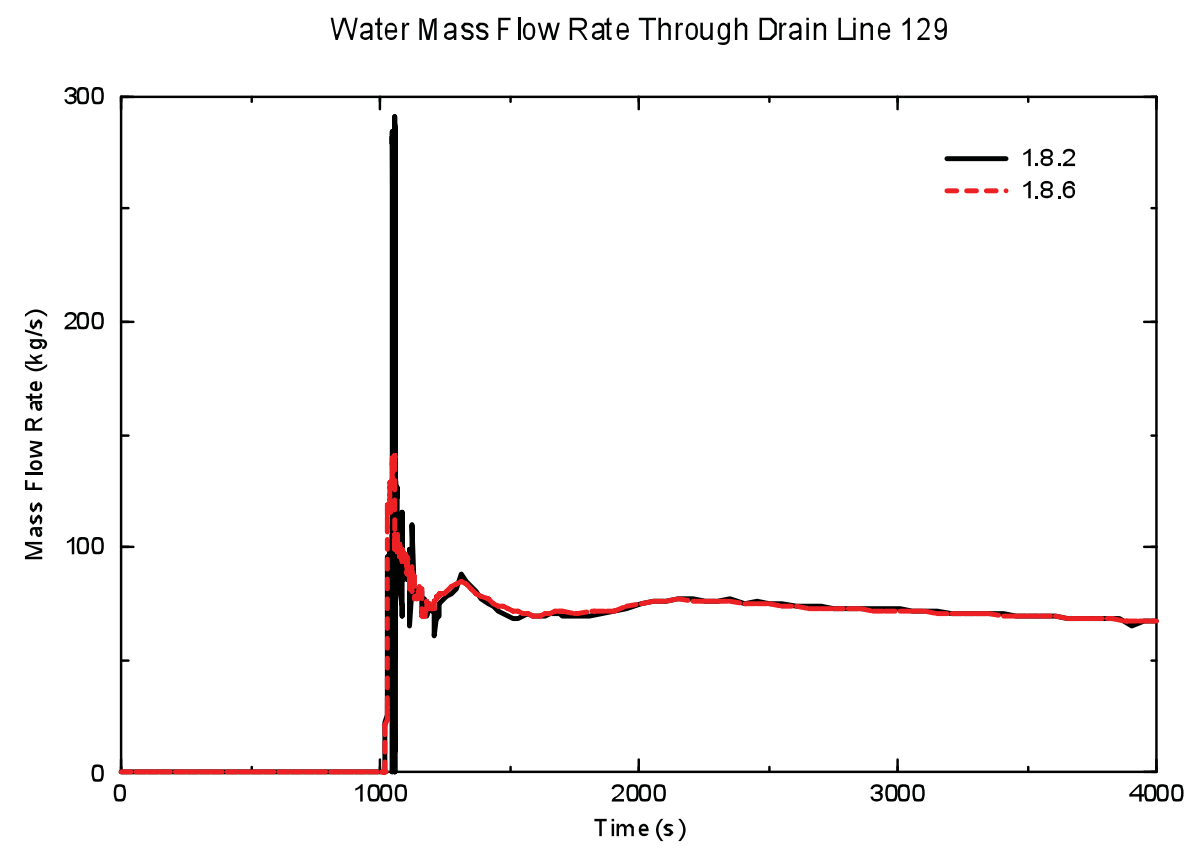

Figure 16. Water mass flow rate through drain line 129.

Integrated Mass Flow Through Drain Line 129

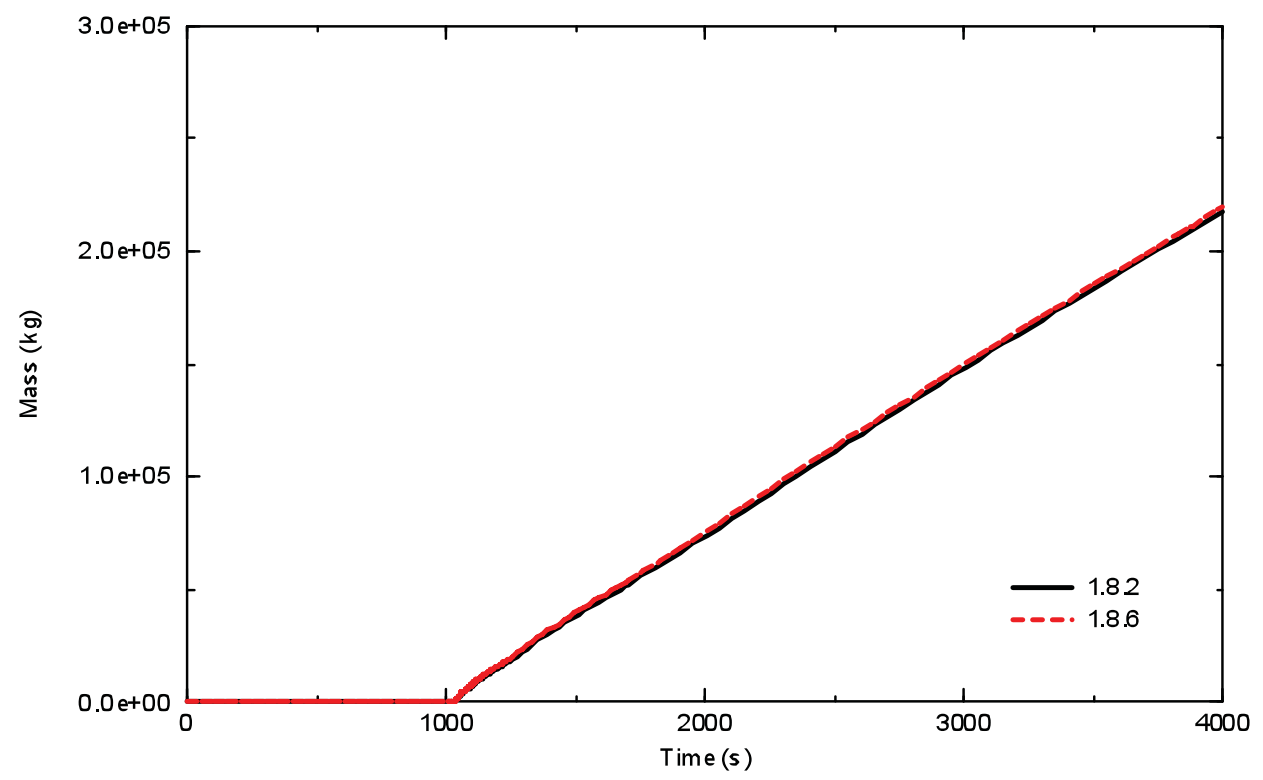

Figure 17. Integrated mass flow through drain line 129. 


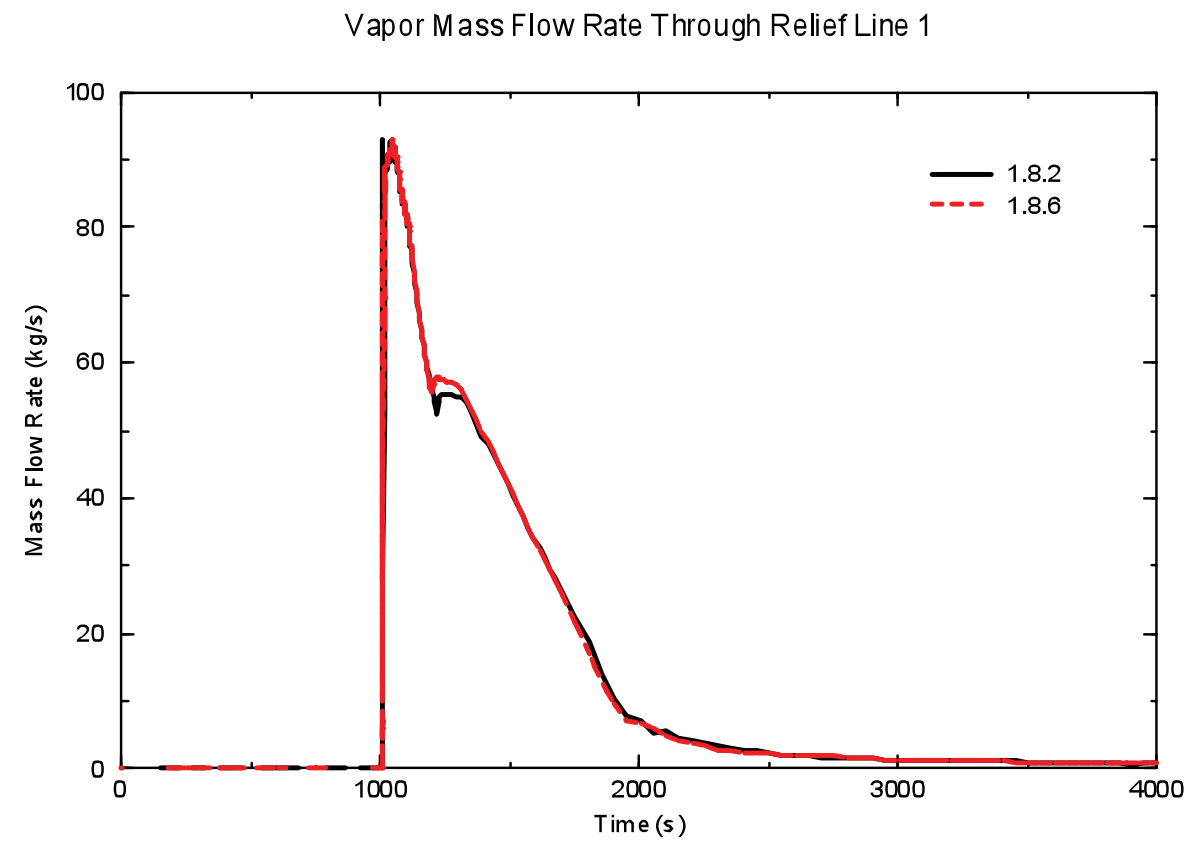

18. Vapor mass flow rate through relief line 1.

Integrated Vapor Mass Flow Through Relief Line 1

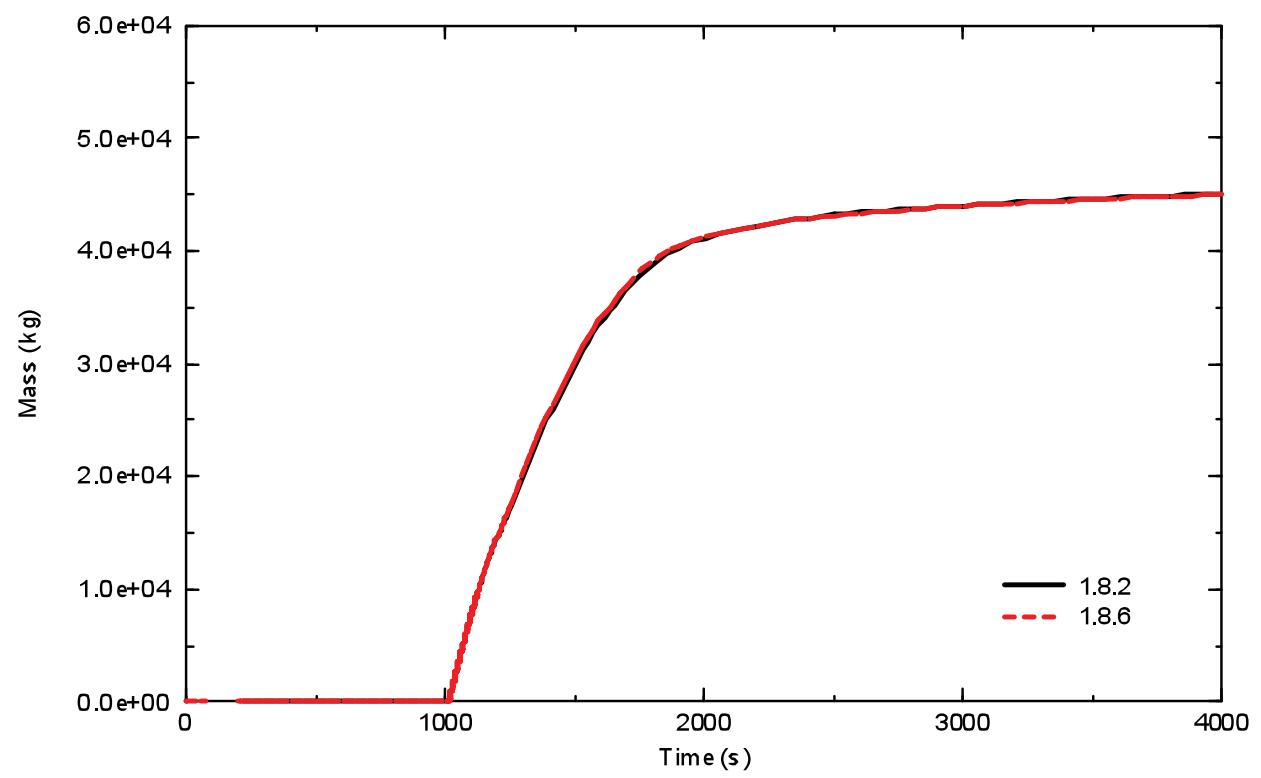

Figure 19. Integrated vapor mass flow through relief line 1. 


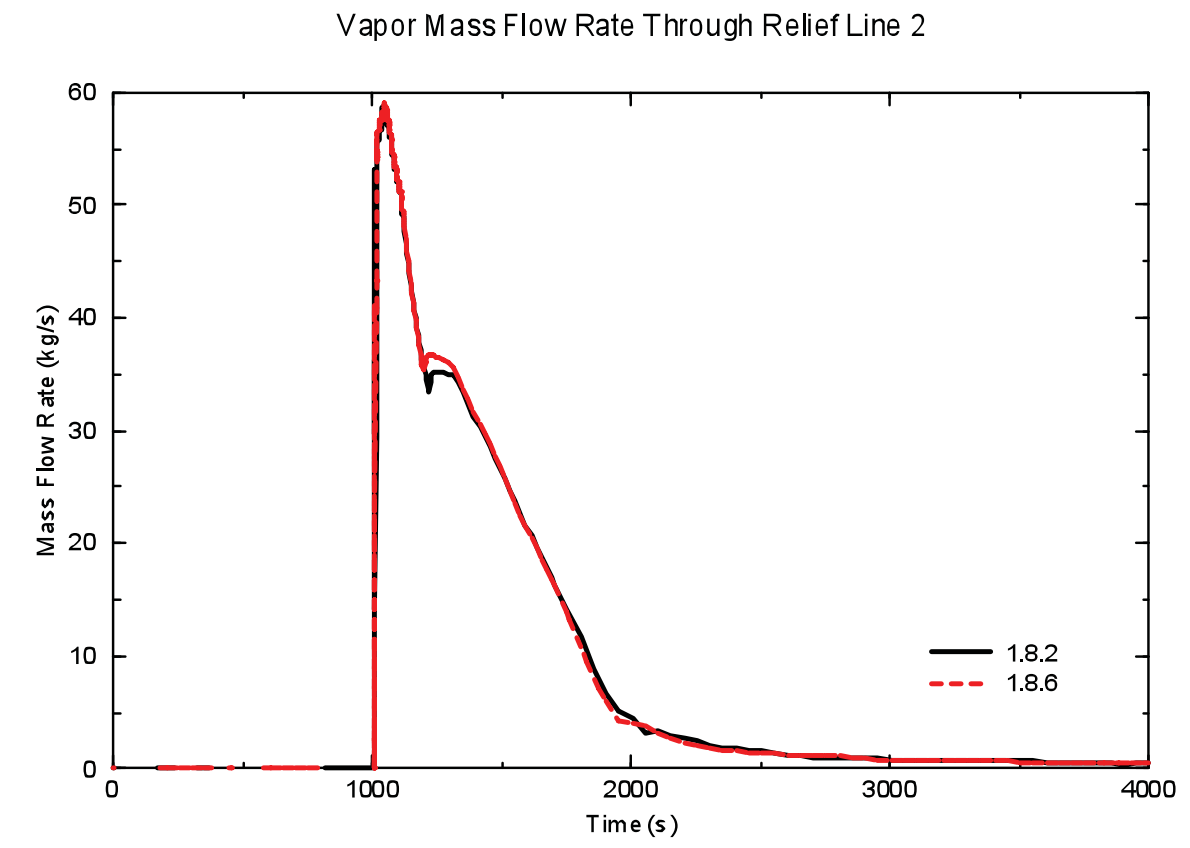

Figure 20. Vapor mass flow rate through relief line 2.

Integrated Vapor Mass Flow Through Relief Line 2

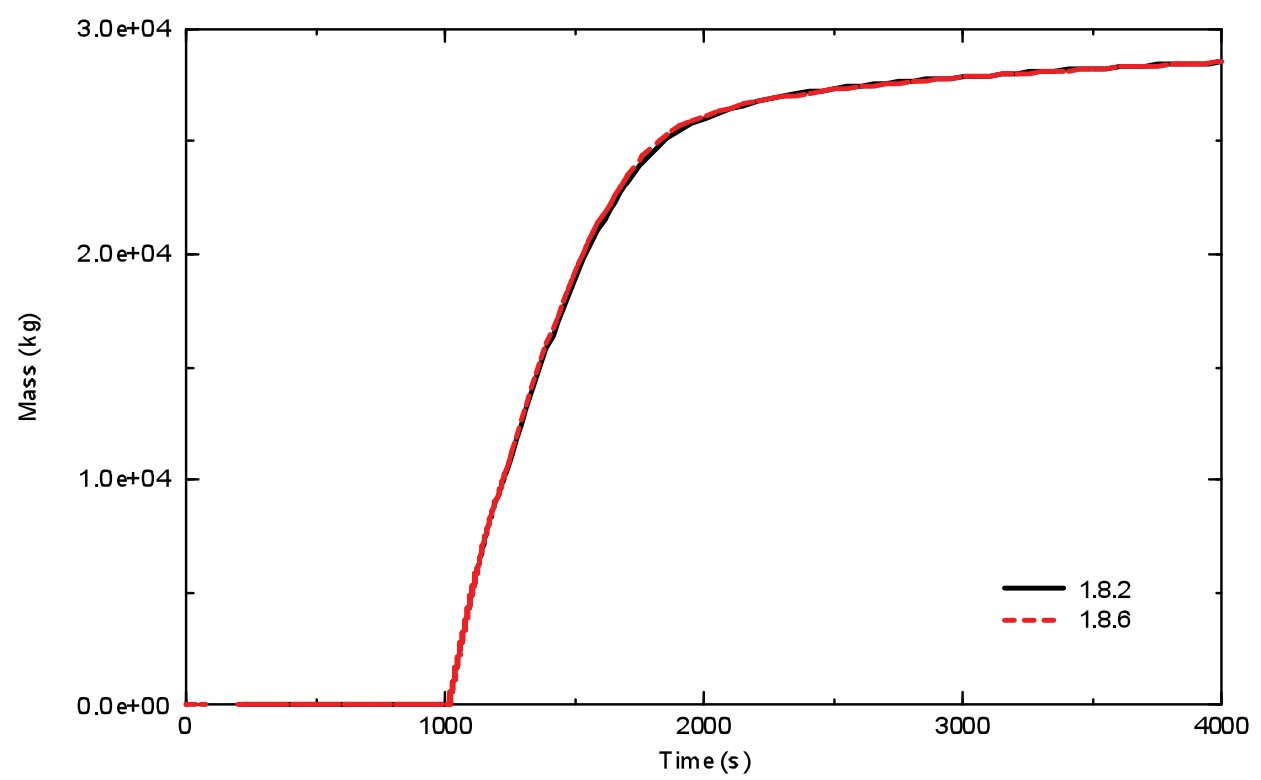

Figure 21. Integrated vapor mass flow through relief valve 2. 


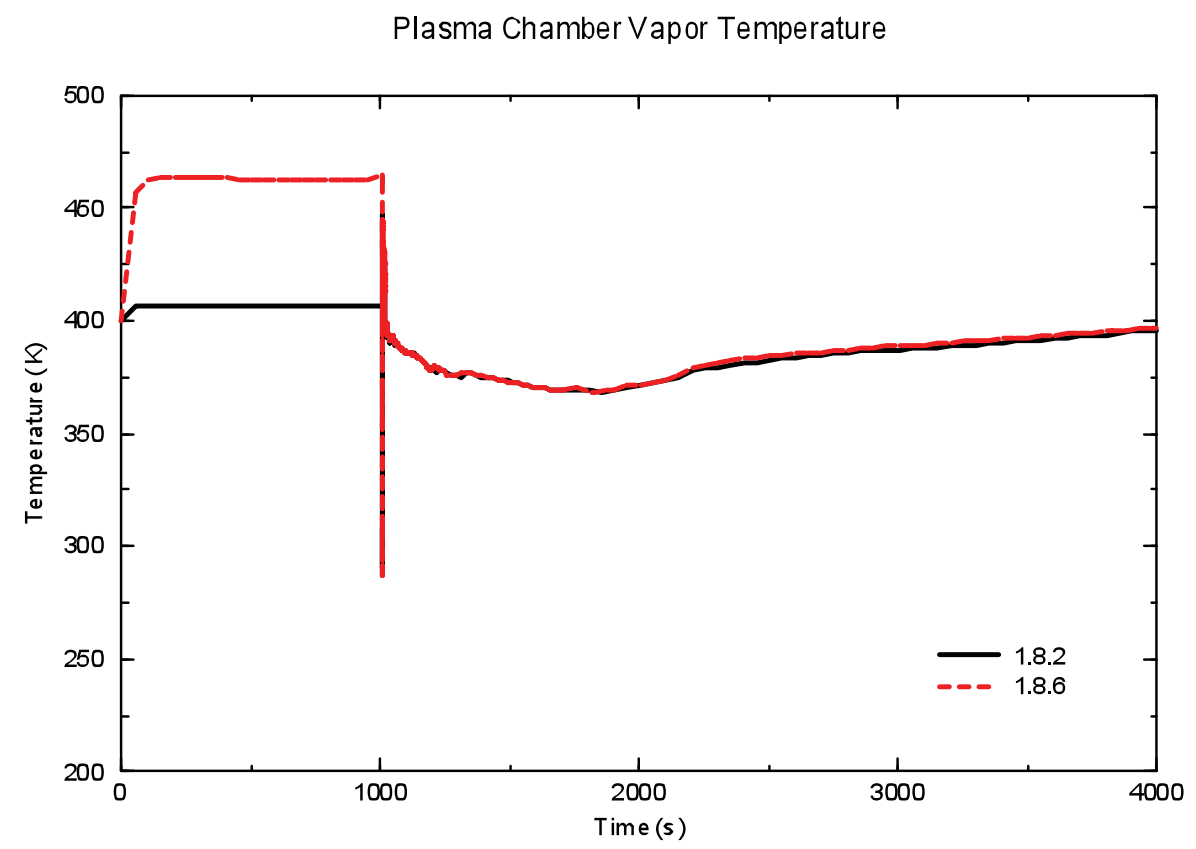

Figure 22. Plasma chamber vapor temperature.

Plasma Chamber Pressure

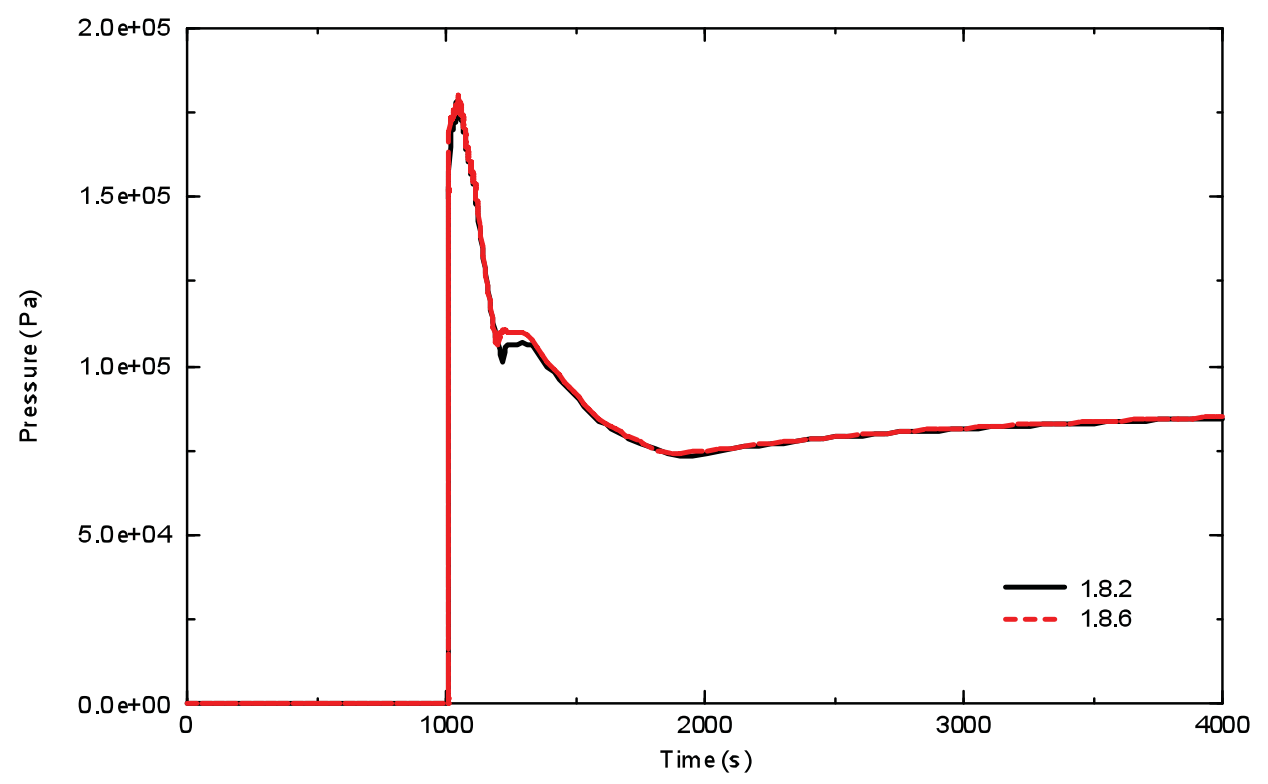

Figure 23. Plasma chamber pressure. 


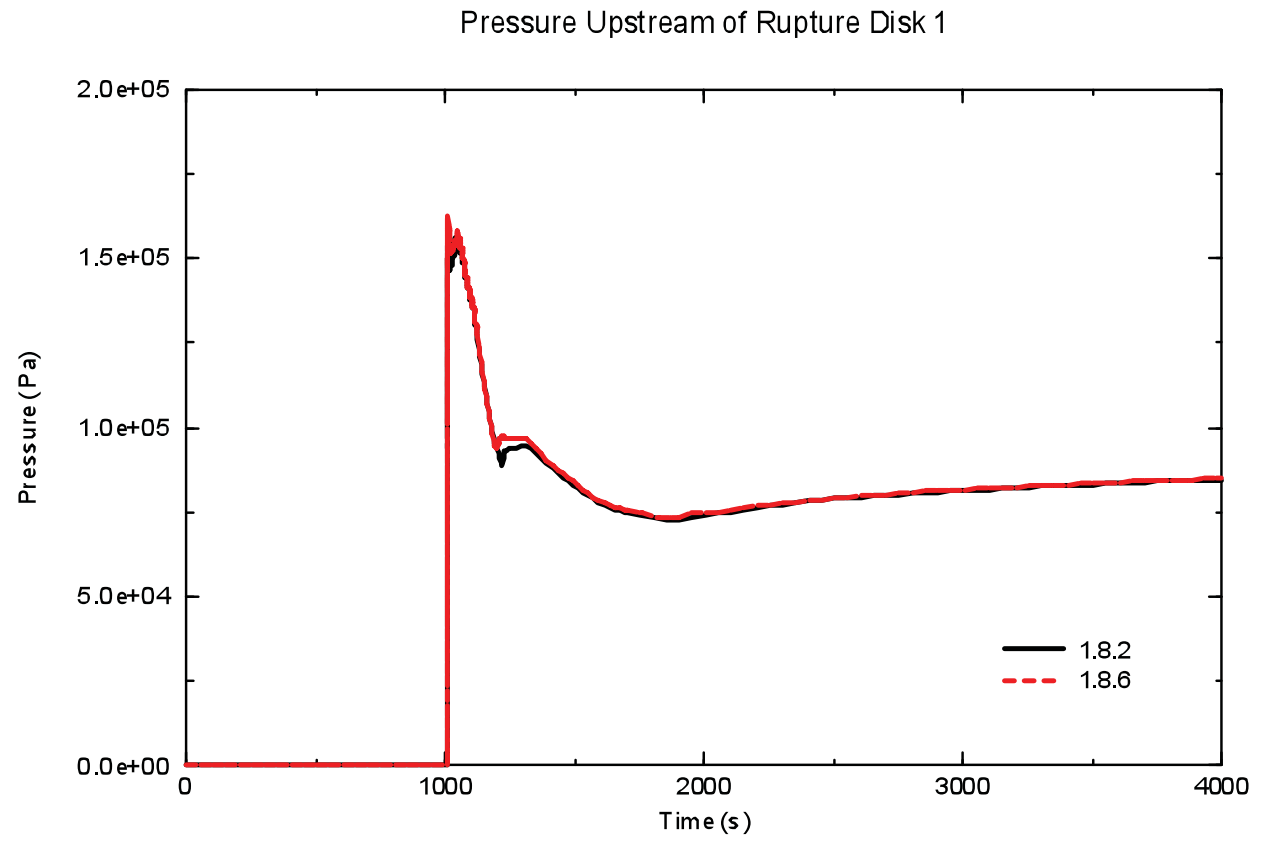

Figure 24. Pressure upstream of rupture disk 1.

Pressure Between Rupture Disks 1 and 2

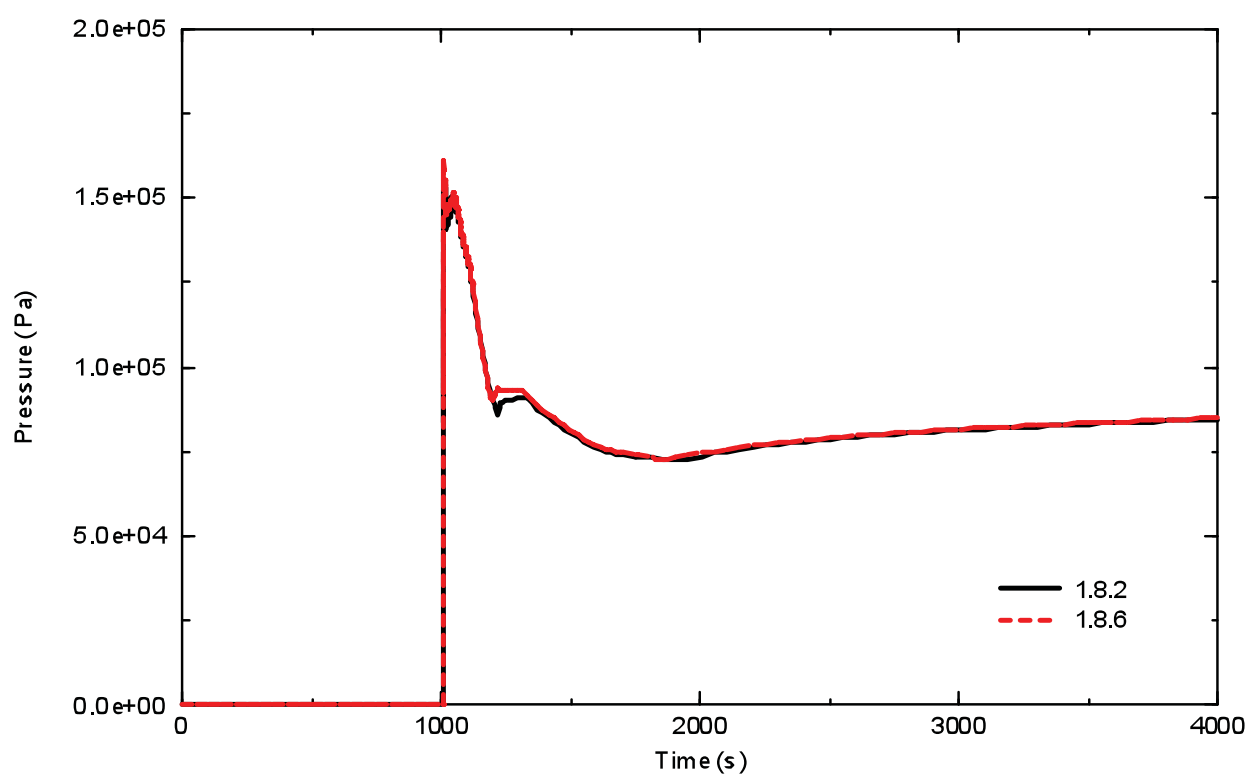

Figure 25. Pressure between rupture disks 1 and 2 . 


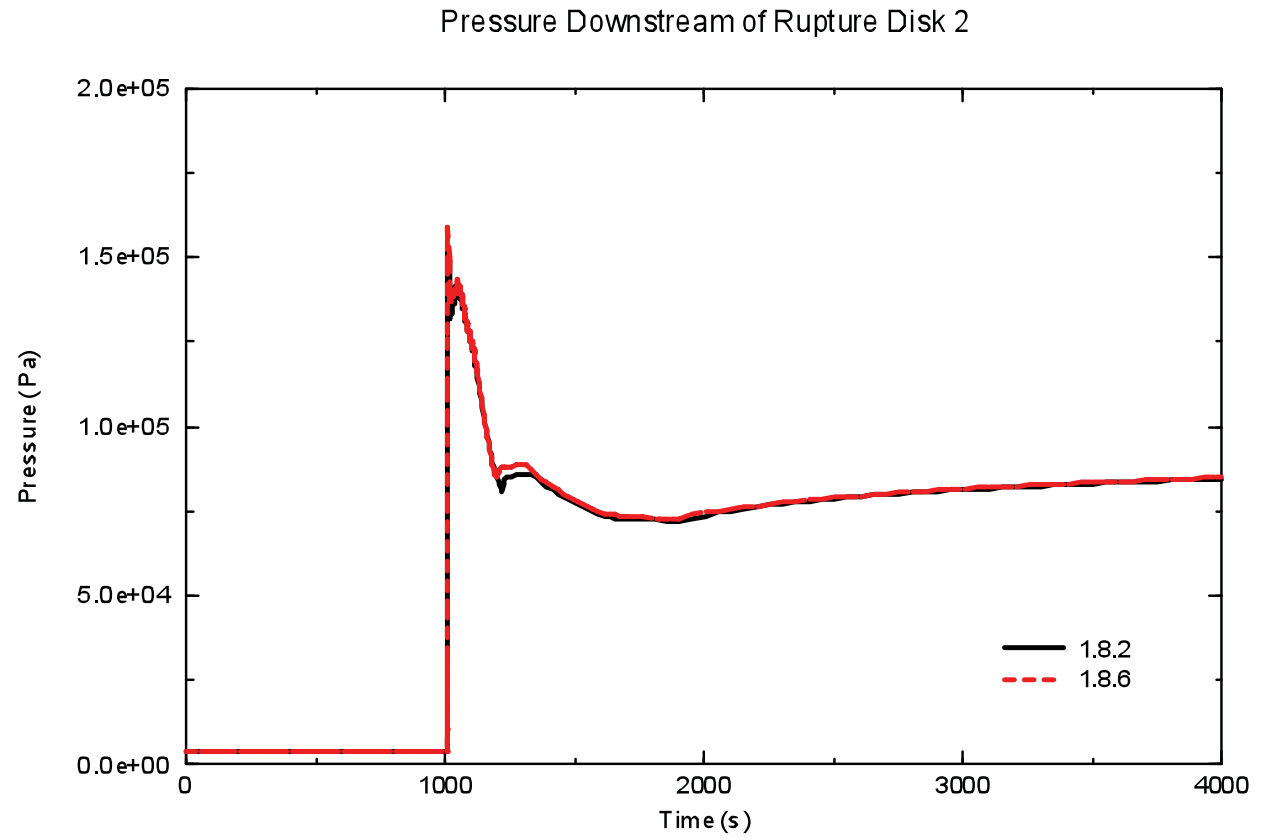

Figure 26. Pressure downstream of rupture disk 2 .

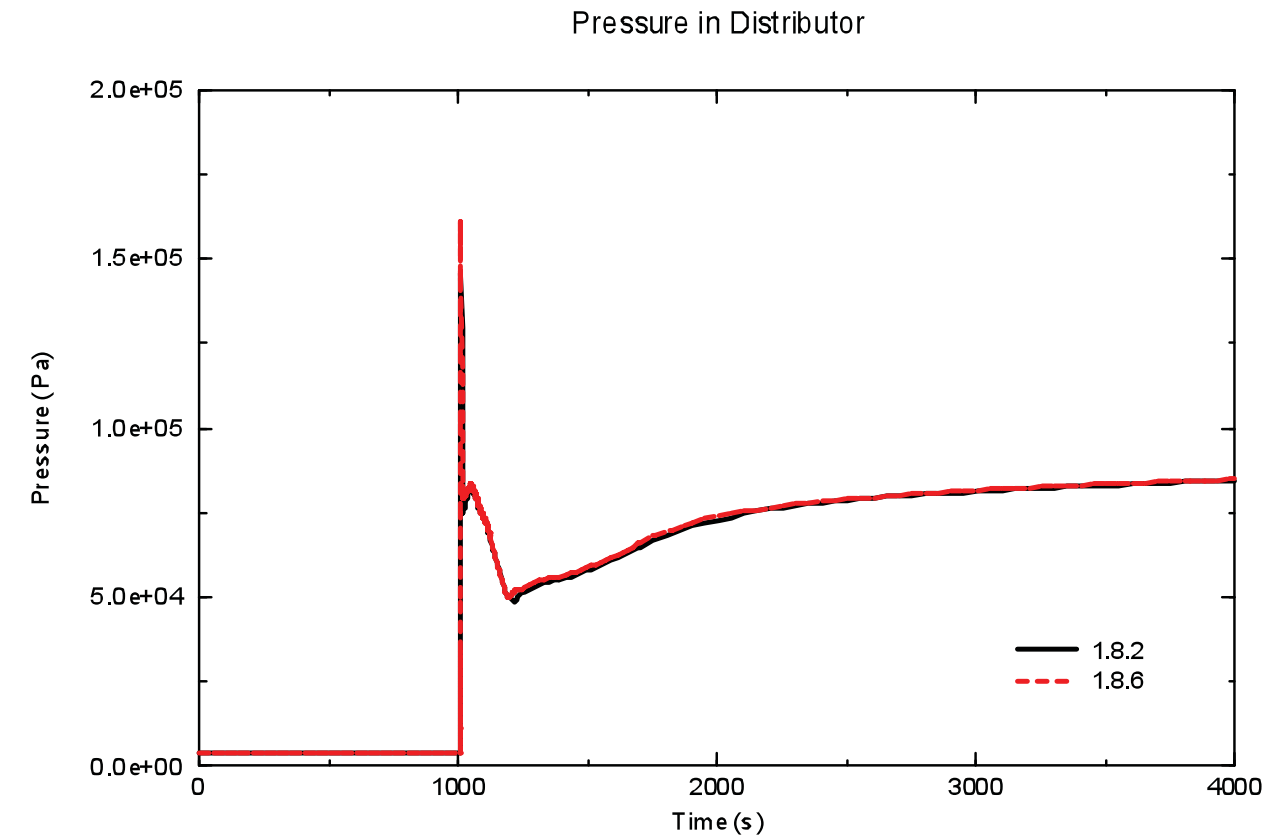

Figure 27. Pressure in distributor. 


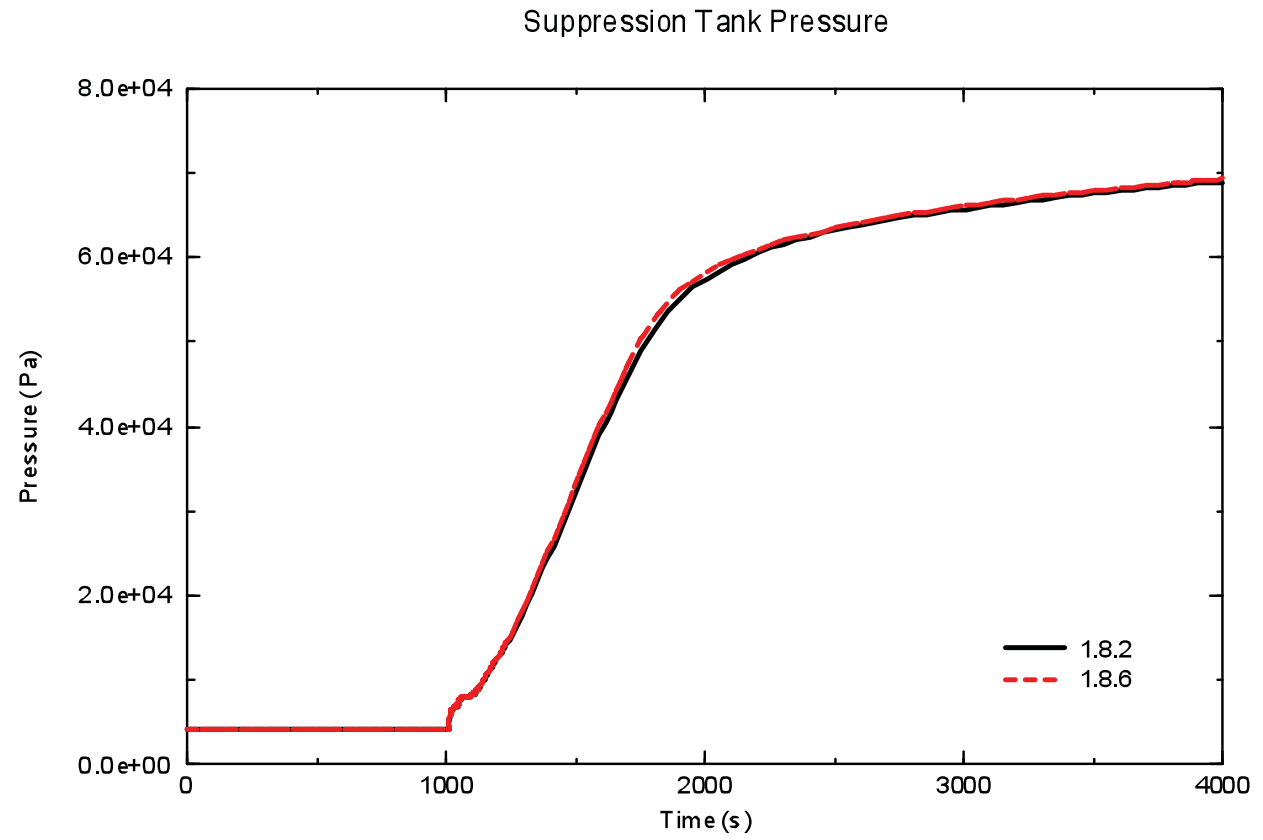

Figure 28. Suppression tank pressure.

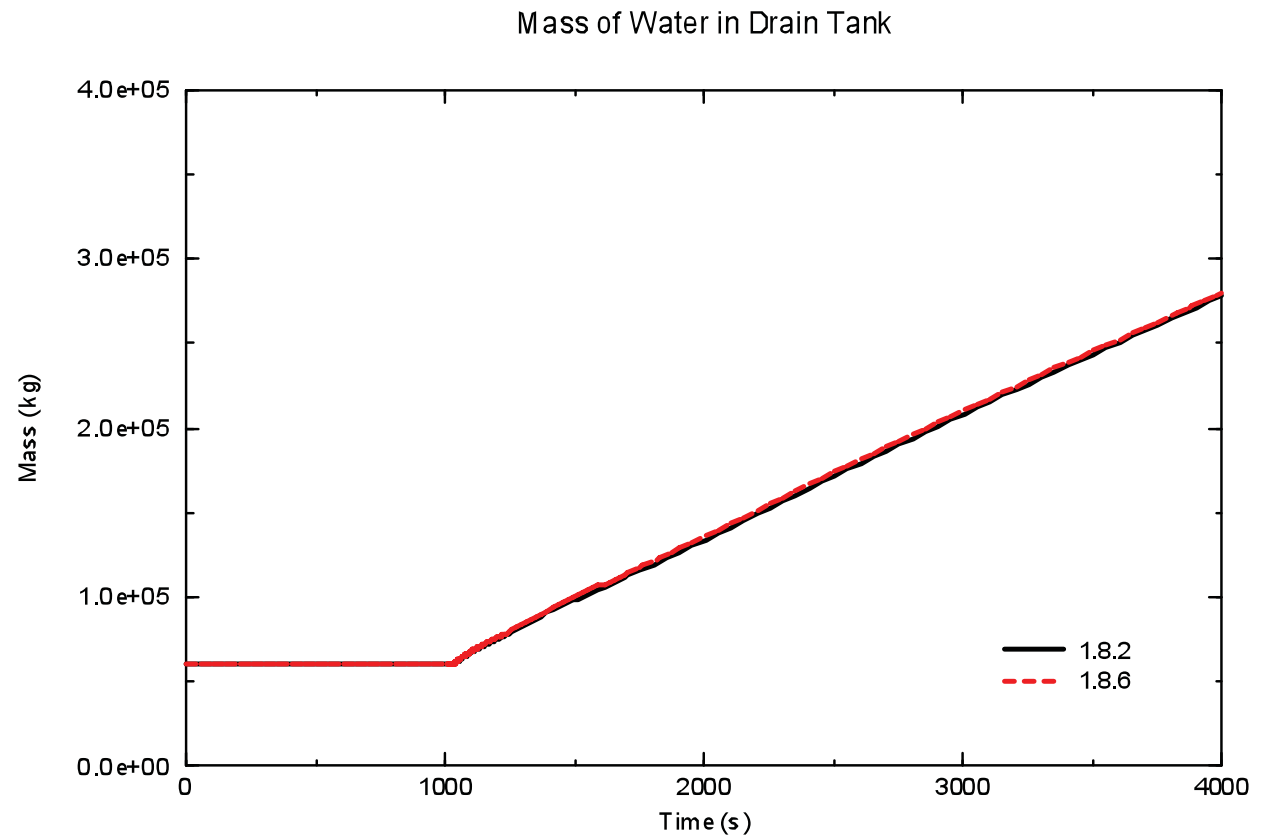

Figure 29. Mass of water in drain tank. 


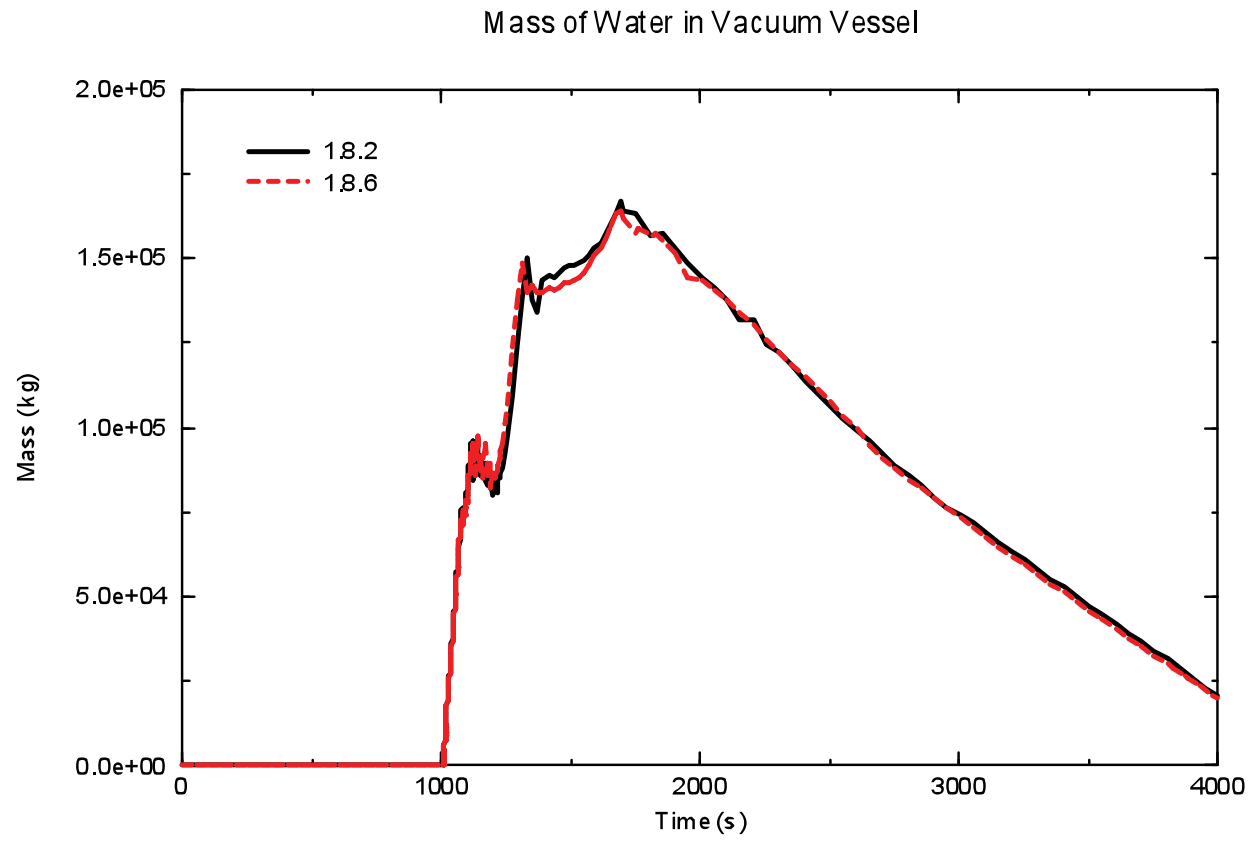

Figure 30. Mass of water in the vacuum vessel.

Volume of Water in Drain Tank

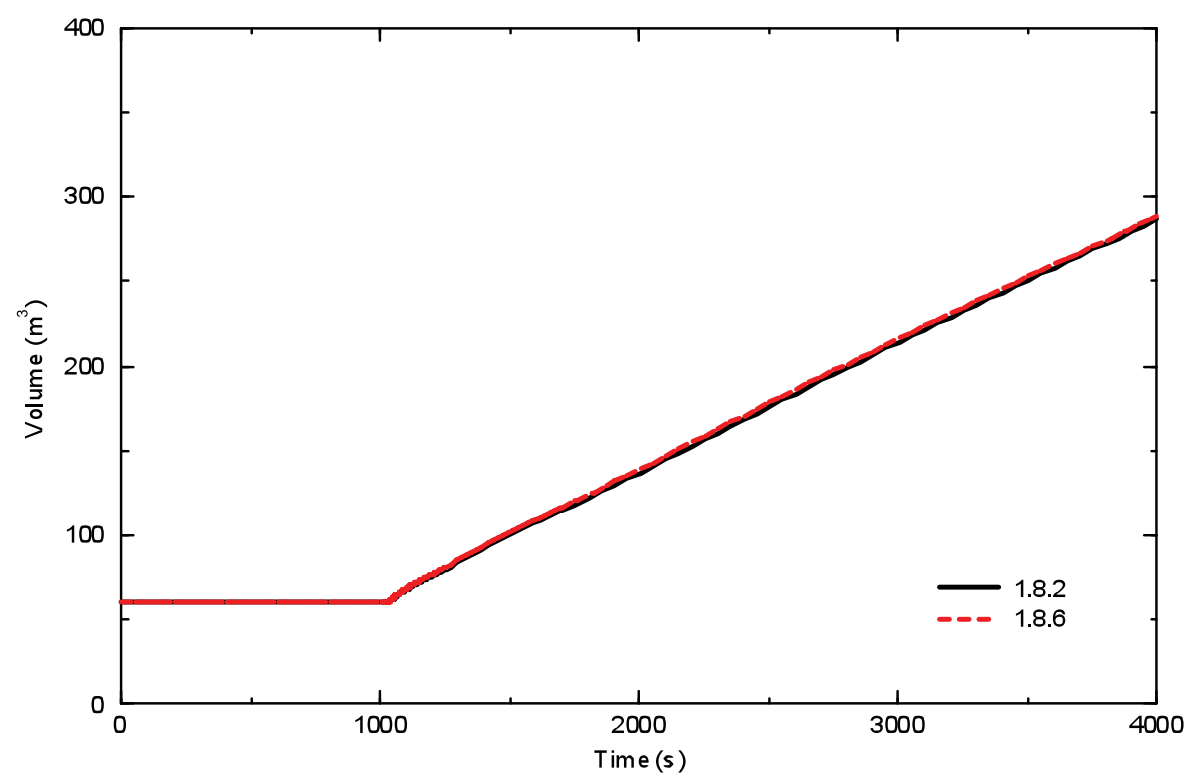

Figure 31. Volume of water in drain tank. 


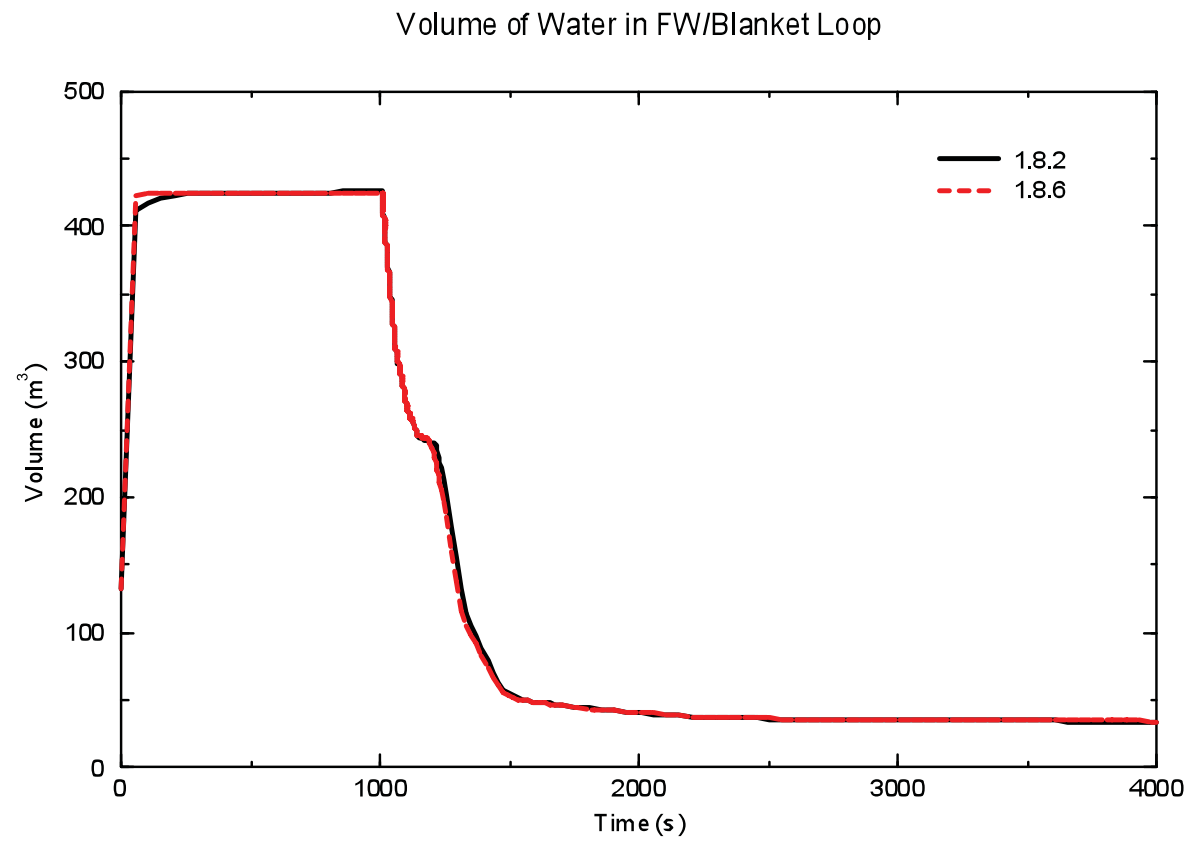

Figure 32. Volume of water in first wall blanket.

Volume of Water in Vacuum Vessel

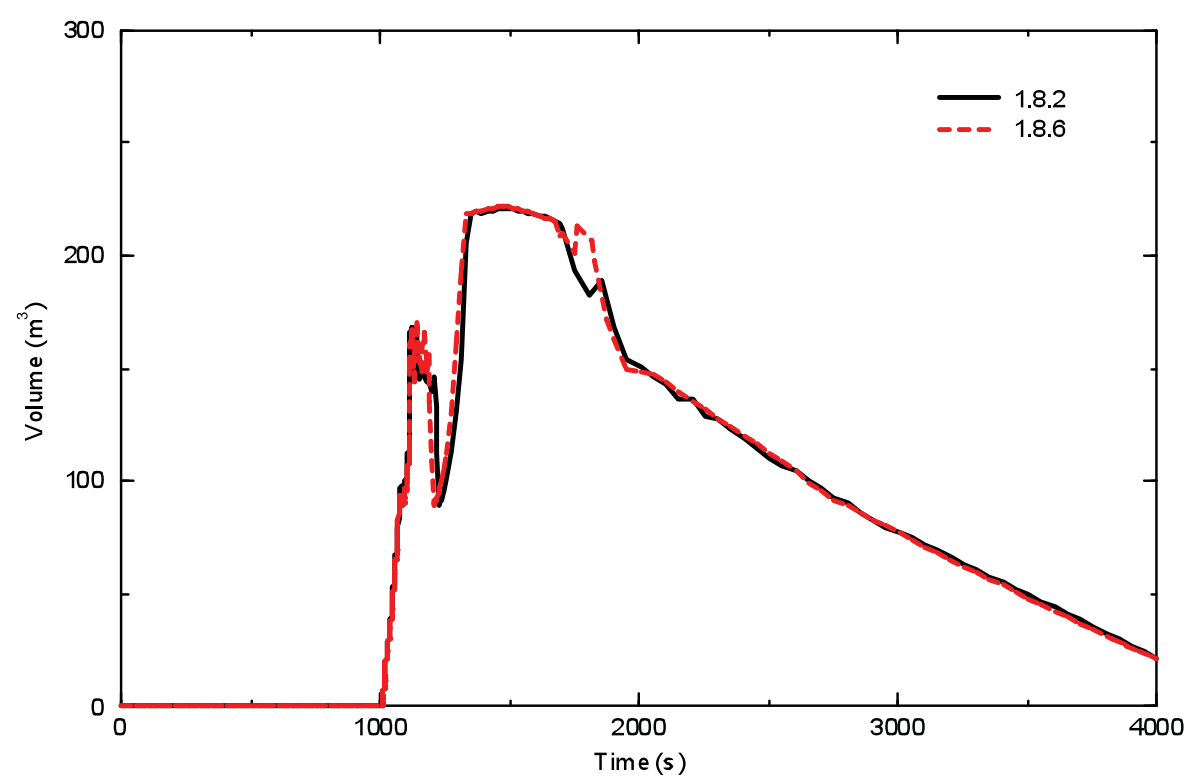

Figure 33. Volume of water in vacuum vessel. 


\subsection{Large Ex-vessel Break}

This postulated event is a double-ended pipe rupture of the largest cooling pipe of the VV cooling system outside of the building. In such an event, coolant will be discharged at a high rate onto the roof of the tritium building. The plasma is assumed to continue burning for 1000 seconds, which is a conservative assumption because the nominal ITER pulse length is 475 seconds. It is assumed that no additional plasma pulses will be started after the accident until the VV coolant loop is repaired.

Figures 34 through 44 contain the results generated by this accident. Viewing the figures we see that there is little difference between most of the results generated by MELCOR 1.8.6 and the pedigreed version of MELCOR 1.8.2. Some differences in flow rates occur, but even the significant difference in flow rate that occurs briefly before the flow chokes at 1,006 seconds (Figure 40) does not significantly alter the integrated flow (Figure 41).

Overall the agreement between the two versions of the code for this accident is excellent.

Liquid F low from Break- 26

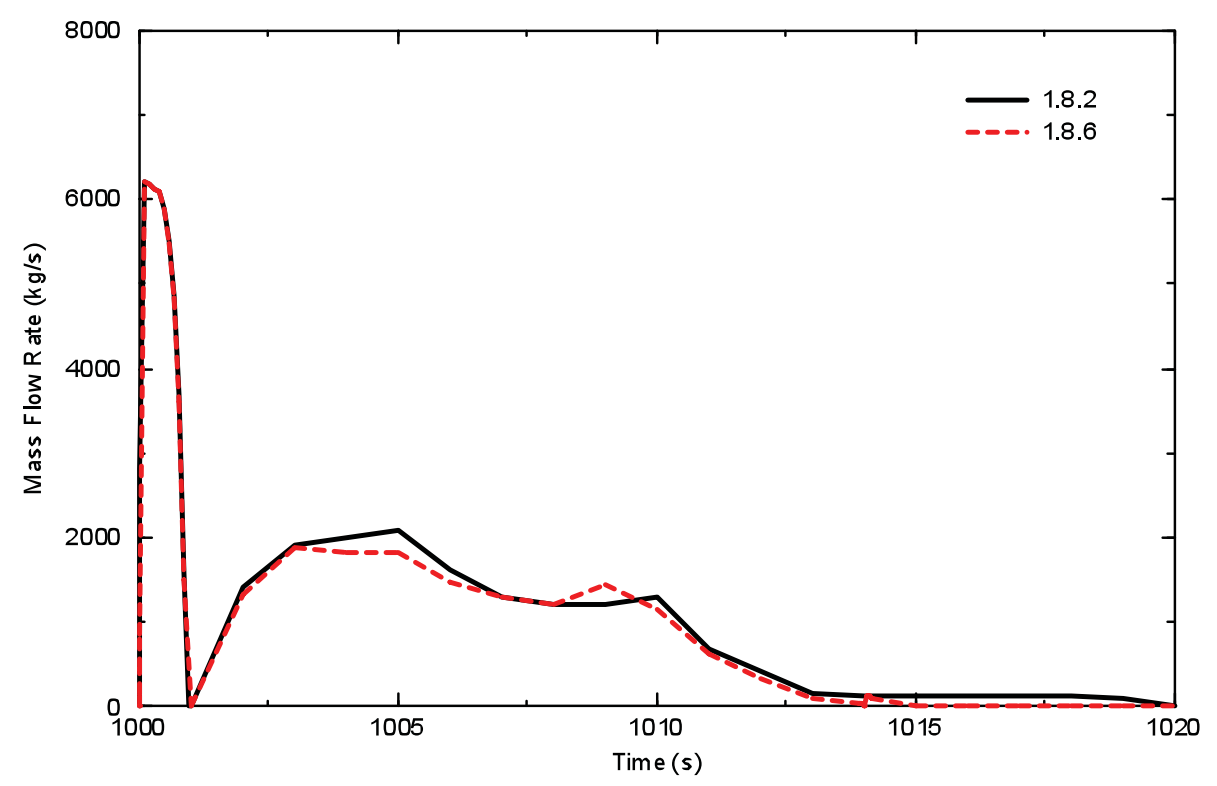

Figure 34. Liquid mass flow rate from break-26. 


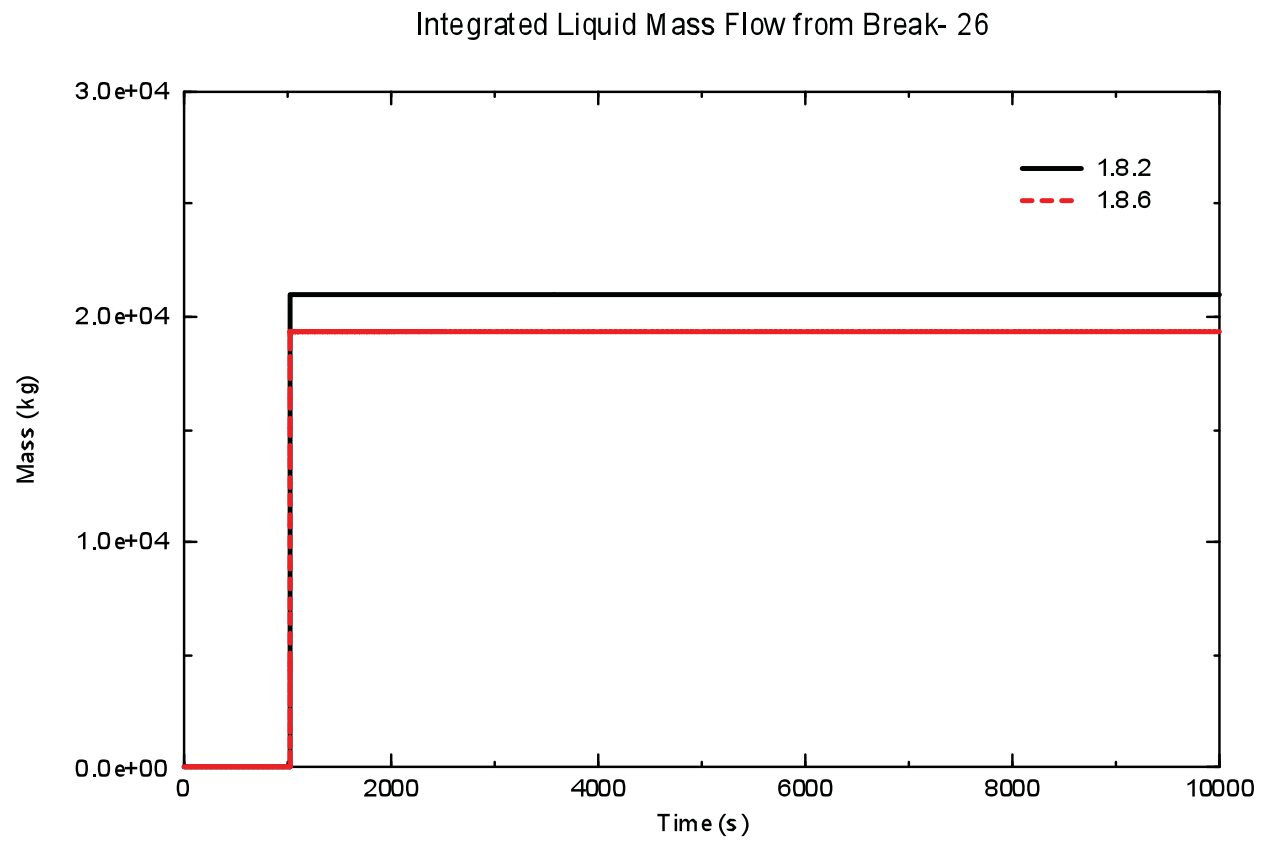

Figure 35. Integrated liquid mass flow from break-26.

Vapor Flow from Break- 26

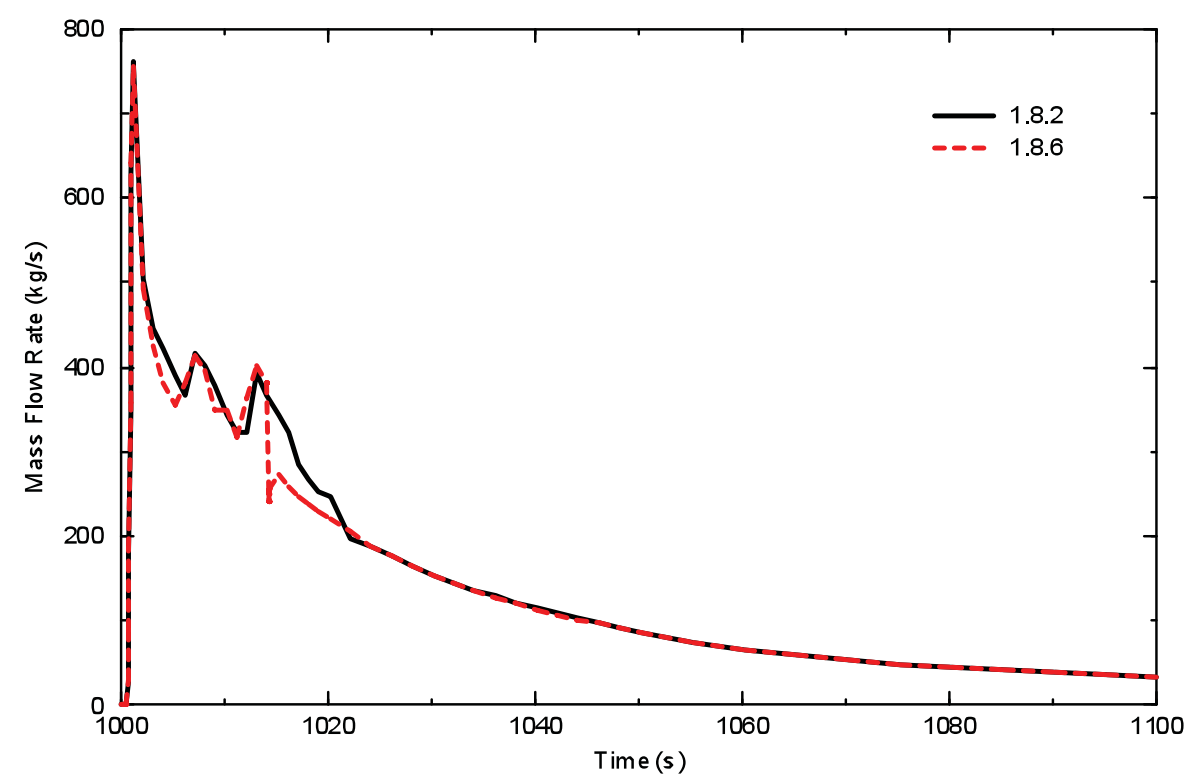

Figure 36. Vapor mass flow rate from break-26. 


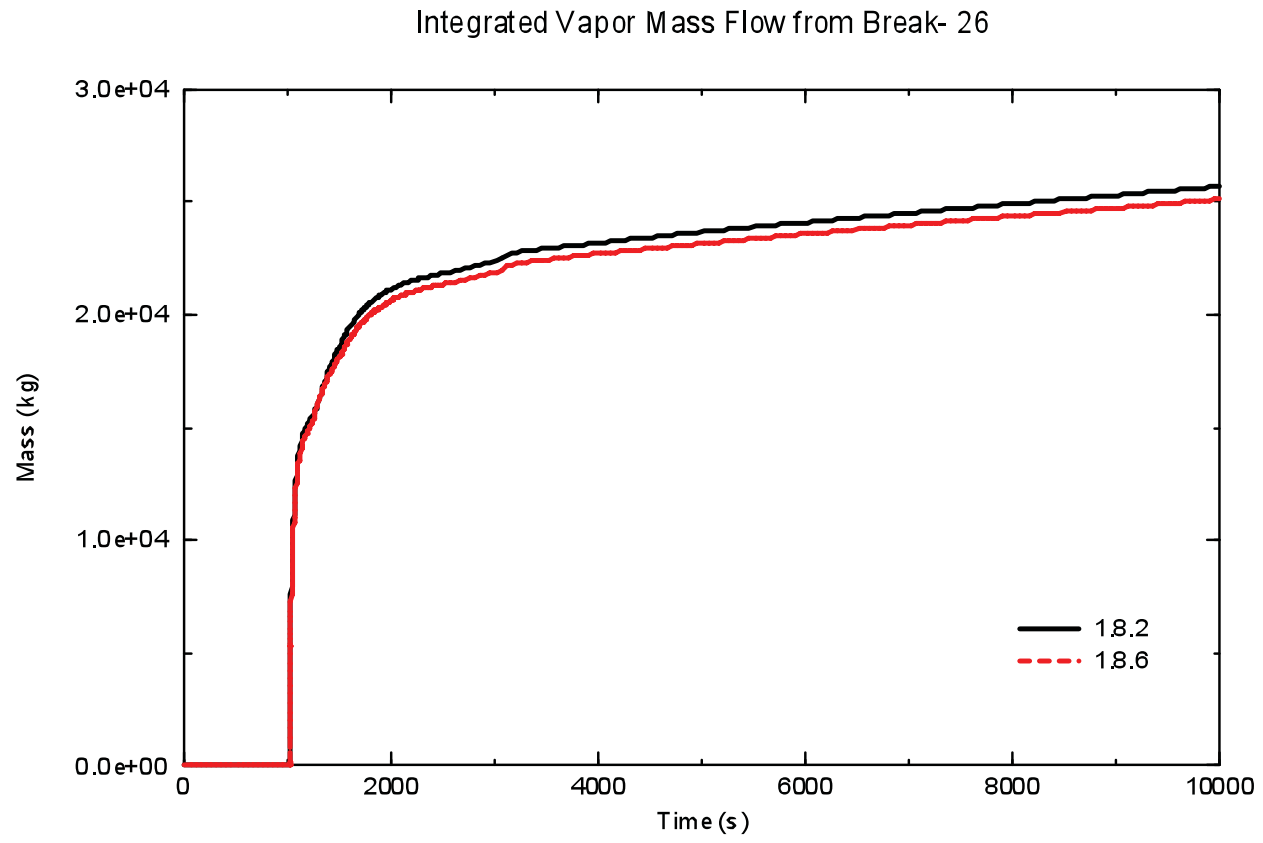

Figure 37. Integrated vapor mass flow from break-26.

Liquid F low from Break- 38

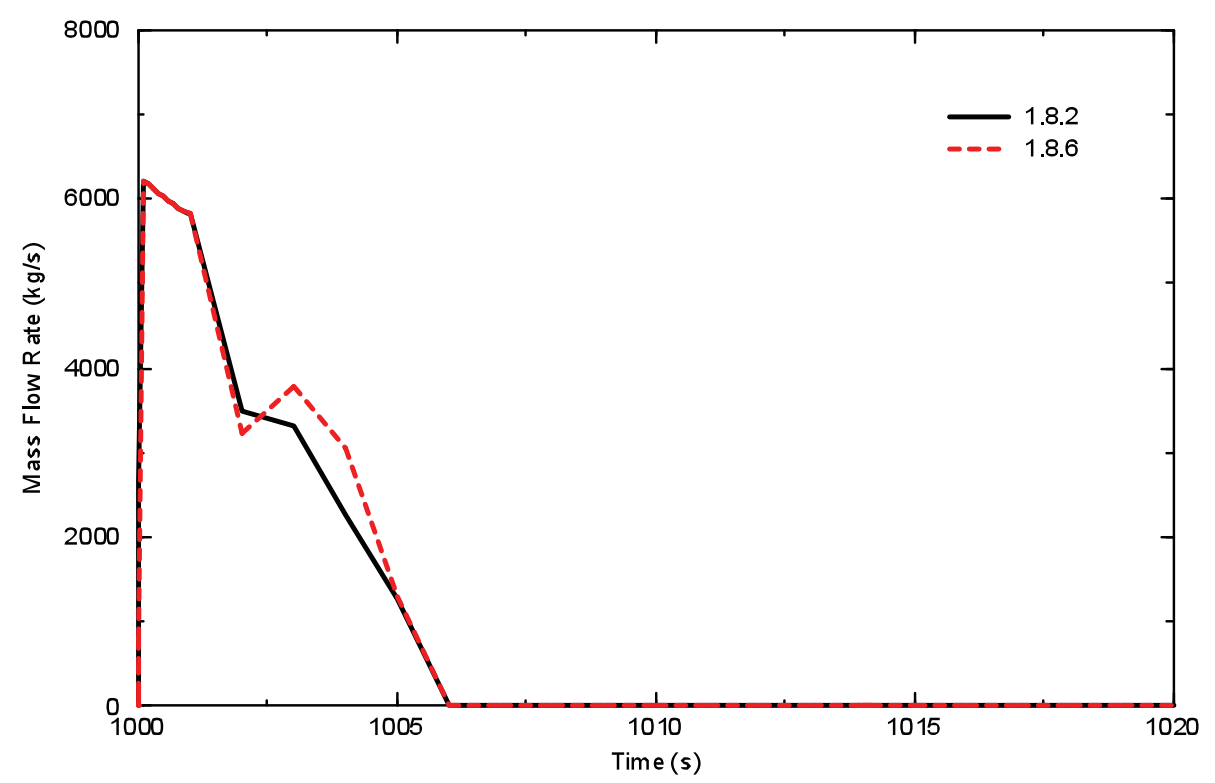

Figure 38. Liquid mass flow rate from break-38. 


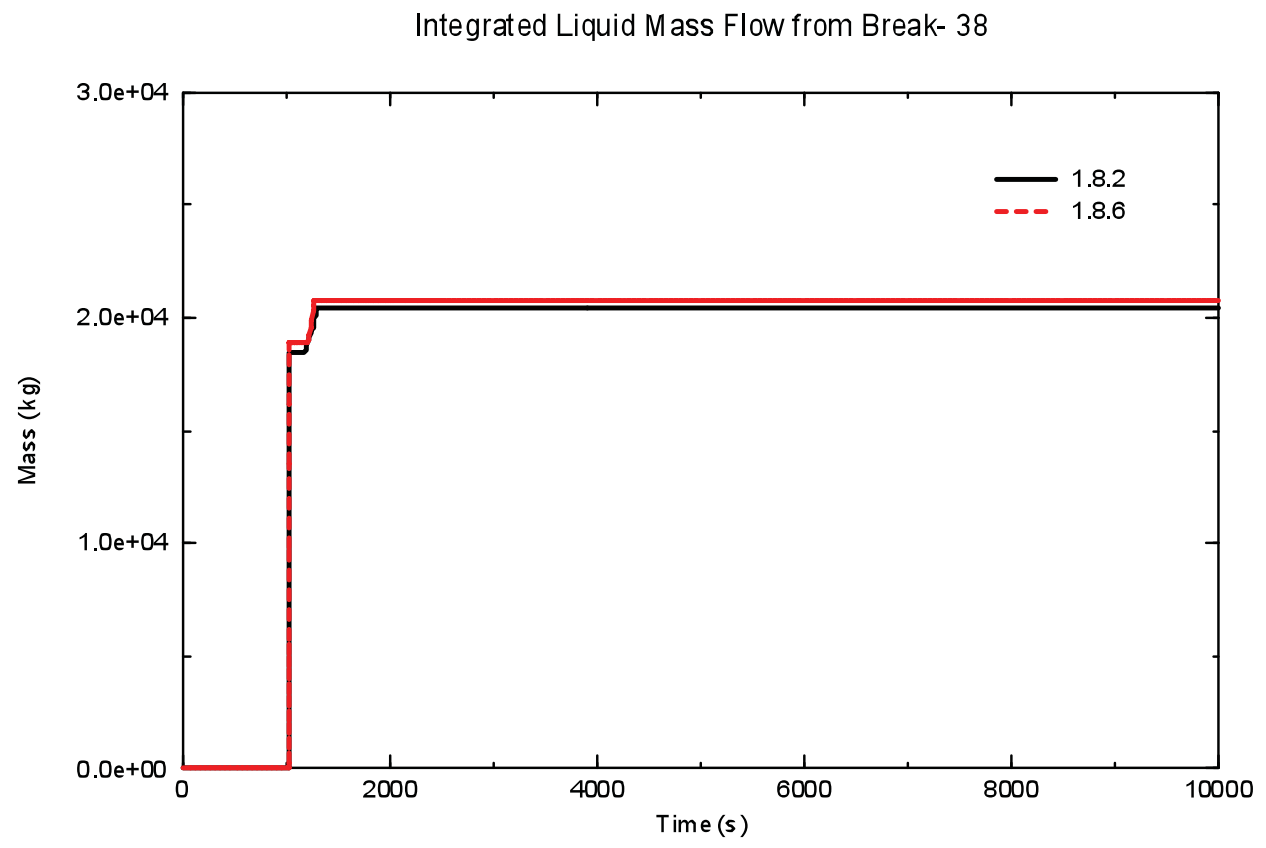

Figure 39. Integrated liquid mass flow from break-38.

Vapor F low from Break- 38

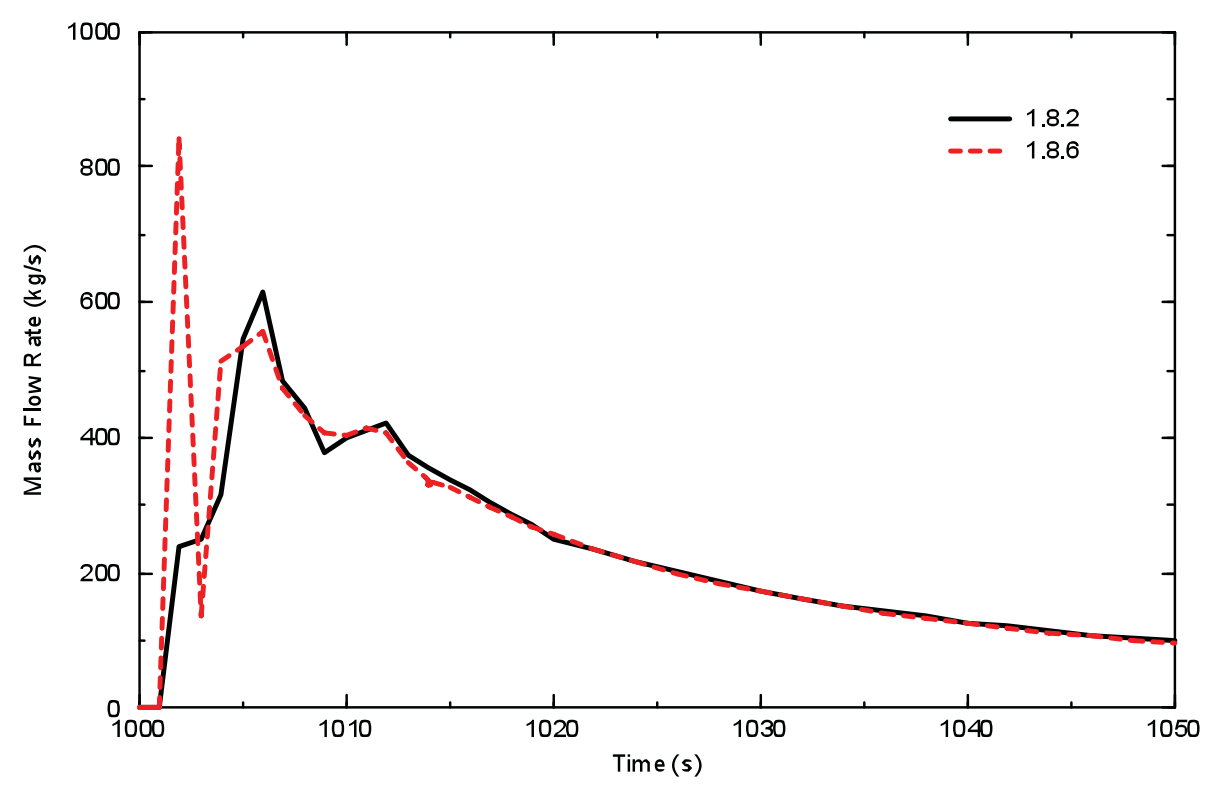

Figure 40. Vapor mass flow rate from break-38. 


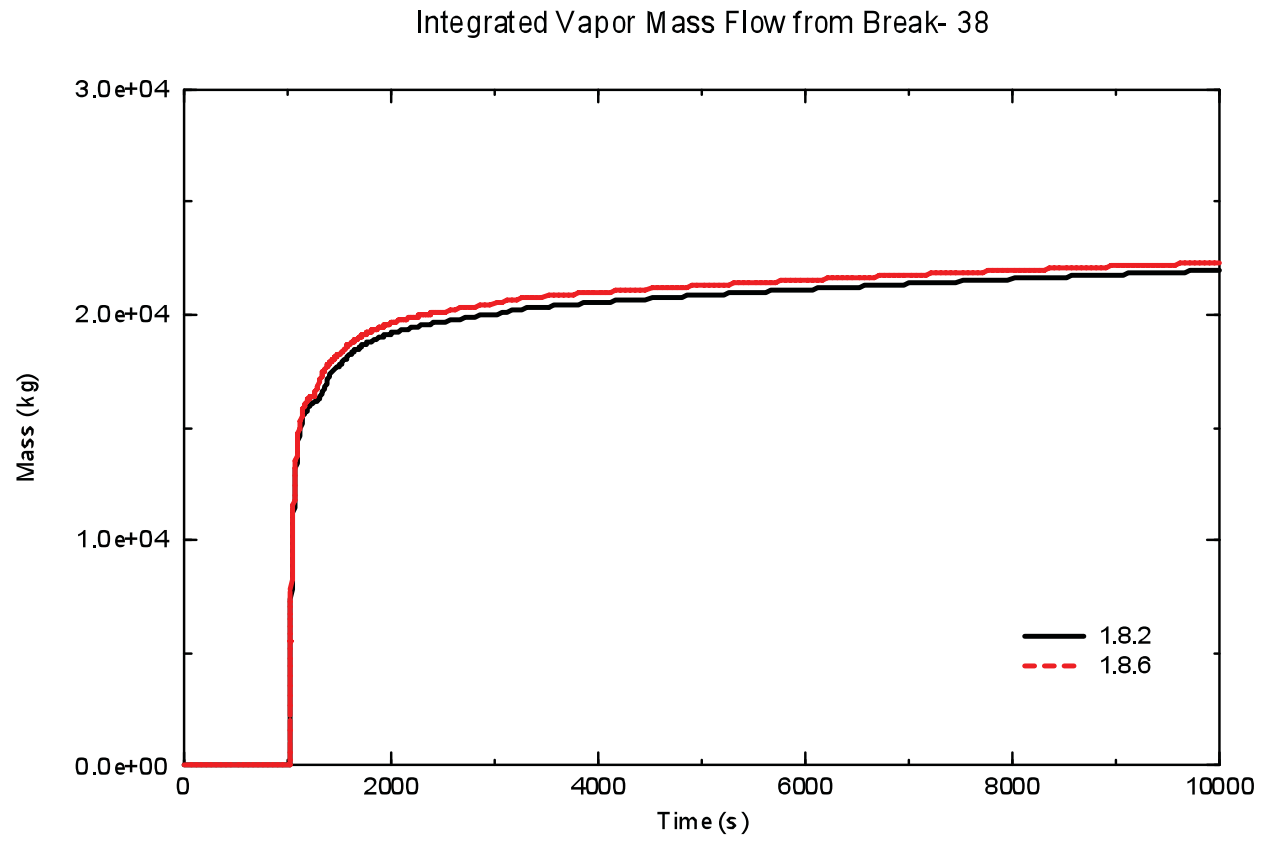

Figure 41. Integrated vapor mass flow rate from break-38.

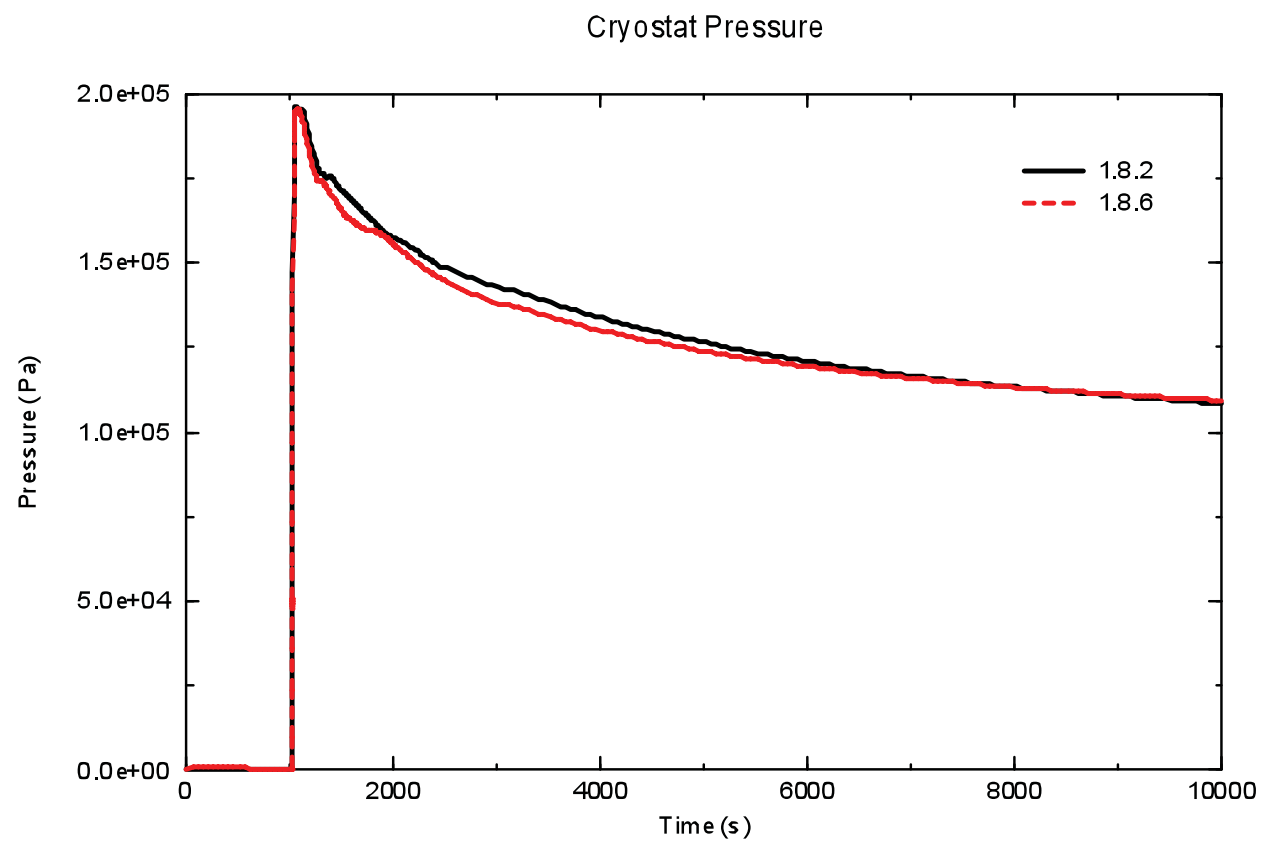

Figure 42. Cryostat pressure. 


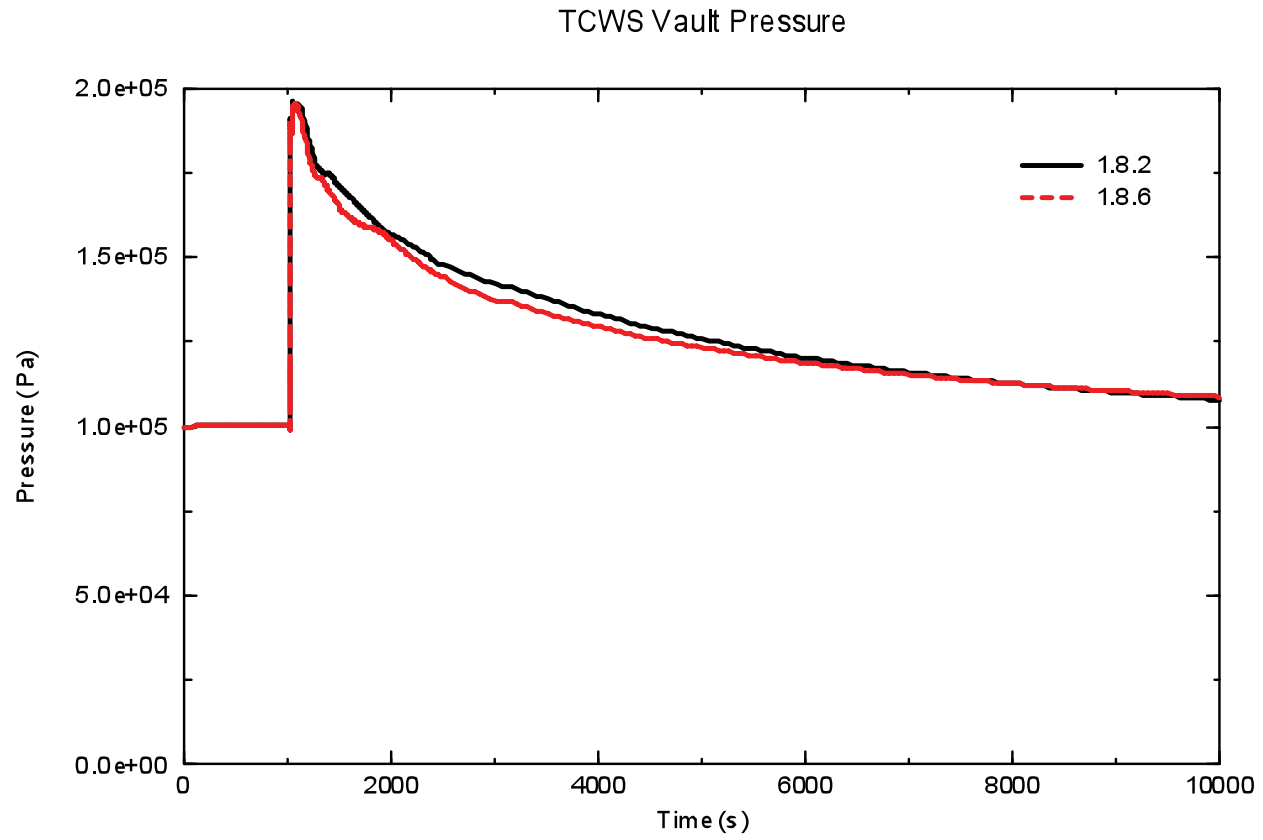

Figure 43. TCWS vault pressure.

Vapor Temperature in TCWS Vault

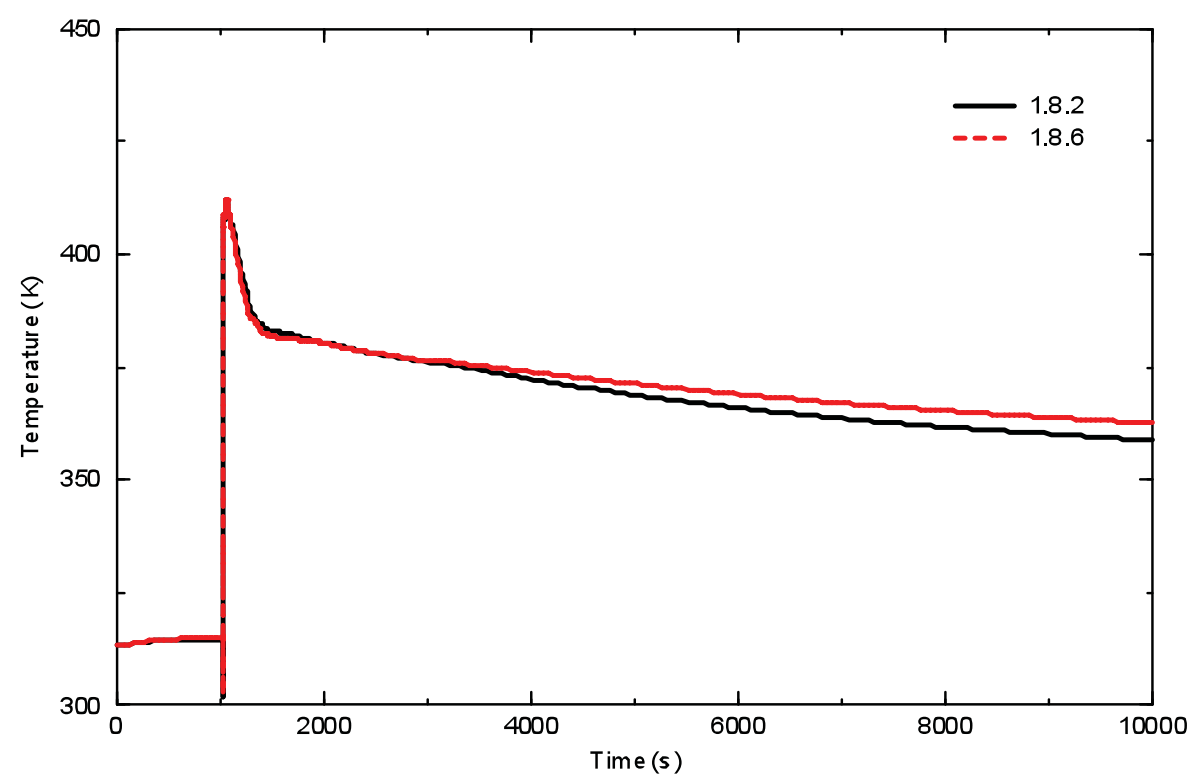

Figure 44. Vapor temperature in TCWS vault. 


\subsection{VV \& Cryostat Boundary Failure Accident}

For this accident it is assumed that energy from a magnet fault results in an intense electrical arc that is sufficient to melt the wall of the VV pumping duct and the cryostat boundary. This event impairs both the first barrier (VV) and the second barrier (cryostat) by producing two $1 \mathrm{~m}^{2}$ ruptures, resulting in a pathway that connects the interior of the VV to the cryostat air space room, thus allowing the tritium and activated dust in the VV to migrate into the cryostat, the cryostat air space room, and the gallery.

The wall rupture of the VV pumping duct results in a double-ended break of the two VV cooling loops. 50\% of the break flow area is assumed to create a flow path into the $\mathrm{VV}$, and the other $50 \%$ into the cryostat. The total break size is $0.1 \mathrm{~m}^{2}$. The pressure difference between the cryostat (500 Pa) and the VV primary heat transport system (PHTS) (1.1 MPa) causes the VV coolant to blow down as a steam/water mixture into the VV and cryostat.

The magnet damage from the arc event includes a simultaneous break of a magnet cooling line, releasing 4.5 $\mathrm{K}$ helium from the TF magnet coils $\left(21 \mathrm{~m}^{3}\right)$ into the cryostat at a spill rate of $231 \mathrm{~kg} / \mathrm{s}$ during the first $2.5 \mathrm{~s}$ and $60 \mathrm{~kg} / \mathrm{s}$ thereafter. Atmospheric air from the cryostat space room will enter the cryostat when this barrier fails.

Figures 45 and 46 contain the helium mass flow rates from the cryostat space room to the cryostat corresponding to flow paths 001 and 021 . Viewing the figures we see that there is significantly more noise in MELCOR 1.8.2, but that flow rates level off at longer times, to slightly different values. The difference in the integrated value beyond 45,000 seconds is apparent in Figure 47. Similar results for nitrogen through the same flow paths are shown in Figures 48, 49, and 50, respectively. Similar differences, though larger in magnitude, are observed.

The vapor mass flow rates from the VV to the cryostat through flow paths 014 and 024 and are presented in Figures 51 and 52, respectively. The integrated mass flow through the two flow paths are presented in Figures 53 and 54. There is a large discrepancy for the integrated flow through path 024 in particular, due entirely to higher flow rates in MELCOR 1.8 .2 between 1500 and 3500 seconds.

The source of these differences in flow rates is not known, but may be related to the change to double precision calculations in MELCOR 1.8.6.

Figures 55 and 56 present the time history of the vapor and liquid temperature in the cryostat. There is excellent agreement between the temperature results produced by the two versions of the code.

The mass of airborne dust, the mass of dust in the pool, and dust deposited on the cryostat structure are presented in Figures 57, 58, and 59, respectively. A larger amount of dust reaches the cryostat in MELCOR 1.8.2 due to higher vapor flow rates. A large difference in deposition is also observed. This was due to the fact that dust was being washed off of heat structures by liquid water in MELCOR 1.8.2. When this wash-off is disabled, deposition behavior is similar; note again that the total dust deposited is lower as less dust reaches the cryostat in MELCOR 1.8.6.

For this accident there is again good agreement between the predicted results from the two versions of the code, even given the change described above. 


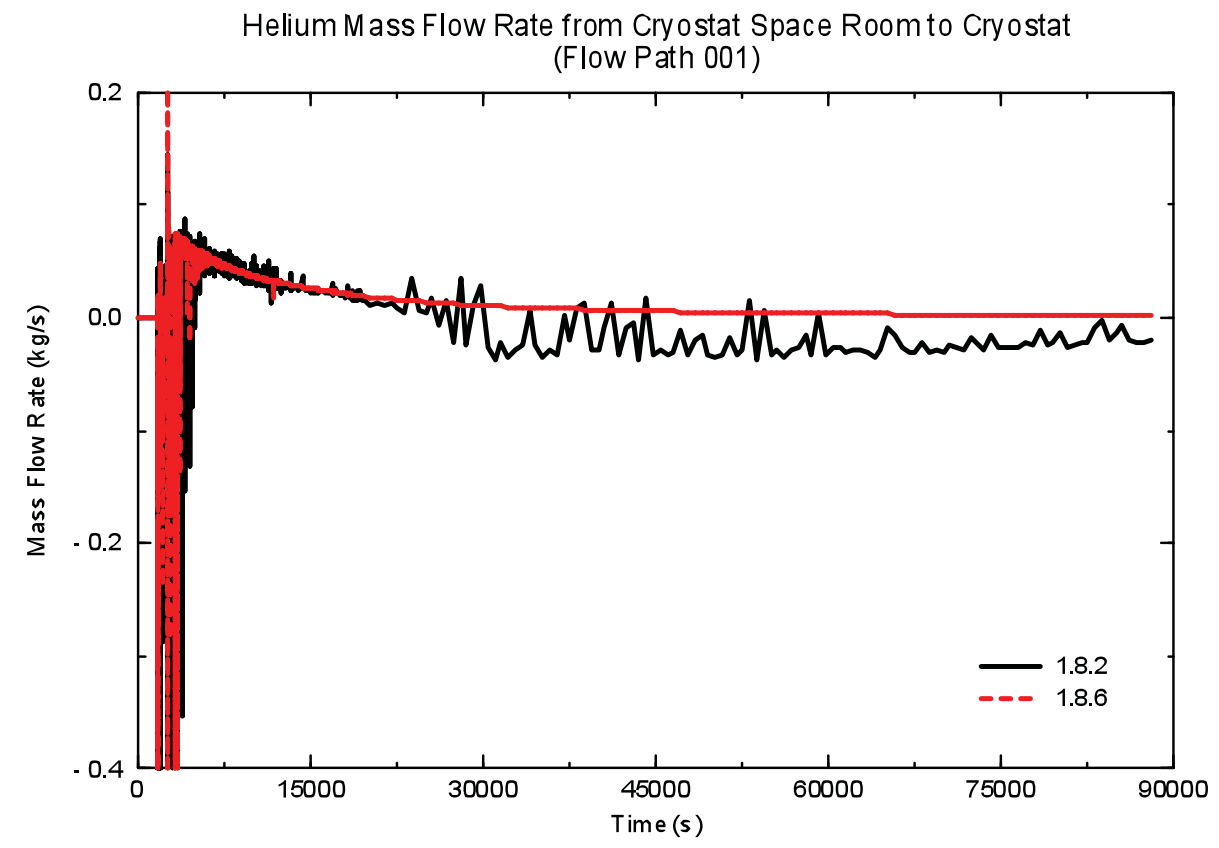

Figure 45. Helium mass flow rate from cryostat space room to cryostat (flow path 001).

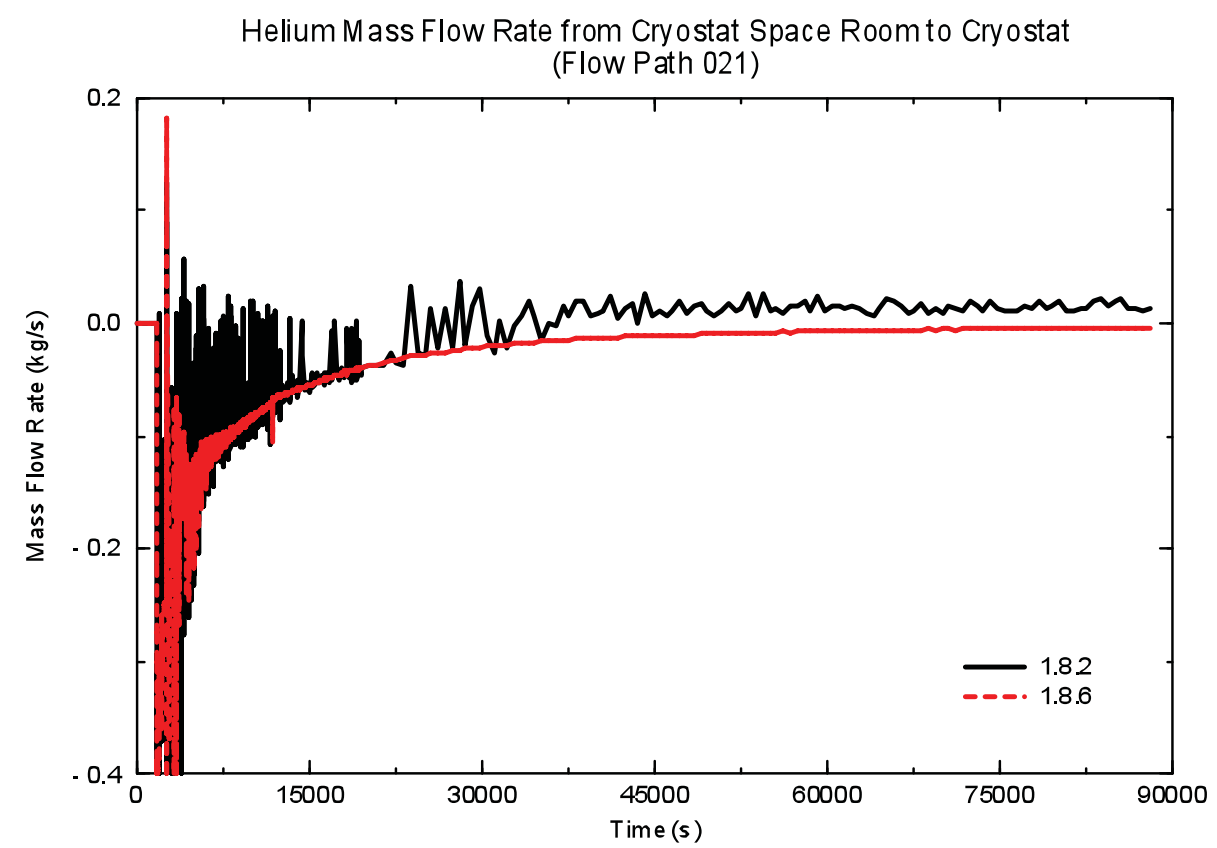

Figure 46. Helium mass flow rate from cryostat space room to cryostat (flow path 021). 


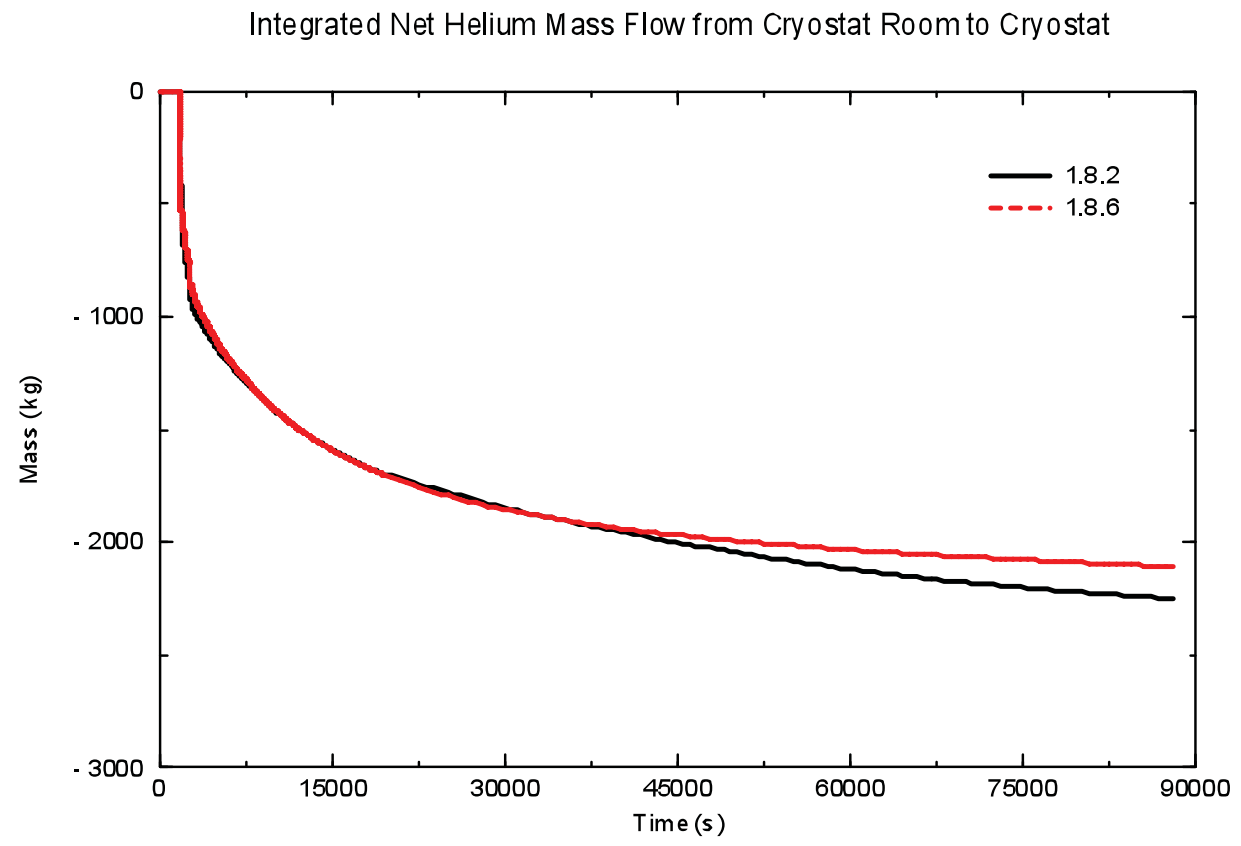

Figure 47. Integrated net helium mass flow from cryostat room to cryostat.

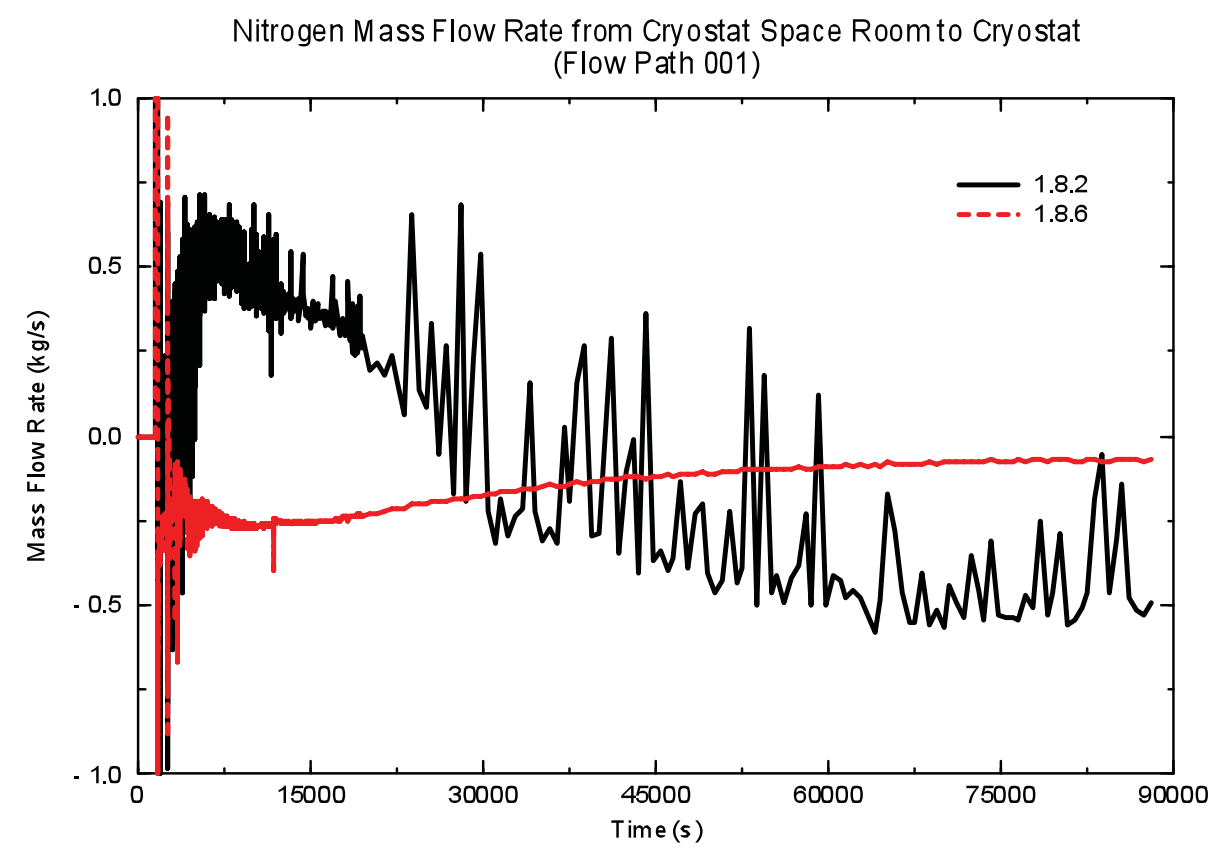

Figure 48. Nitrogen mass flow rate from cryostat space room to cryostat (flow path 001). 


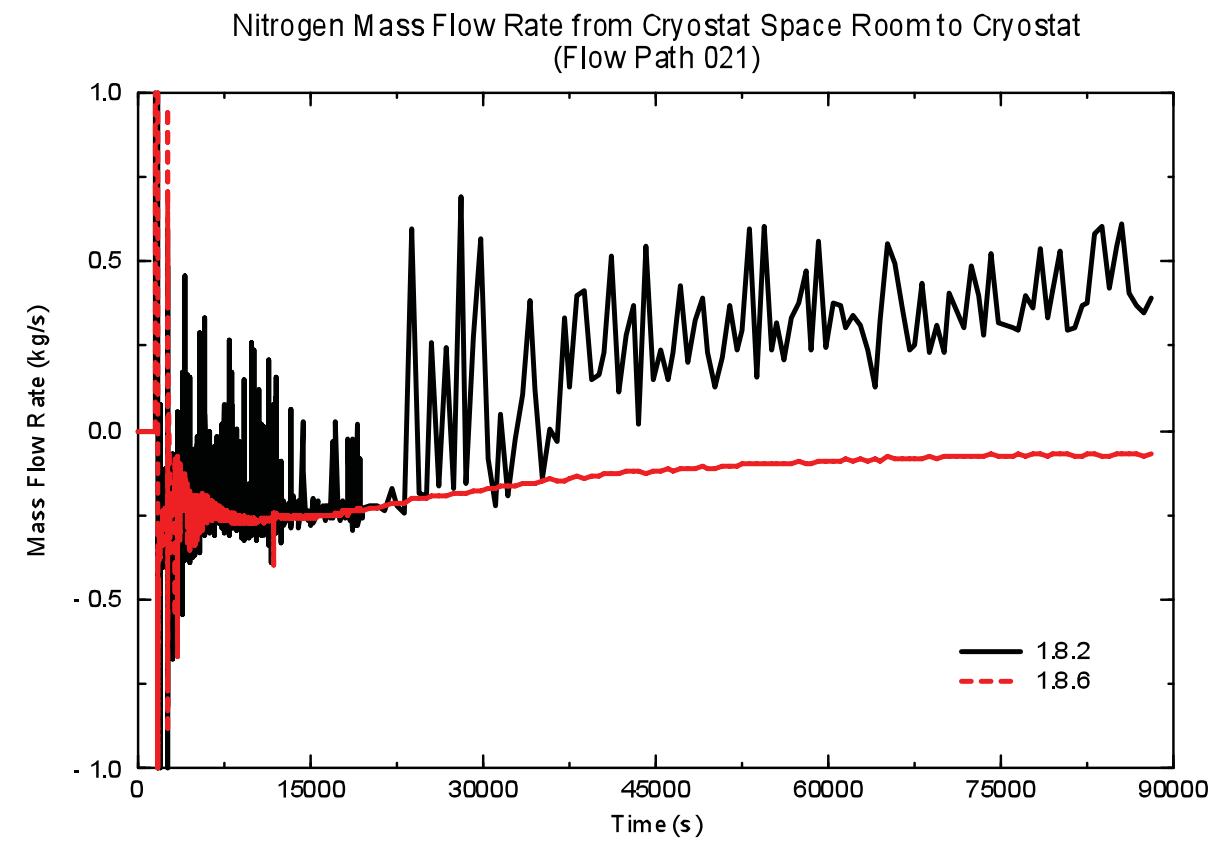

Figure 49. Nitrogen mass flow rate from cryostat space room to cryostat (flow path 021 ).

Integrated Net Nitrogen Mass Flow from Cryostat Space Room to Cryostat

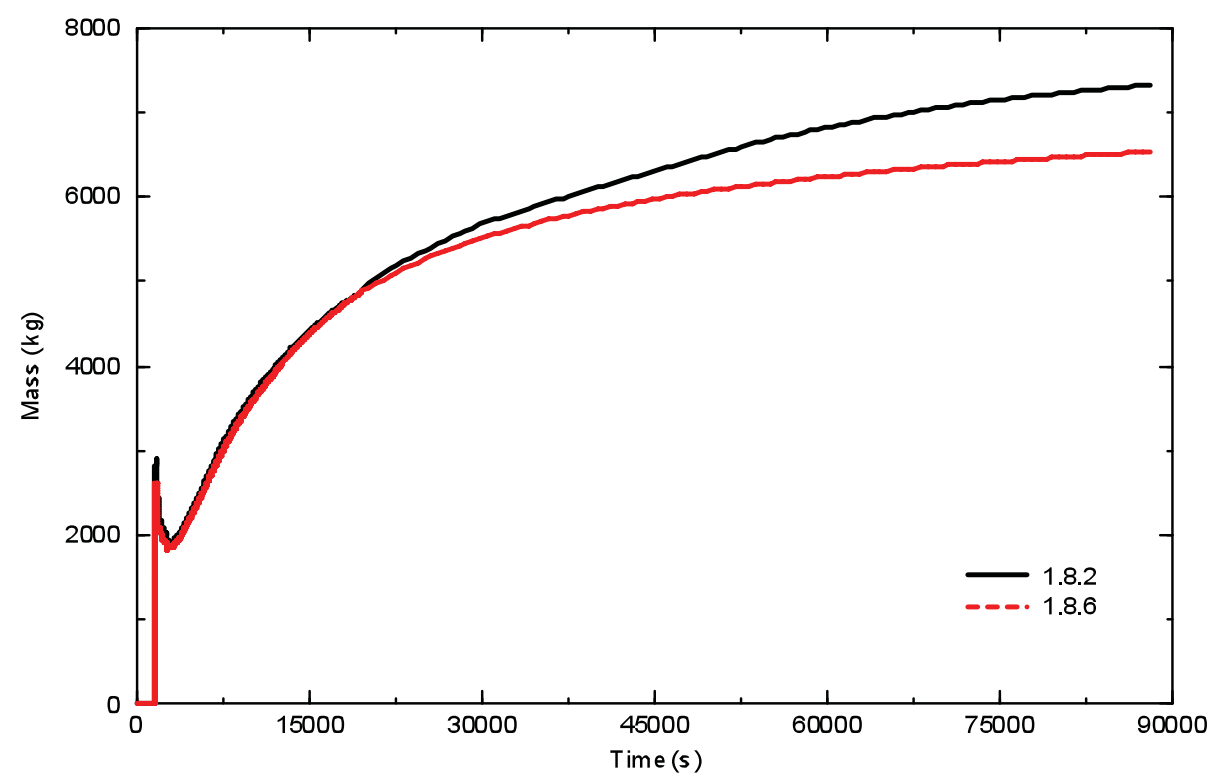

Figure 50. Integrated net nitrogen mass flow from cryostat space room to cryostat. 


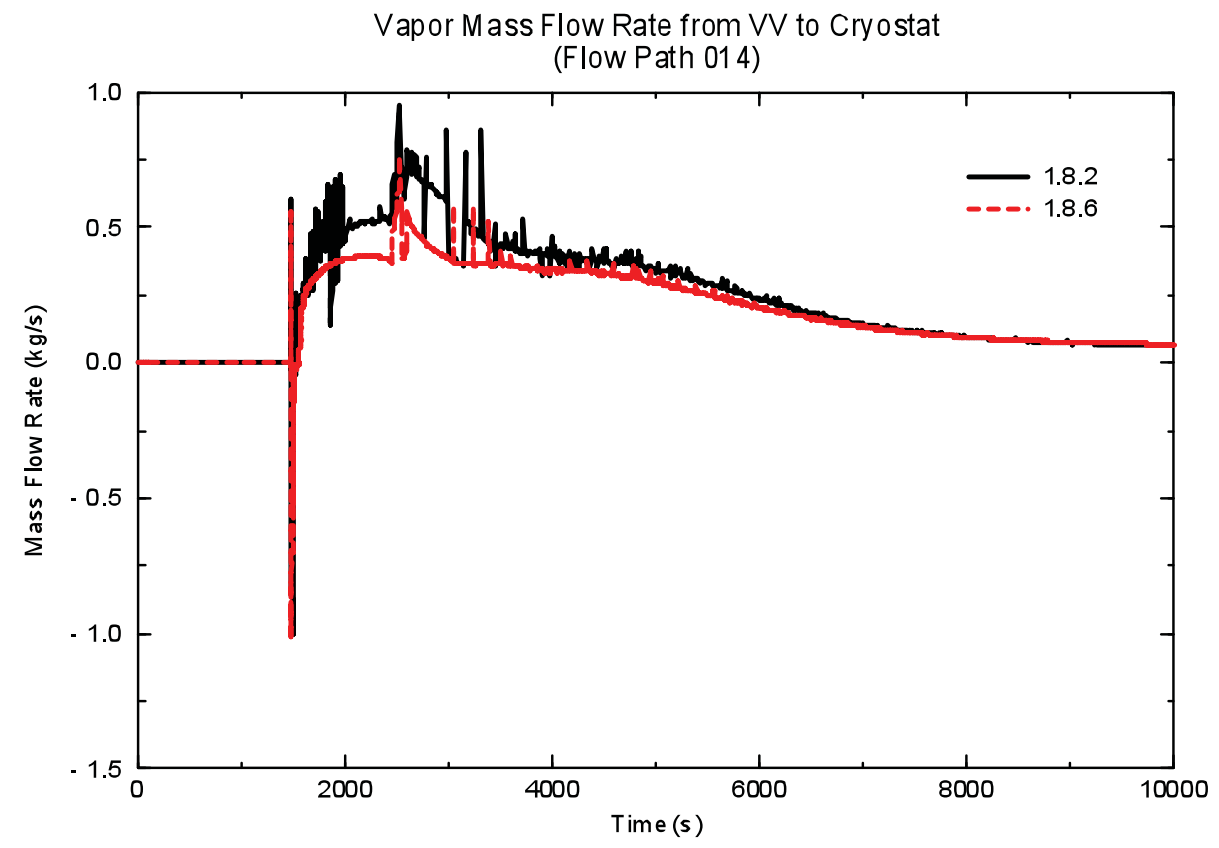

Figure 51. Vapor mass flow rate from VV to cryostat (flow path 014).

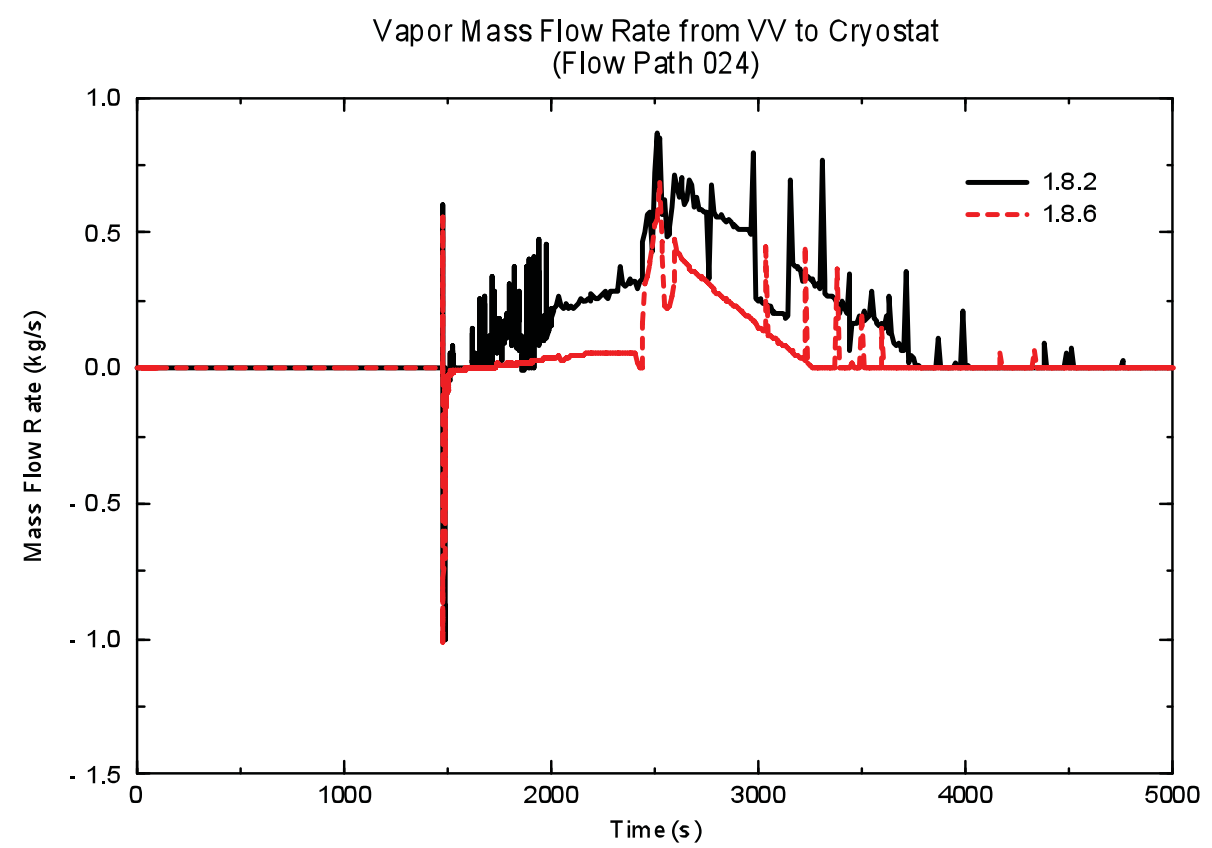

Figure 52. Vapor mass flow rate from VV to cryostat (flow path 024). 


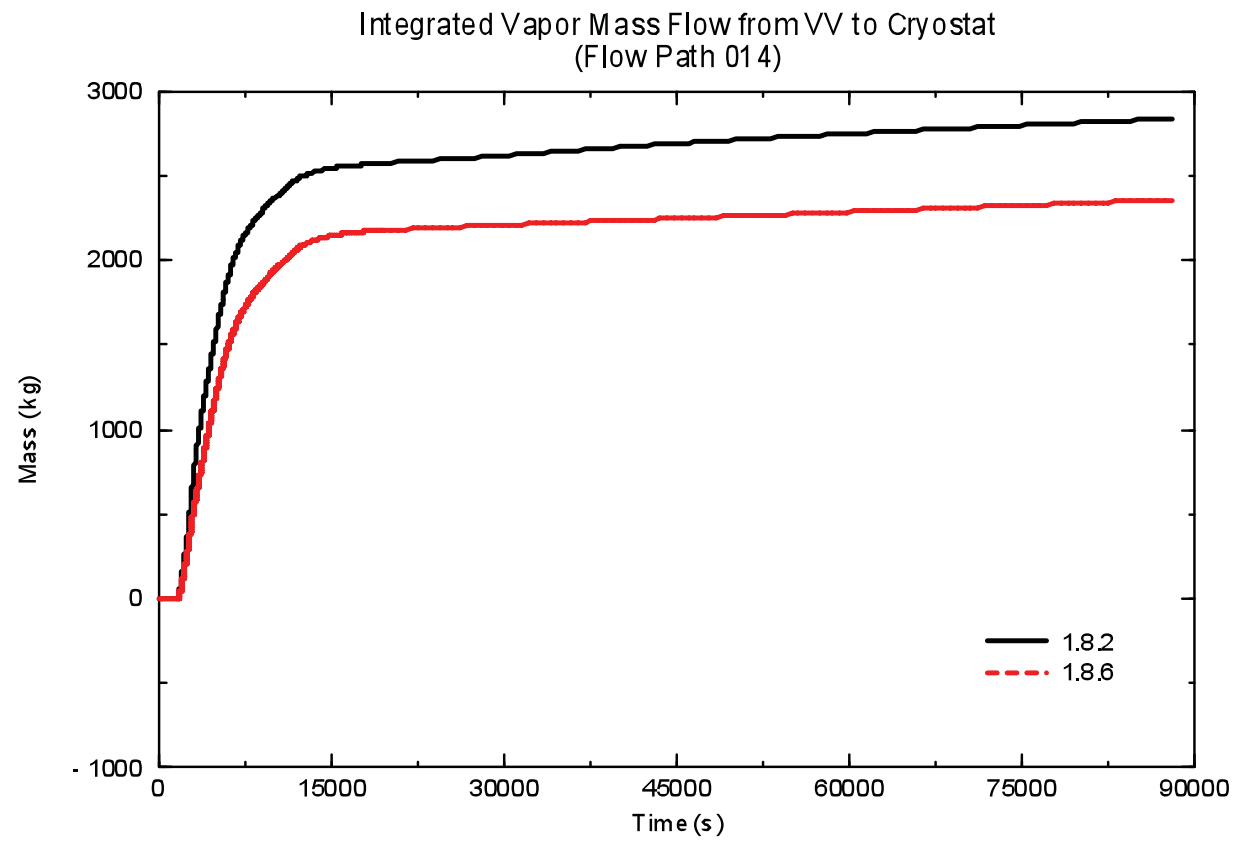

Figure 53. Integrated vapor mass flow from VV to cryostat (flow path 014).

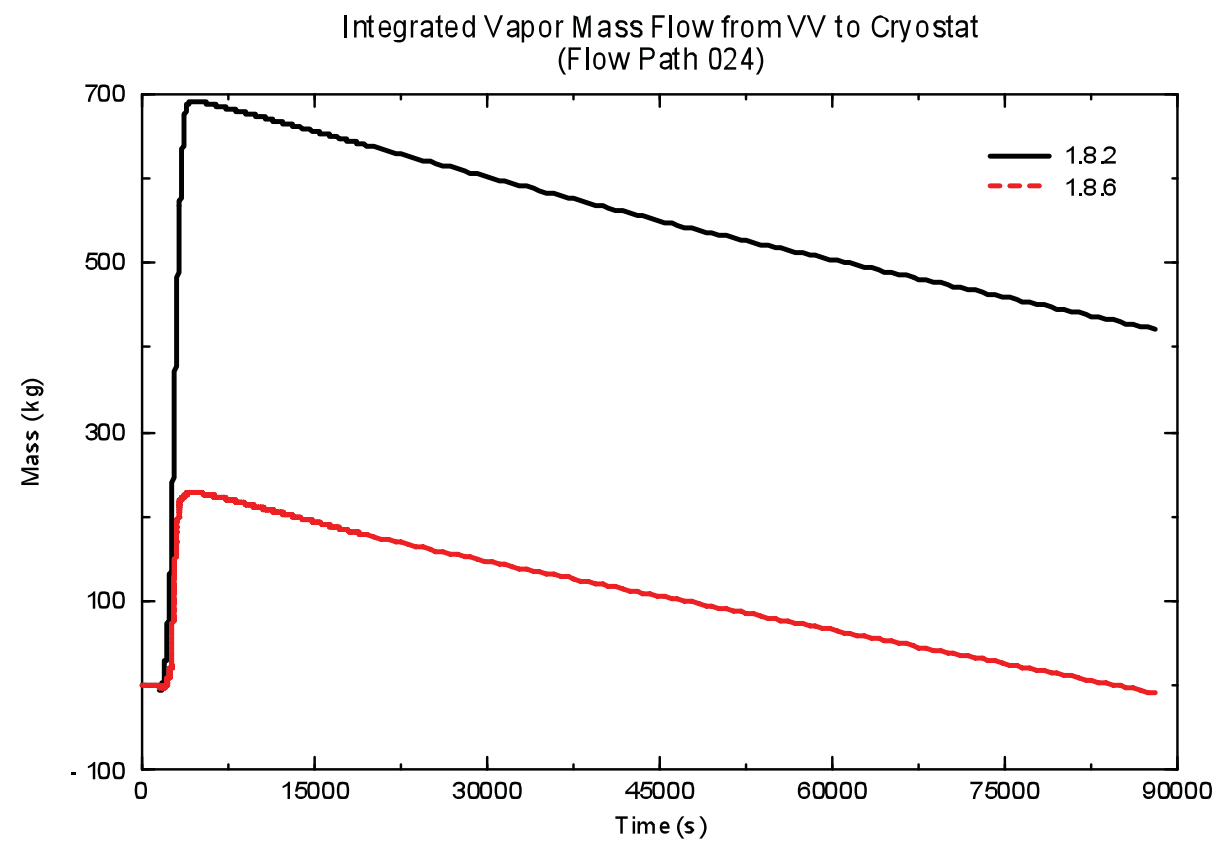

Figure 54. Integrated vapor mass flow from VV to cryostat (flow path 024). 


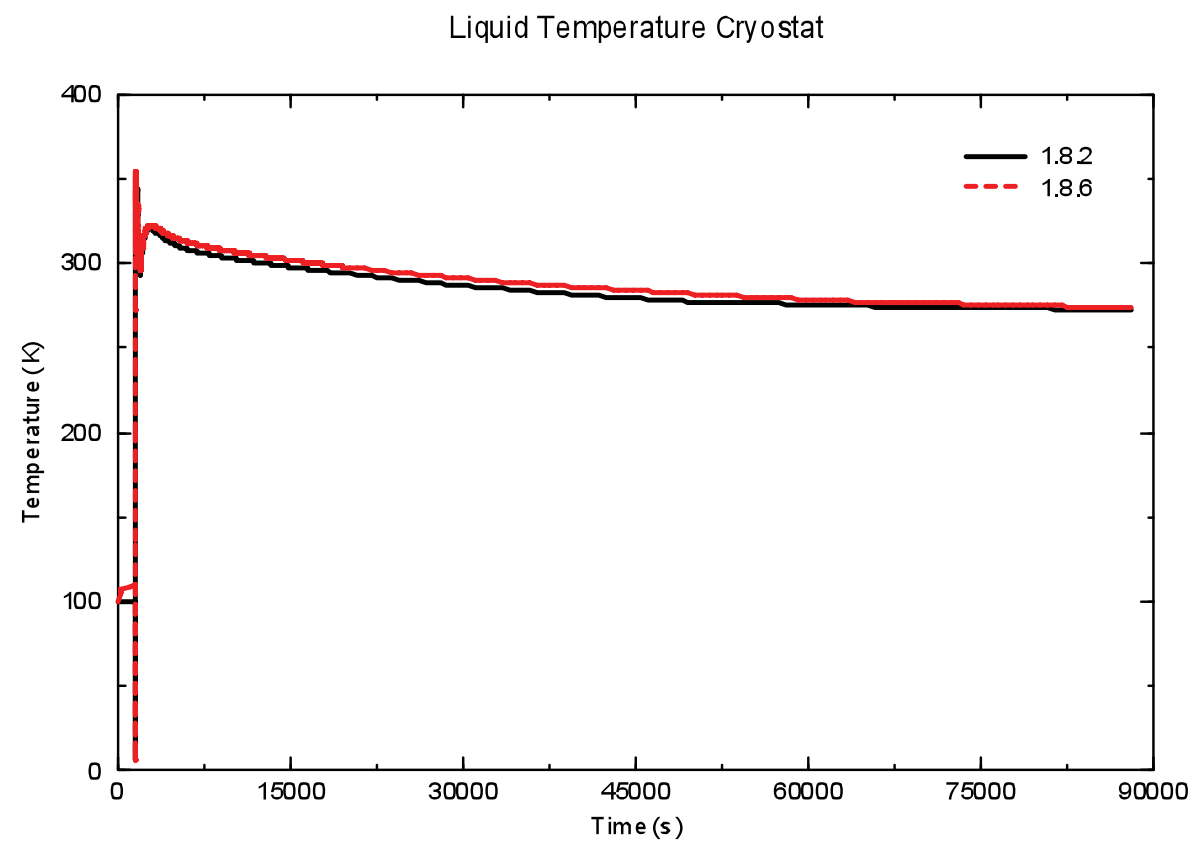

Figure 55. Liquid temperature in cryostat.

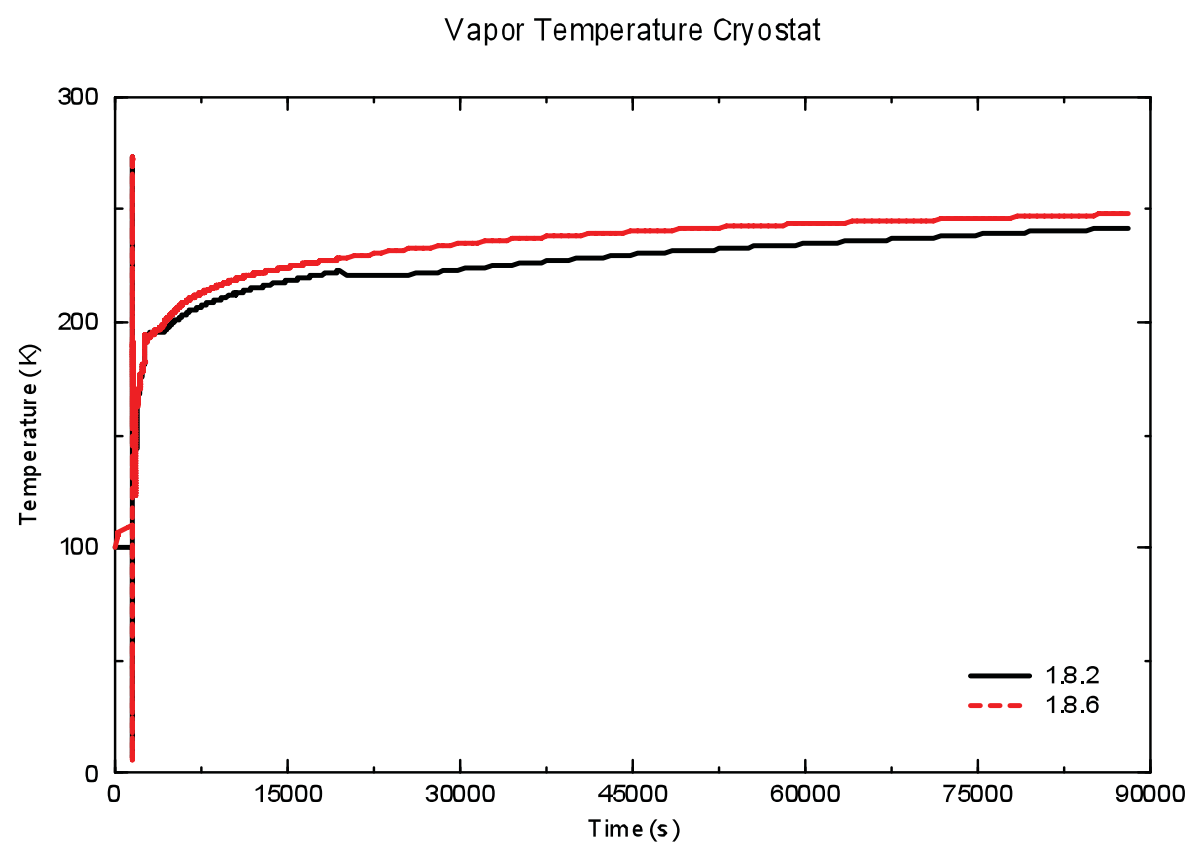

Figure 56. Vapor temperature in cryostat. 


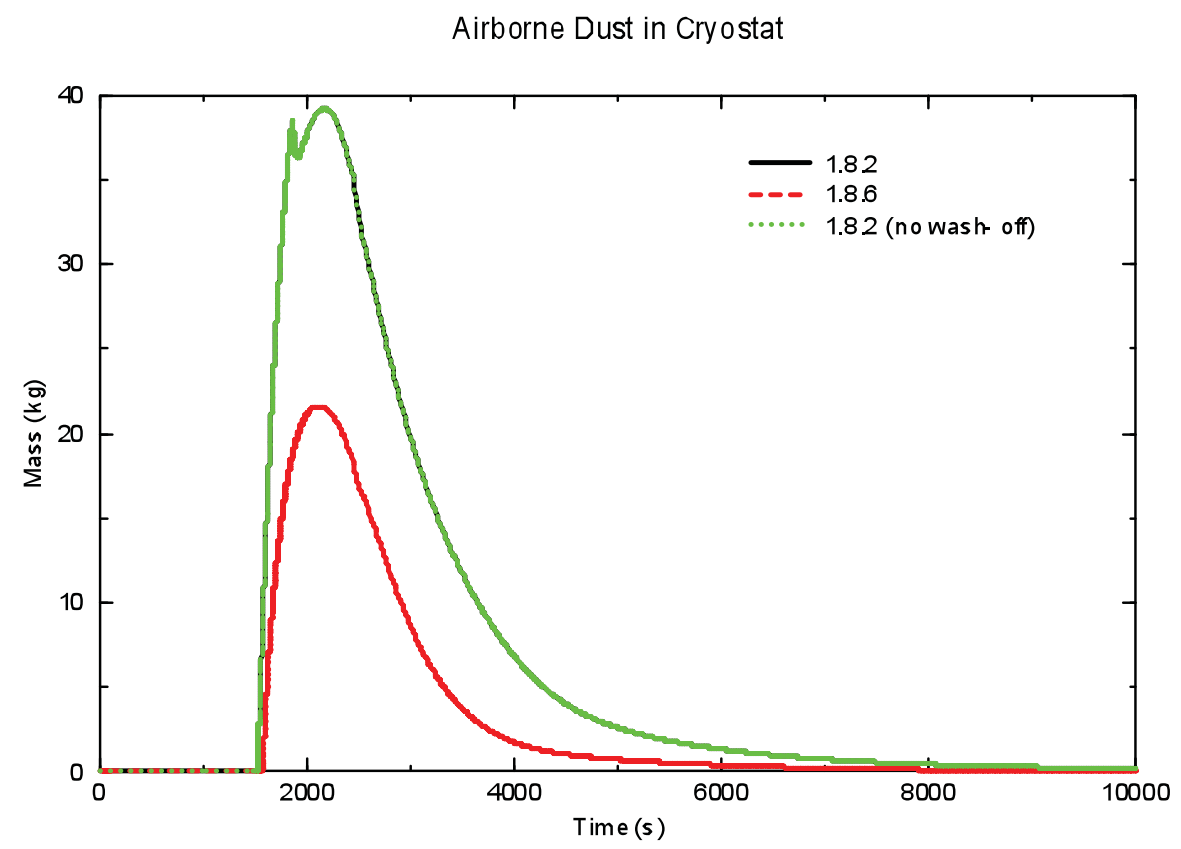

Figure 57. Airborne dust in cryostat.

\section{Cryostat Dust in Pool}

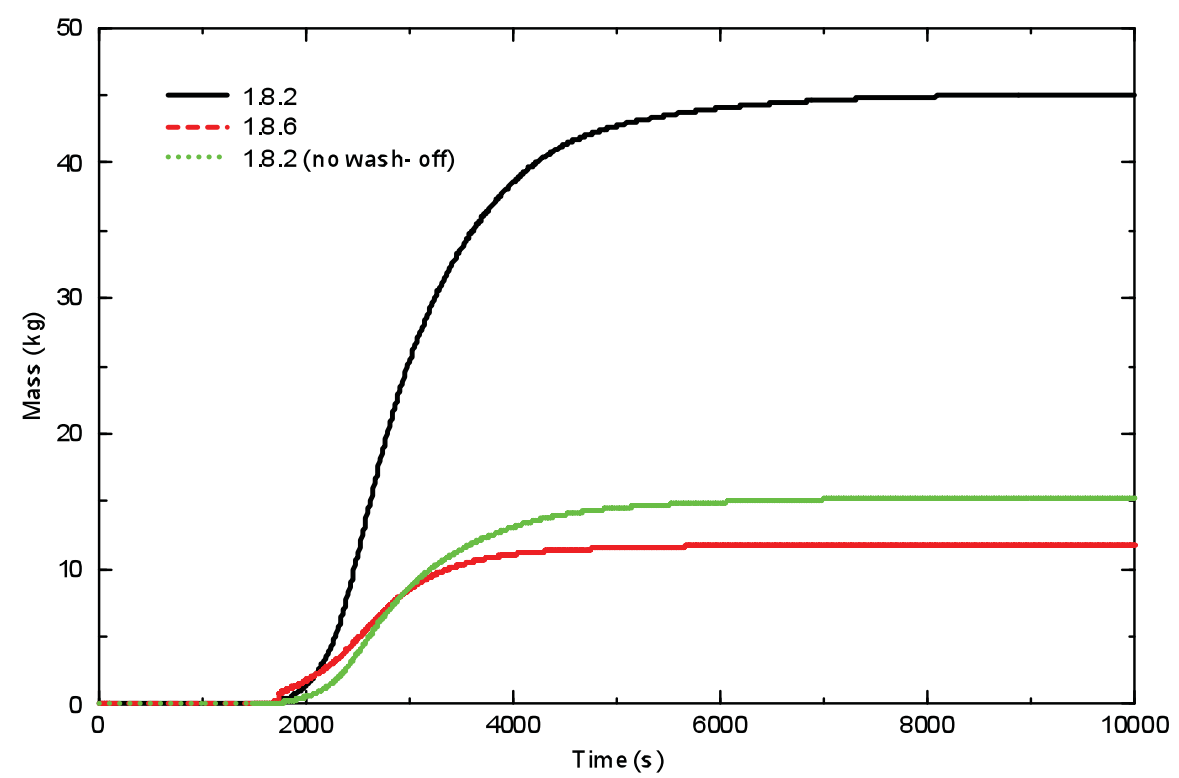

Figure 58. Cryostat dust in pool. 


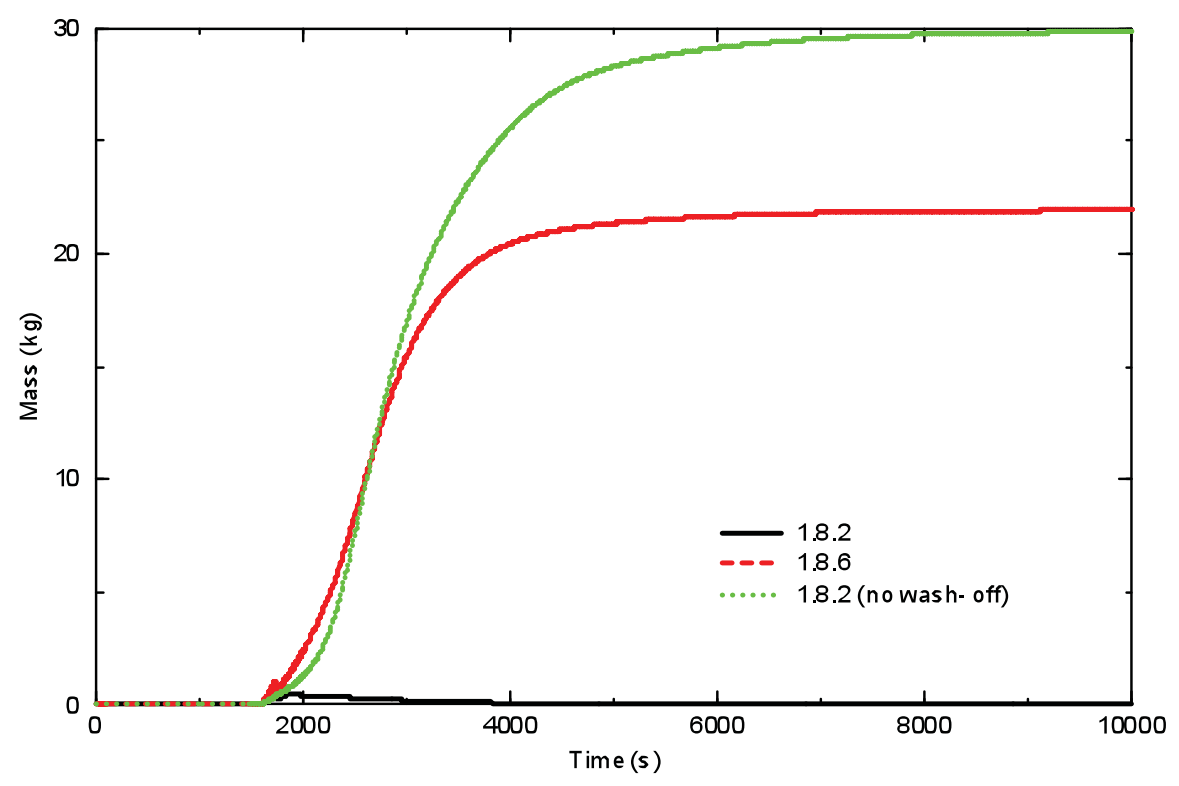

Figure 59. Cryostat dust deposited on heat structures.

\section{Developmental Test Problems Comparison}

Modifications were first made to MELCOR 1.8.2 between 1995 and 1997 by the INL and documented in [2$4,6]$. These references describe developmental test problems that were run in order to assess the execution of this modified version of the MELCOR 1.8.2 code. These test problems were re-run with the pedigreed version of MELCOR 1.8.2 and described in the MELCOR 1.8.2 pedigree report [7]. The same decks used in that report were modified to run in MELCOR 1.8.6, with a comparison of the results below.

\subsection{Water Freezing Test Problem}

\subsubsection{Water Freezing Test Problem Model Description}

The first test problem is one which demonstrates the capability of the fusion version of MELCOR to model the freezing of water in the event that a coolant pipe break in the cryostat were to occur. This test problem, described in [4] and repeated here for clarity, consists of one control volume and one heat structure. The volume and height of the control volume are $20,300 \mathrm{~m}^{3}$ and $32 \mathrm{~m}$, respectively. The control volume is initially filled with steam and air. The mixture of steam and air is assumed to have a total pressure of $1.0 \mathrm{E}+05 \mathrm{~Pa}$ and a temperature of $373 \mathrm{~K}$. The partial pressure of the steam was assumed to be $0.9999 \mathrm{E}+05 \mathrm{~Pa}$. The heat structure within this control volume is stainless steel with a surface area of $6,040 \mathrm{~m}^{2}$ and an initial temperature of $4.5 \mathrm{~K}$. The heat structure was placed six meters above the floor of the control volume, extends $20 \mathrm{~m}$ vertically, and is $0.487 \mathrm{~m}$ thick. The dimensions of this problem are characteristic of those of the cryostat and magnet structures of the 1995 version of the ITER design. Ten thermal nodes were placed in this structure, which vary in thickness from $0.005 \mathrm{~m}$ at the front surface (adjacent to the steam) and $0.1 \mathrm{~m}$ at the back of the structure. The back surface is assumed to be adiabatic, while at the front surface the normal MELCOR heat transfer package was applied. This test problem is depicted schematically in Figure 60. 


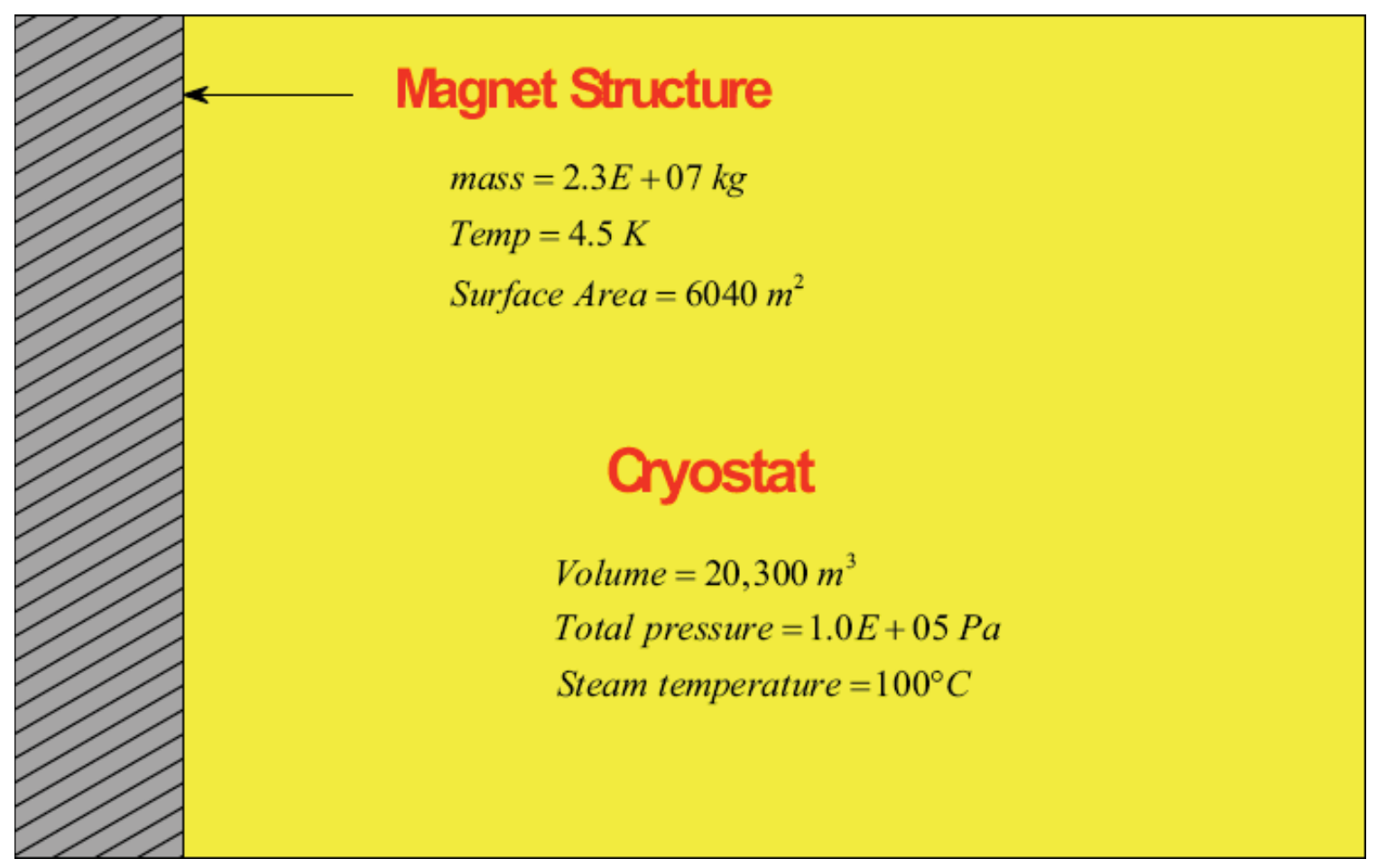

Figure 60. Single cell test problem for MELCOR ice freezing modifications.

\subsubsection{Water Freezing Test Problem Results}

The results of the comparison between the fusion pedigreed version of MELCOR 1.8.2 and MELCOR 1.8.6 for this test problem are contained in Figures 61 through 64. Figure 61 contains the heat structure front surface temperatures. The peak temperature for the magnet heat structure in MELCOR 1.8.6 was approximately $181 \mathrm{~K}$ occurring at approximately 50 seconds into the transient. The peak heat structure temperature corresponding to the pedigreed version of MELCOR 1.8.2 was $172 \mathrm{~K}$ and occurred at 60 seconds into the transient. Figure 62 shows the pressure variation in the control volume for the two cases. The pressure in MELCOR 1.8.6 decreases at a faster rate than for 1.8.2, however by 200 seconds the pressure in the control volume for both cases is approximately the same (600-800 Pa). Figure 63 contains the history of the vapor temperature in the control volume. The vapor temperature in MELCOR 1.8.6 drops from $373 \mathrm{~K}$ down to $273 \mathrm{~K}$ by 185 seconds. By 225 seconds, no liquid remains, and the temperature drops sharply from the triple point. In MELCOR 1.8.2, the vapor temperature decreases more gradually, reaching the triple point at 215 seconds and remaining there until 295 seconds. Later in time, the slope of the vapor temperature history changes as the vapor temperature in the control volume comes into equilibrium with the stainless steel (SS) heat structure. This occurs at approximately 450 seconds in MELCOR 1.8.2 and 300 seconds in MELCOR 1.8.6. Figure 64 contains the ice layer thickness on the surface of the magnet heat structure for this test case. The ice layer in MELCOR 1.8 .2 grew to $1.81 \mathrm{~cm}$ but was slightly larger $(1.88 \mathrm{~cm})$ in MELCOR 1.8.6. Both remained constant for the remainder of the transient.

The differences observed in this case are due to a change in the way MELCOR calculates film temperatures and mass transport between the phases. MELCOR 1.8.2 assumes that the film temperature is constant and equal to that of the surface on which it resides; in MELCOR 1.8.6, a temperature distribution is determined across the layer. The condensation is determined by the rate at which water will diffuse through the noncondensable boundary layer of air or helium that develops near the surface of the heat structure. This 
condensation mass flux is proportional to a mass transfer coefficient $h_{D}$ that increases with temperature. The temperature used to evaluate the mass transfer coefficient will simply be the heat structure surface temperature in MELCOR 1.8.2; in MELCOR 1.8.6, an average temperature of the film is used, which in the present case will always be higher (Figure 65). The increased mass transfer coefficient is seen in Figure 66. Some differences may also occur due to the aforementioned change to double precision calculations in the thermodynamics package. In particular, MELCOR 1.8.2 predicts a significantly greater fog mass in the cryostat (Figure 67).

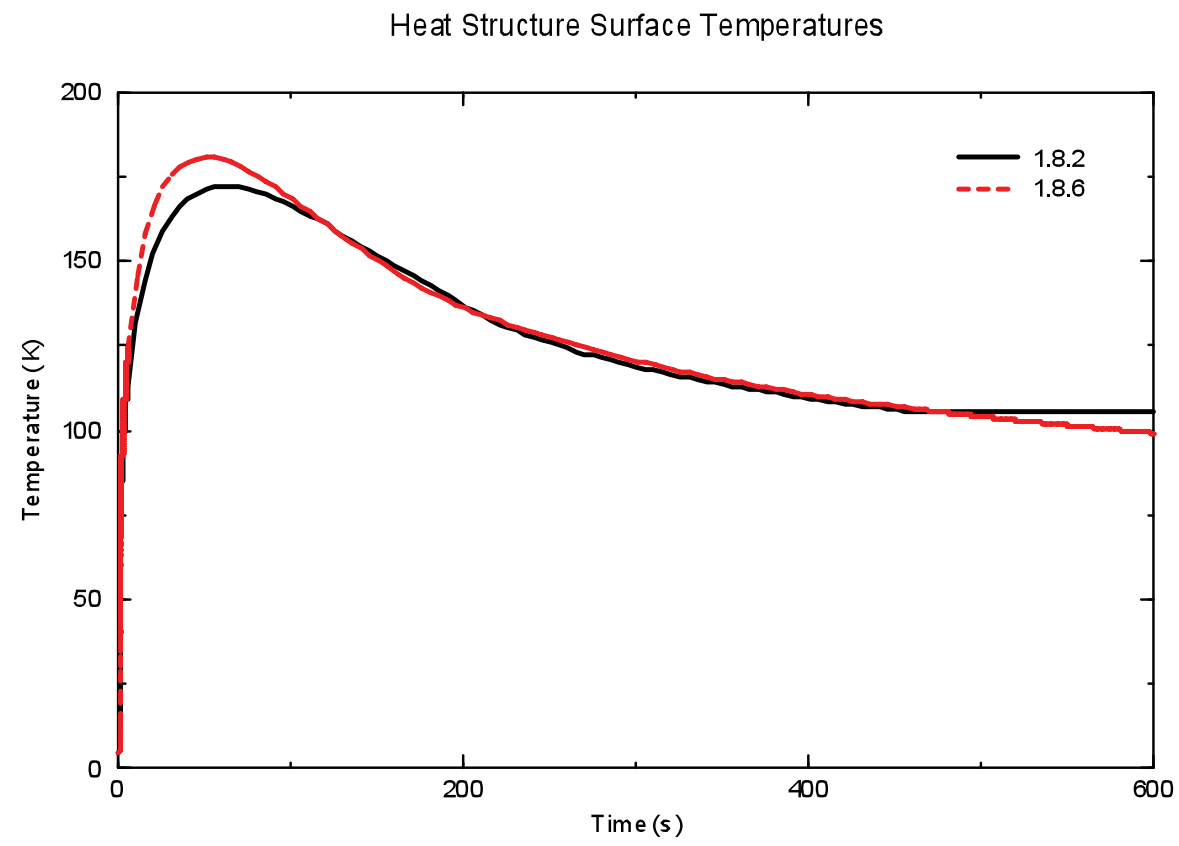

Figure 61. Magnet heat structure front surface temperature. 


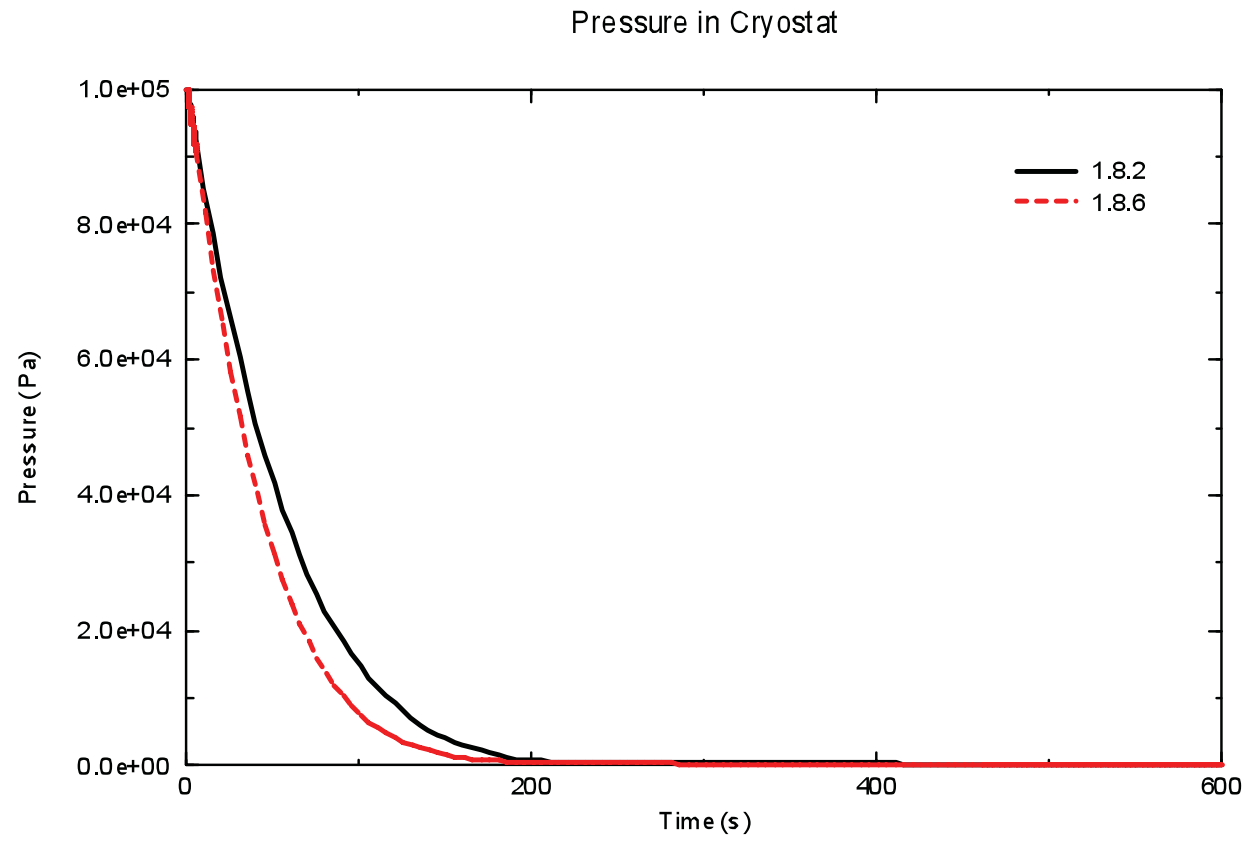

Figure 62. Cryostat pressure.

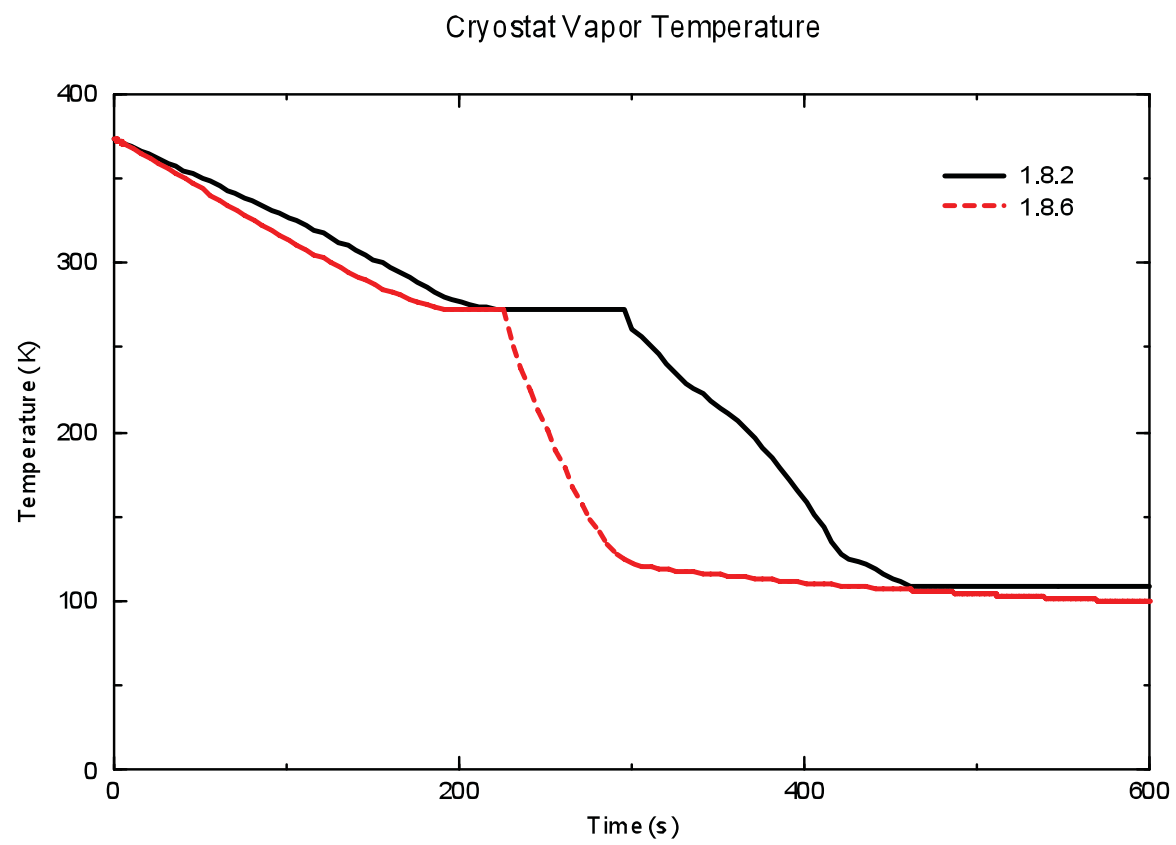

Figure 63. Cryostat vapor temperature. 


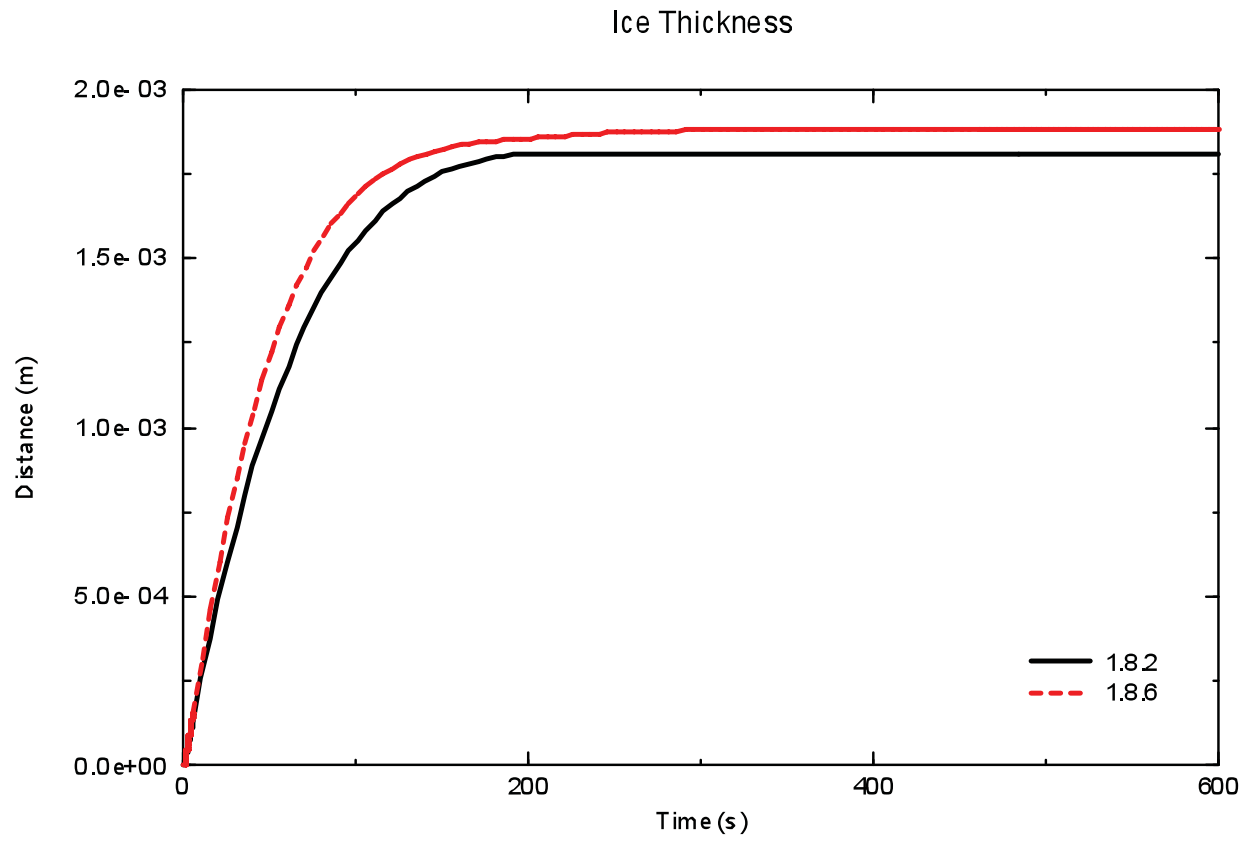

Figure 64. Ice layer thickness on magnet heat structure.

Heat Structure vs. Film Temperature in MELCOR 1.8.6

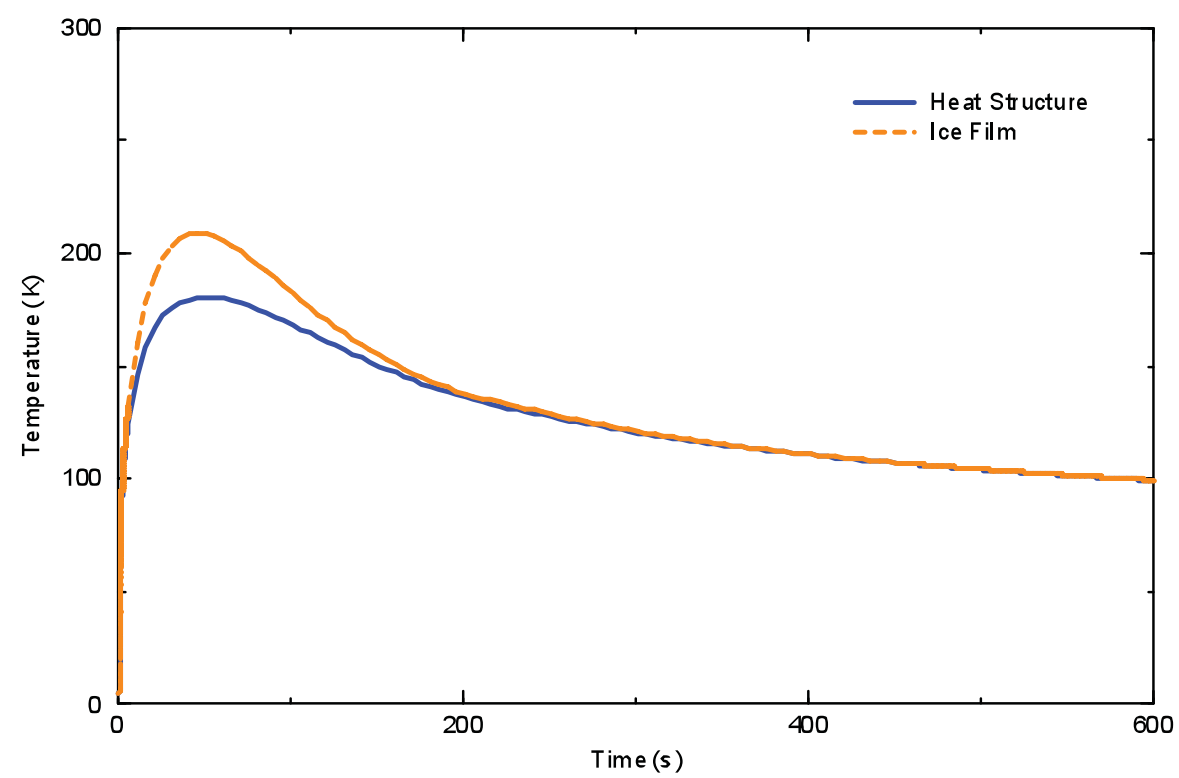

Figure 65. Heat structure surface and ice film temperatures in MELCOR 1.8.6. 


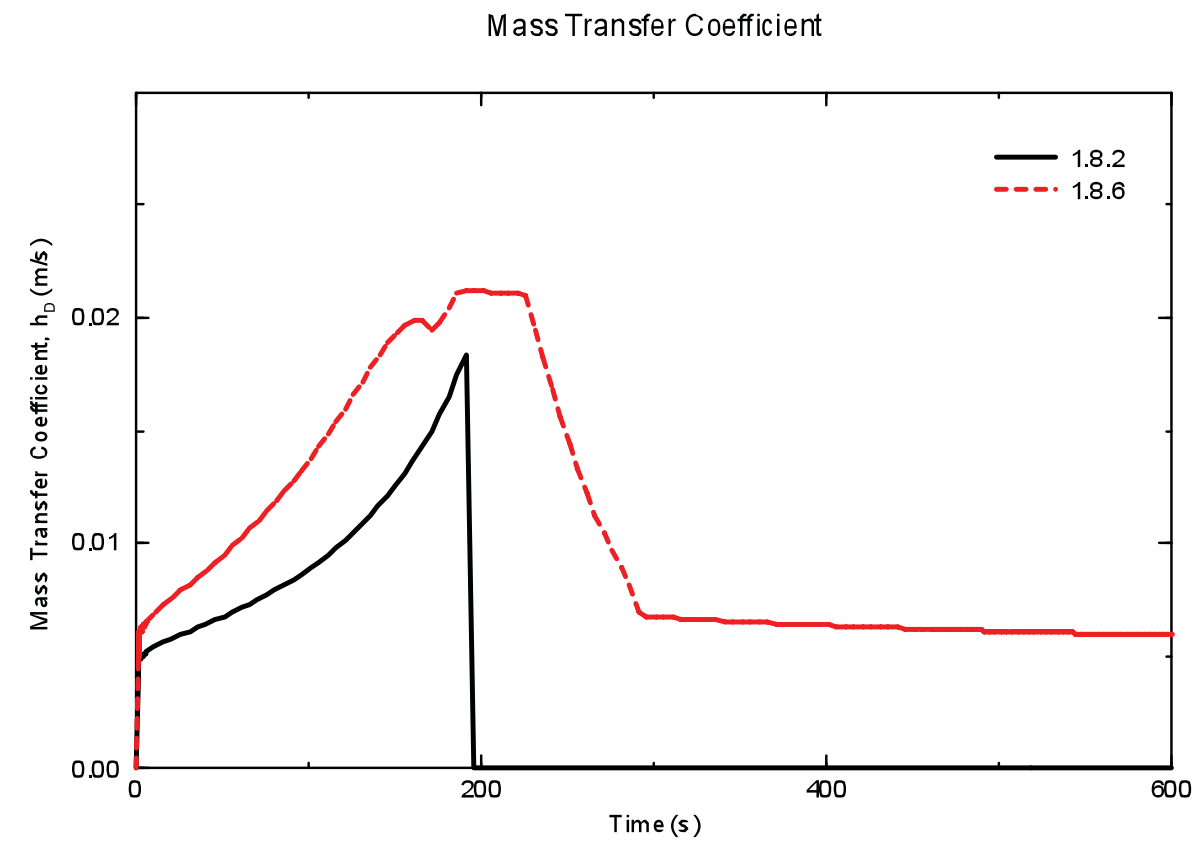

Figure 66. Mass transfer coefficient for ice layer freezing.

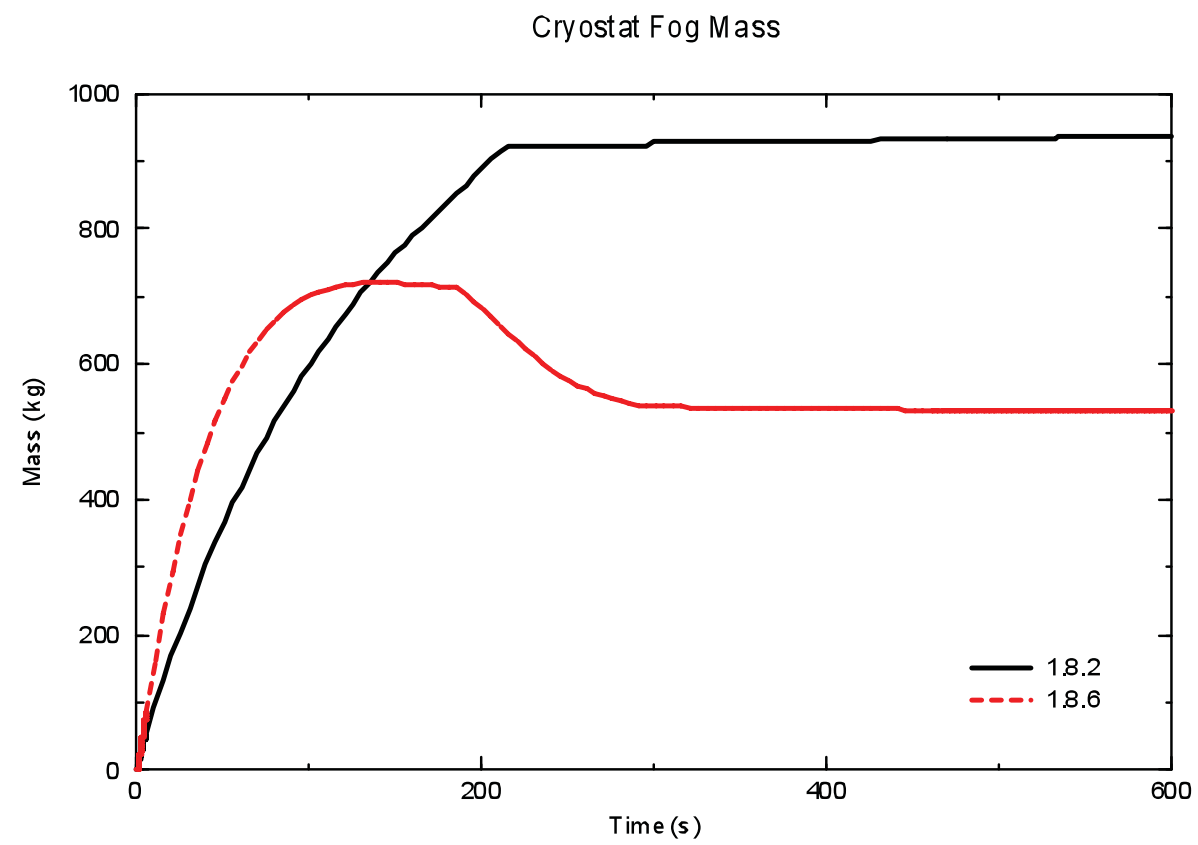

Figure 67. Cryostat fog mass. 


\subsection{Air Condensation Test Problem}

\subsubsection{Air Condensation Test Problem Model Description}

The test problem for the air condensation model is the same as that for the single control volume water freezing test problem (Figure 60), but air has replaced the steam in the control volume.

\subsubsection{Air Condensation Test Problem Results}

The results of the comparison between the fusion pedigreed version of MELCOR 1.8.2 and the fusion version of MELCOR 1.8.6 for this test problem are contained in Figures 68 through 75. Figures 68-70 contain pressures within the cryostat volume; MELCOR 1.8.6 predicts slightly lower pressures, for Nitrogen in particular. This was believed to be due to changes in the condensation model of MELCOR 1.8.6: Figures 7173 illustrate the significant differences in condensation. In order to ascertain what effect the condensation model was having on the problem, the MELCOR 1.8.6 condensation model was backported to MELCOR 1.8.2. The results from this case are shown in green in the figures below, where it is apparent that discrepancy is indeed due to changes in the condensation model. As seen in Figure 73, the condensed nitrogen mass increases throughout in the new model to almost $10,000 \mathrm{~kg}$, while it peaks and then decreases to about $6,000 \mathrm{~kg}$ in the earlier model. The change accounts for differences observed in temperatures as well as pressures; MELCOR 1.8.2 with the backported condensation model better matches MELCOR 1.8.6 for both the cryostat air temperature (Figure 74) and magnet heat structure temperature (Figure 75). The front surface temperature, on which the air condenses, peaks at 145 seconds with a temperature of $53.6 \mathrm{~K}$ using pedigreed MELCOR 1.8.2, 54.9 K for MELCOR 1.8.6, and 54.3 for MELCOR 1.8.2 with the backport.

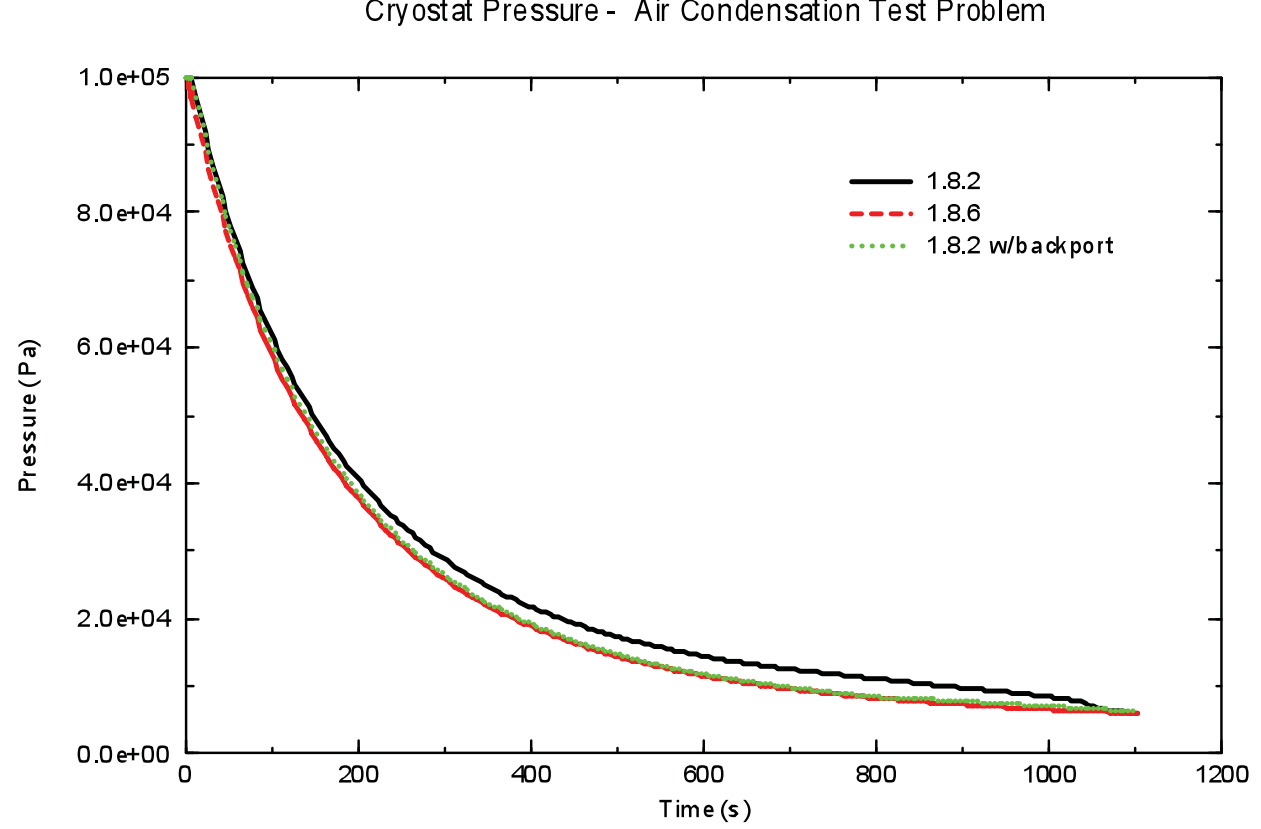

Figure 68. Cryostat pressure. 


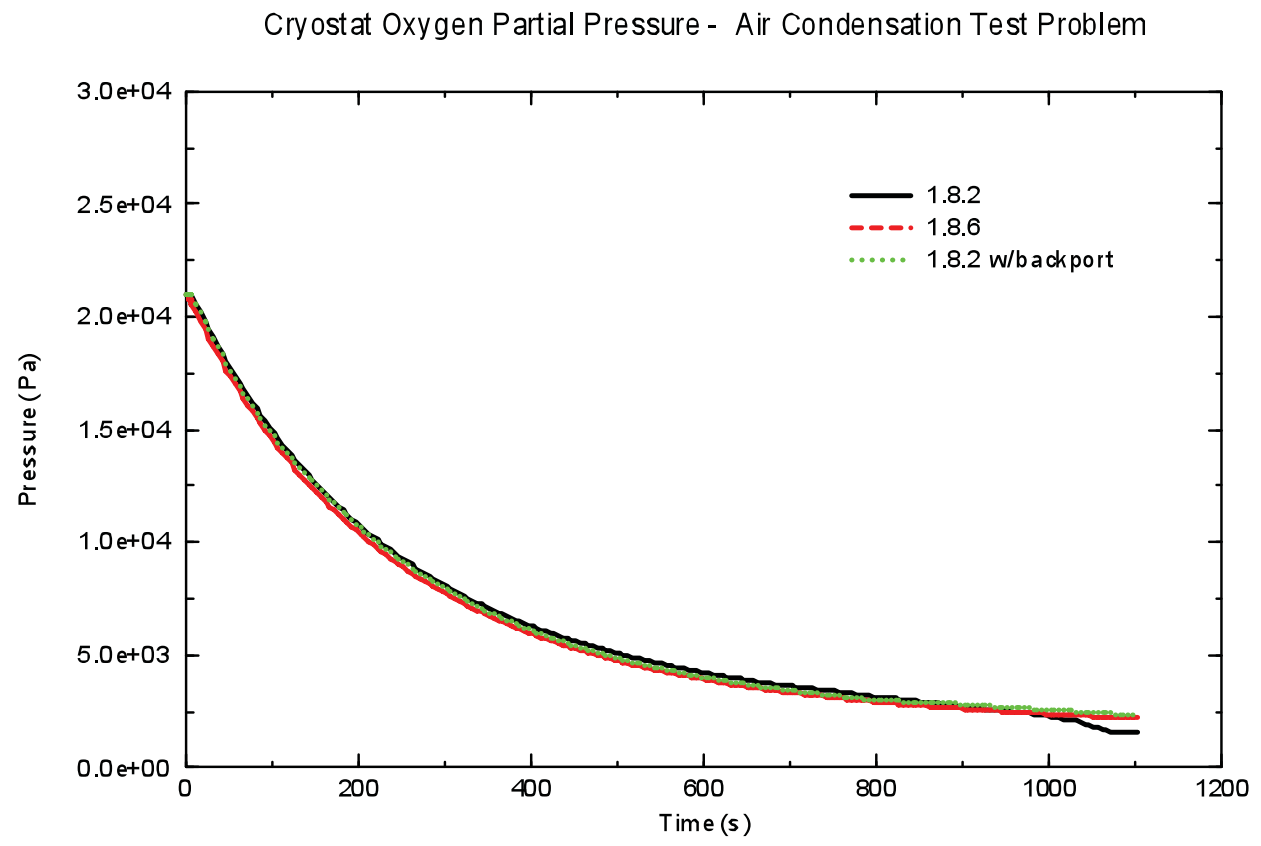

Figure 69. Cryostat oxygen partial pressure.

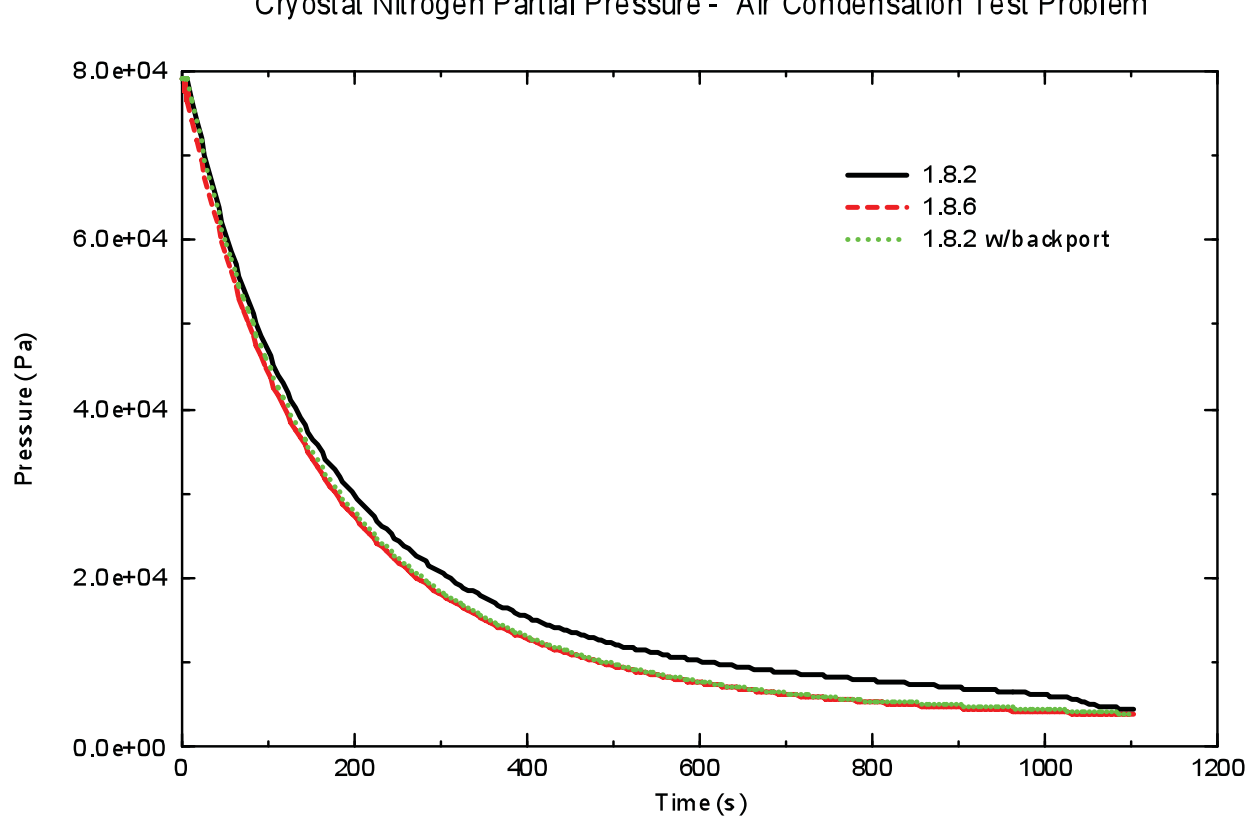

Figure 70. Cryostat nitrogen partial pressure. 


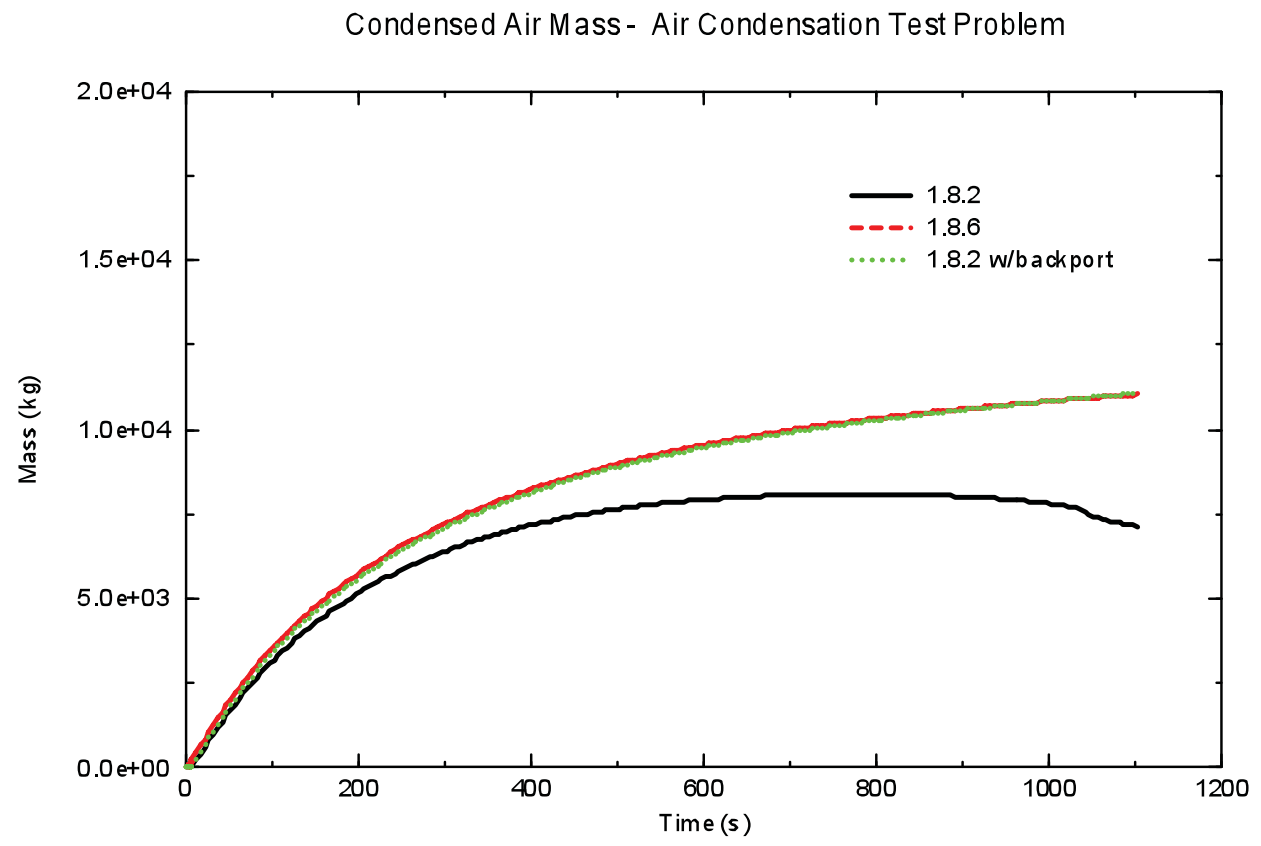

Figure 71. Condensed air mass.

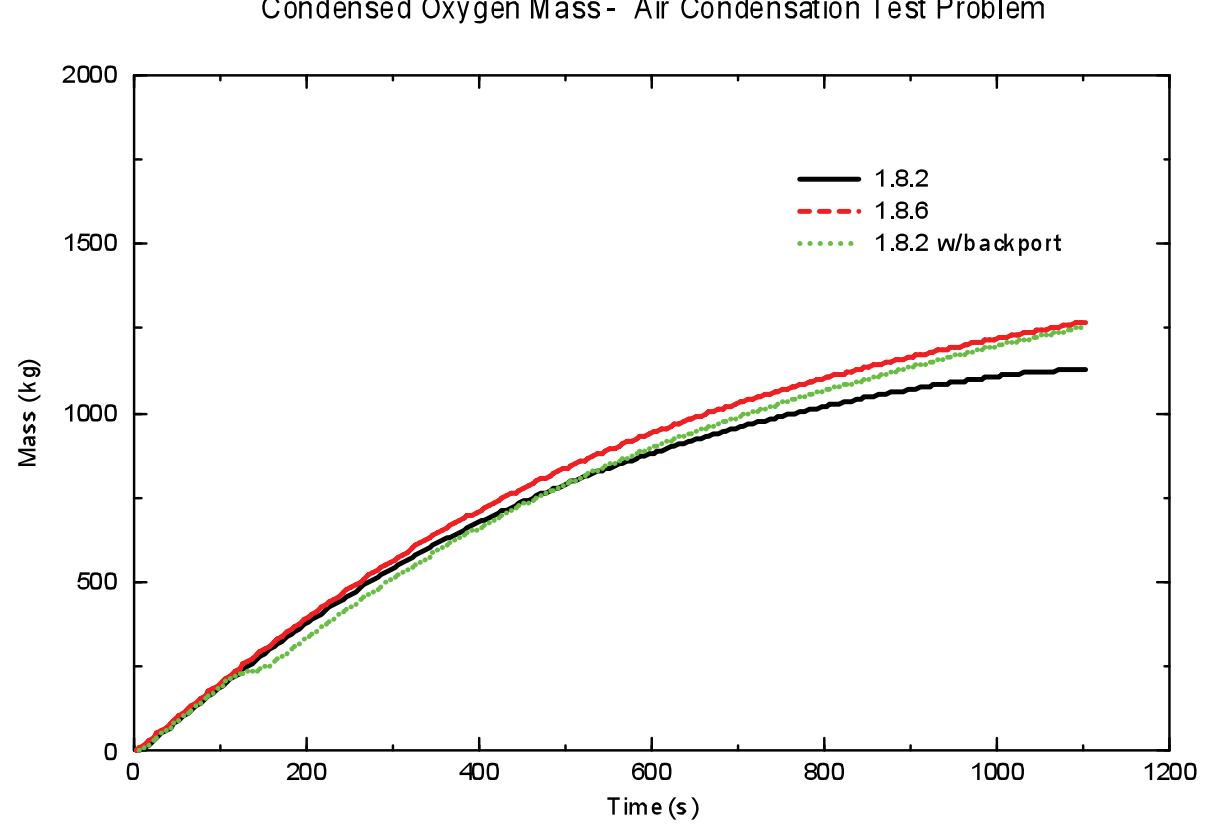

Figure 72. Condensed oxygen mass. 


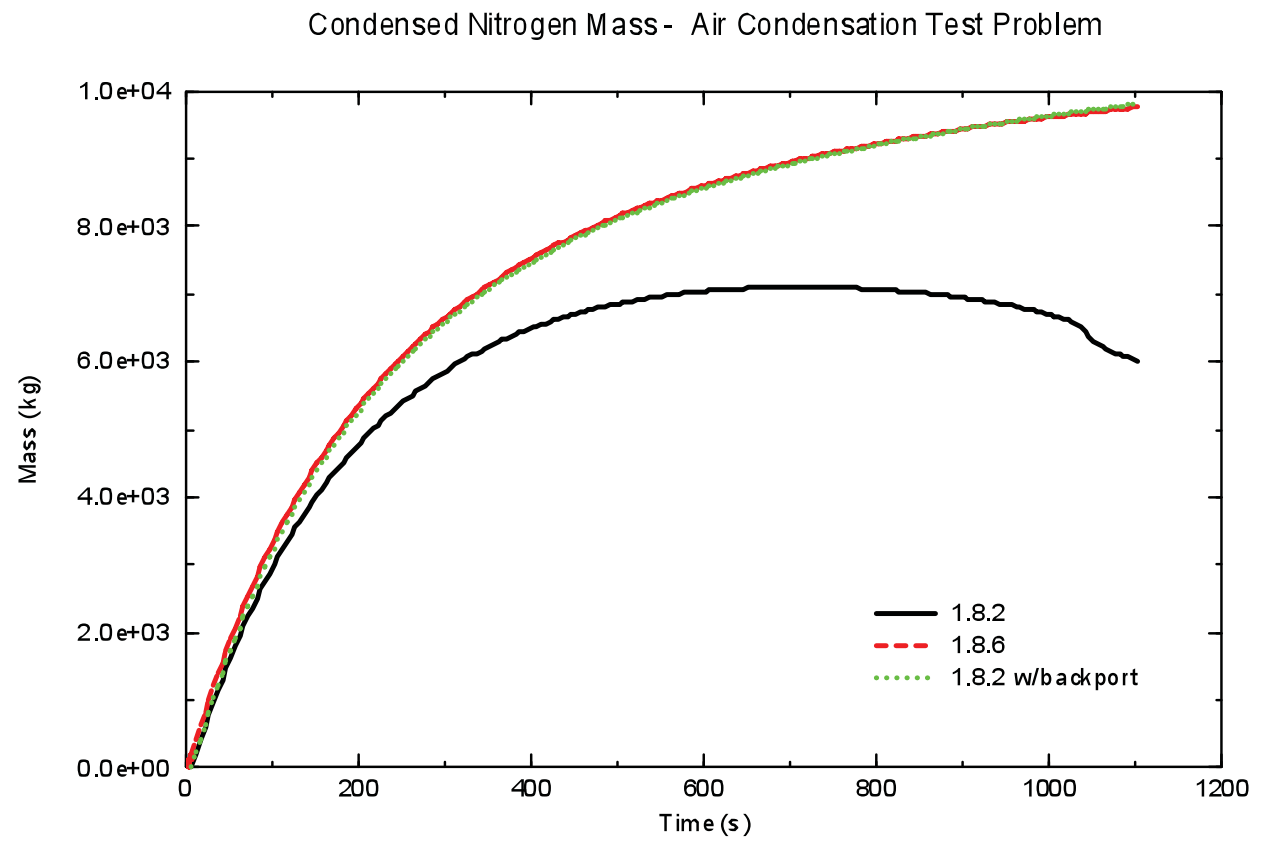

Figure 73. Condensed nitrogen mass.

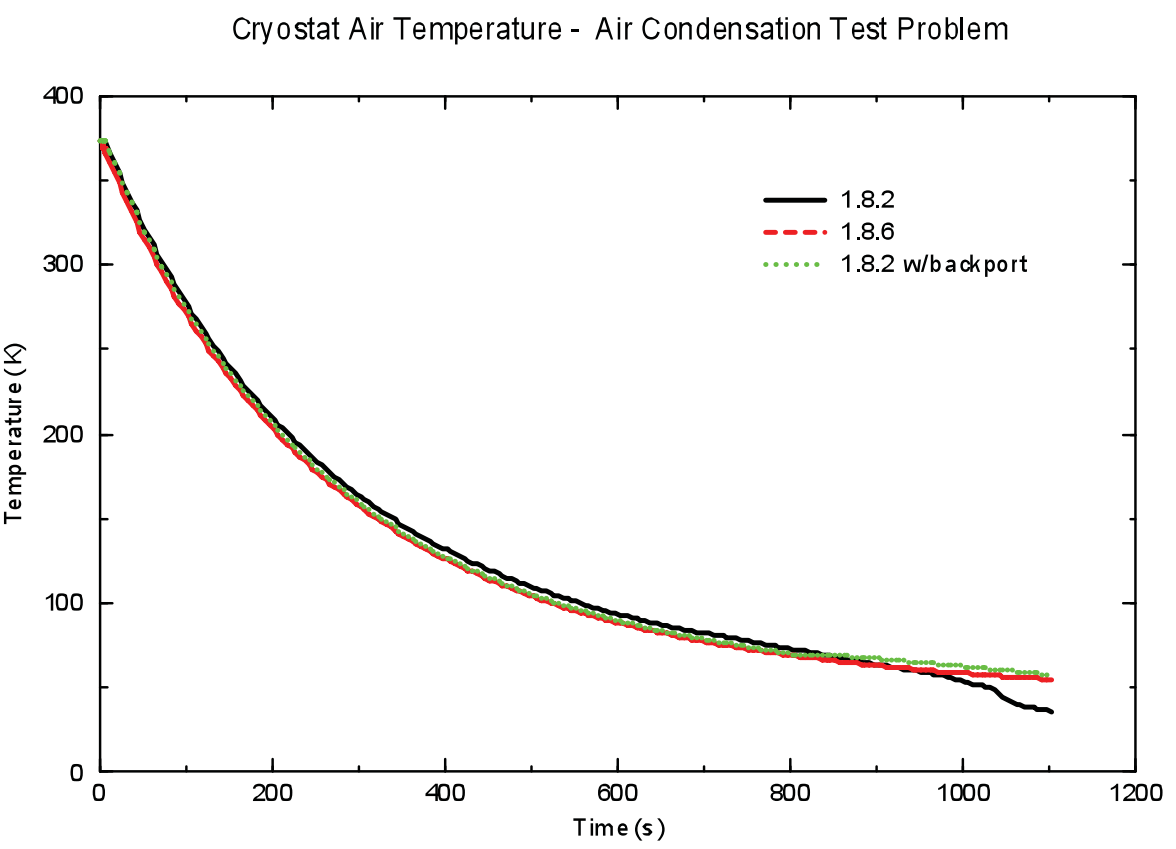

Figure 74. Cryostat air temperature. 


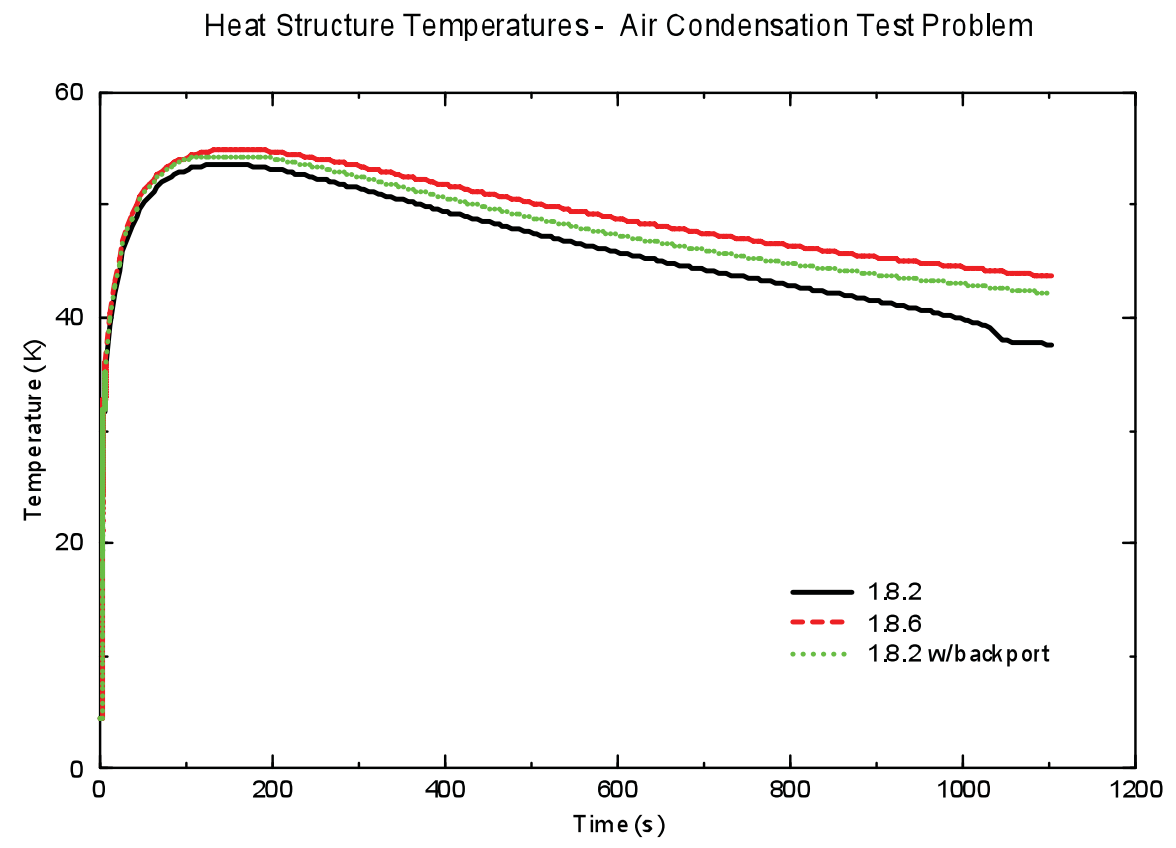

Figure 75. Temperatures at the front surface of the magnet heat structure.

\subsection{Steam Oxidation Test Problem}

This test problem, as described in [4] and repeated here for clarity, consists of one control volume and two heat structures as depicted in Figure 76. A single control volume model was developed that has a volume of $3650 \mathrm{~m}^{3}$ and contains two heat structures clad with $0.005 \mathrm{~m}$ of plasma facing component (PFC) material. These heat structures are stainless steel with a void fraction of $50 \%$, thickness of $0.5 \mathrm{~m}$, and surface areas of $400 \mathrm{~m}^{2}$ and $800 \mathrm{~m}^{2}$. These dimensions are similar to those of the inboard and outboard first wall (FW)/blanket structures, and vacuum vessel, of the 1995 ITER design.

Three nodes were used to model the PFC material per heat structure, with an initial temperature of $1400 \mathrm{~K}$. Three nodes were also used to model the SS FW/blanket structure, with initial temperatures of $500 \mathrm{~K}, 750 \mathrm{~K}$, and $1200 \mathrm{~K}$ going from the back to the front of the heat structure, respectively. The vacuum vessel volume was initially filled with a saturated steam/water mixture at a pressure of $1.0 \mathrm{E}+05 \mathrm{~Pa}$ and a mass of $1.05 \mathrm{E}+05$ $\mathrm{kg}$. 


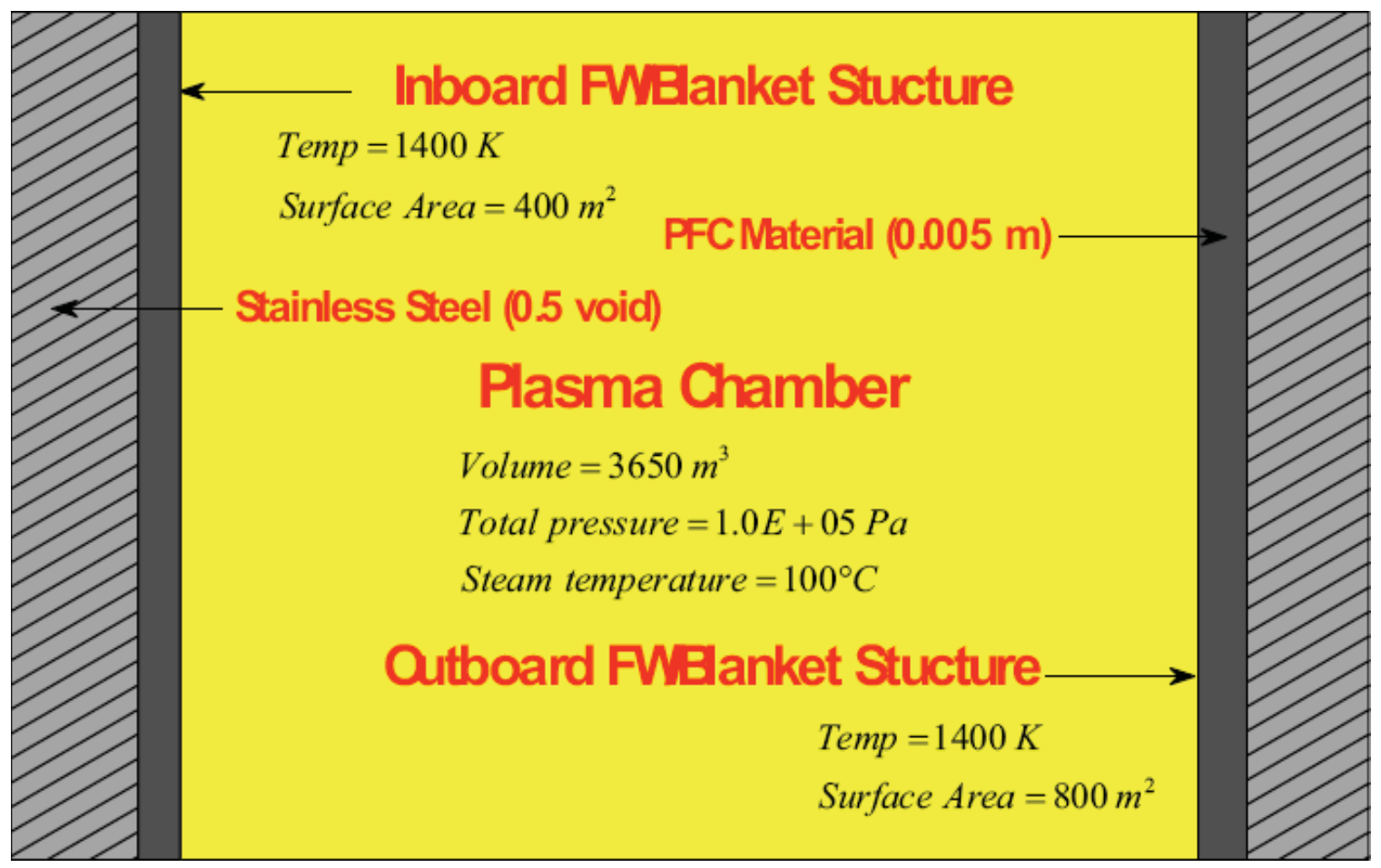

Figure 76. Schematic of the MELCOR model developed for the oxidation model test problem.

\subsubsection{Steam Oxidation Test Problem Results for Beryllium}

Figure 77 contains the FW surface temperature for both versions of the code. Viewing Figure 78 we see basically identical results, which is to be expected given that the oxidation models have not changed from pedigreed MELCOR 1.8.2 to MELCOR 1.8.6.

Figure 79 contains the hydrogen generation history due to the interaction of the hot beryllium surface with the steam. At approximately 500 seconds, the PFC beryllium is completely consumed for both MELCOR 1.8.2 and MELCOR 1.8.6. Again, both versions are in excellent agreement. 


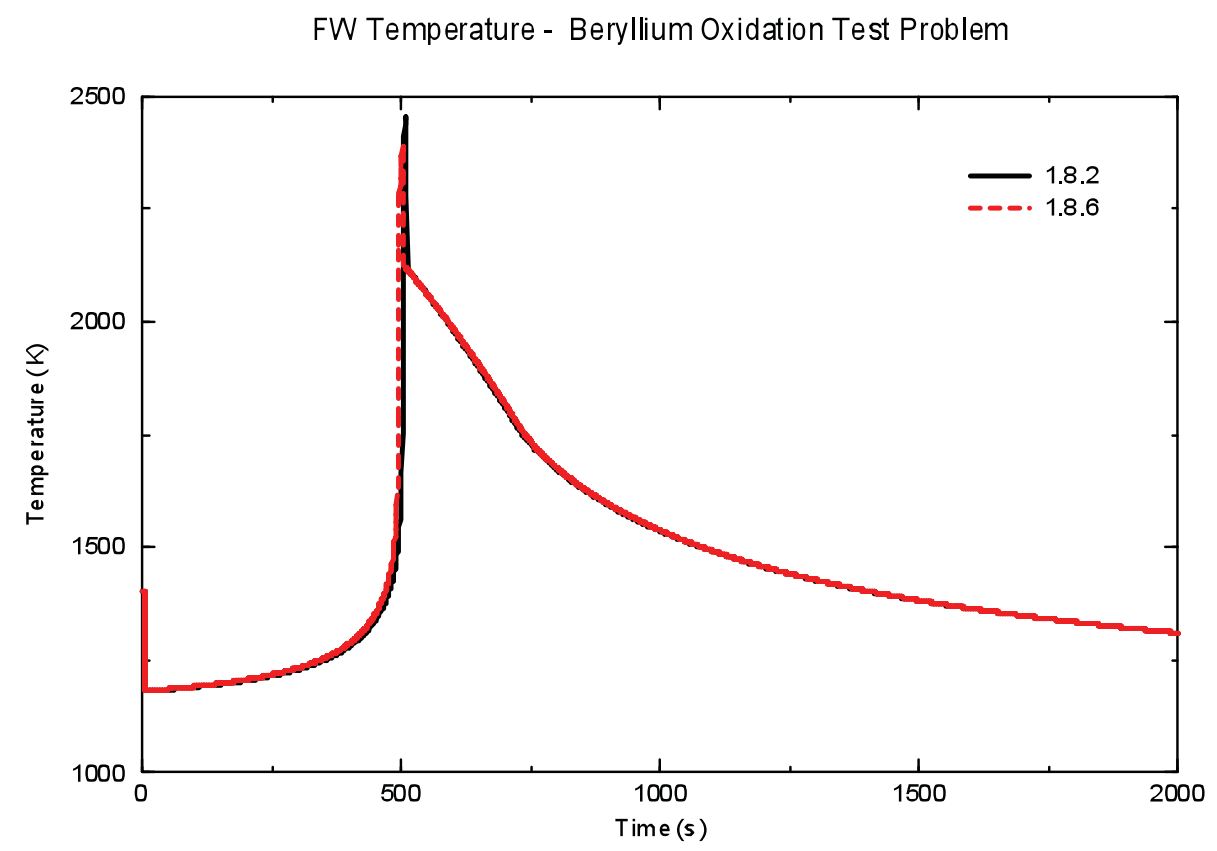

Figure 77. FW temperature with beryllium as PFC.

Hydrogen Generation - Beryllium Oxidation Test Problem

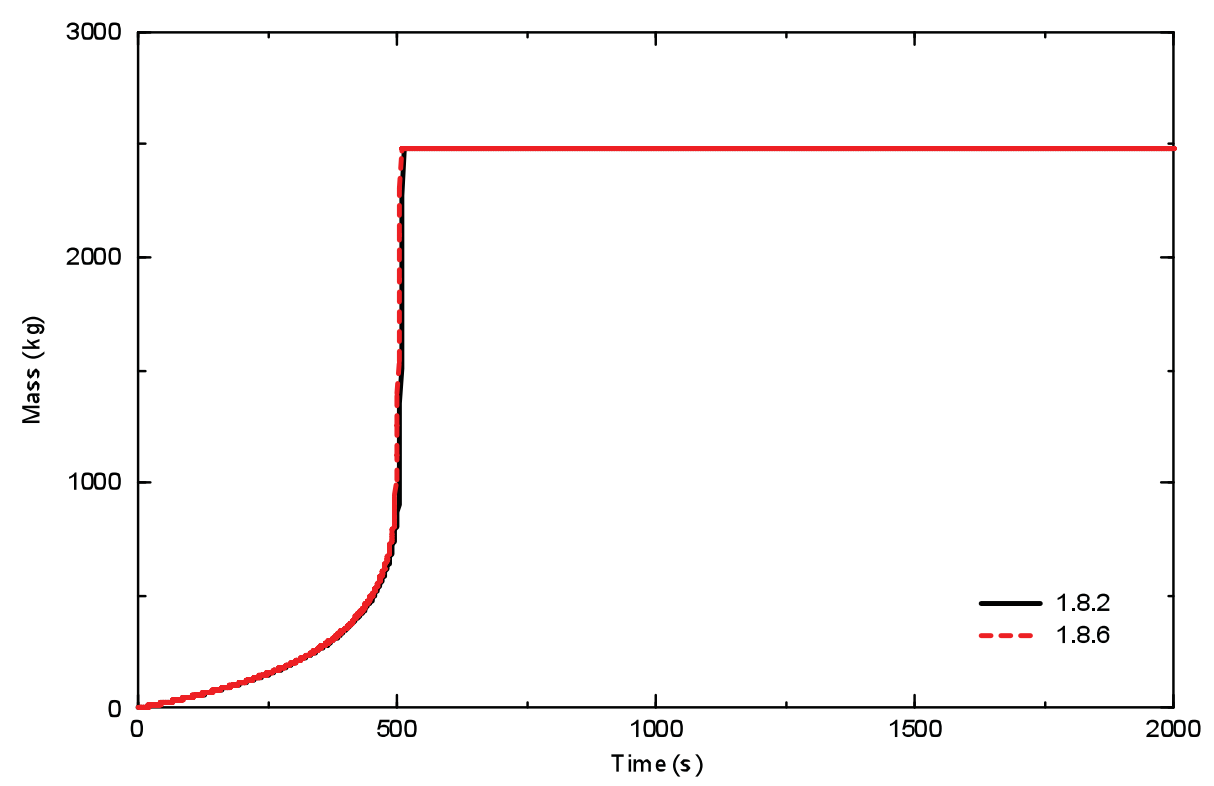

Figure 78. Total hydrogen produced by oxidation with beryllium as PFC. 


\subsubsection{Steam Oxidation Test Problem Results for Tungsten}

The results for the case of steam oxidation of tungsten are presented in Figures 79 and 80 . Figure 79 contains the surface temperature history of the FW using tungsten as the PFC. As with the beryllium results, the oxidation model has not changed, and we see close agreement between both versions of the code.

The histories of the hydrogen generation for this case are presented in Figure 80. The total mass of hydrogen increases for the entire 2000 seconds to over $20 \mathrm{~kg}$, and both versions of the code continue to be in good agreement.

FW Temperature - Tungsten Oxidation Test Problem

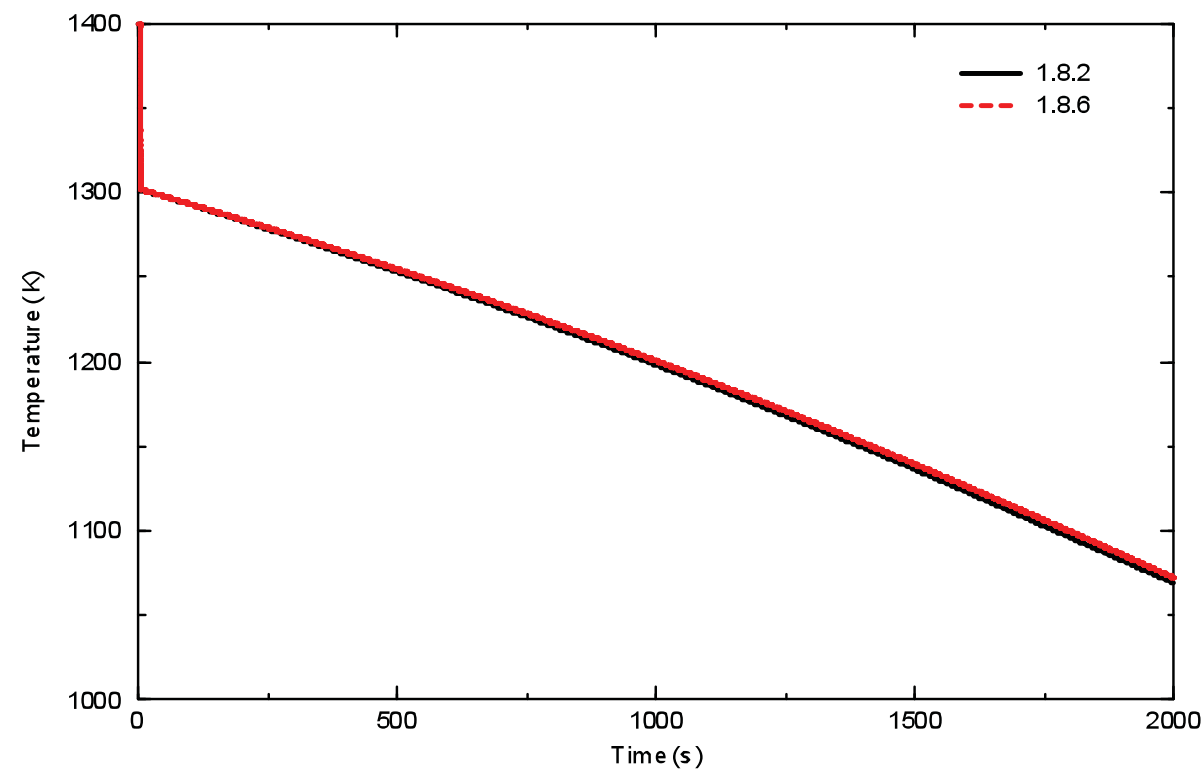

Figure 79. FW temperature with tungsten as PFC. 


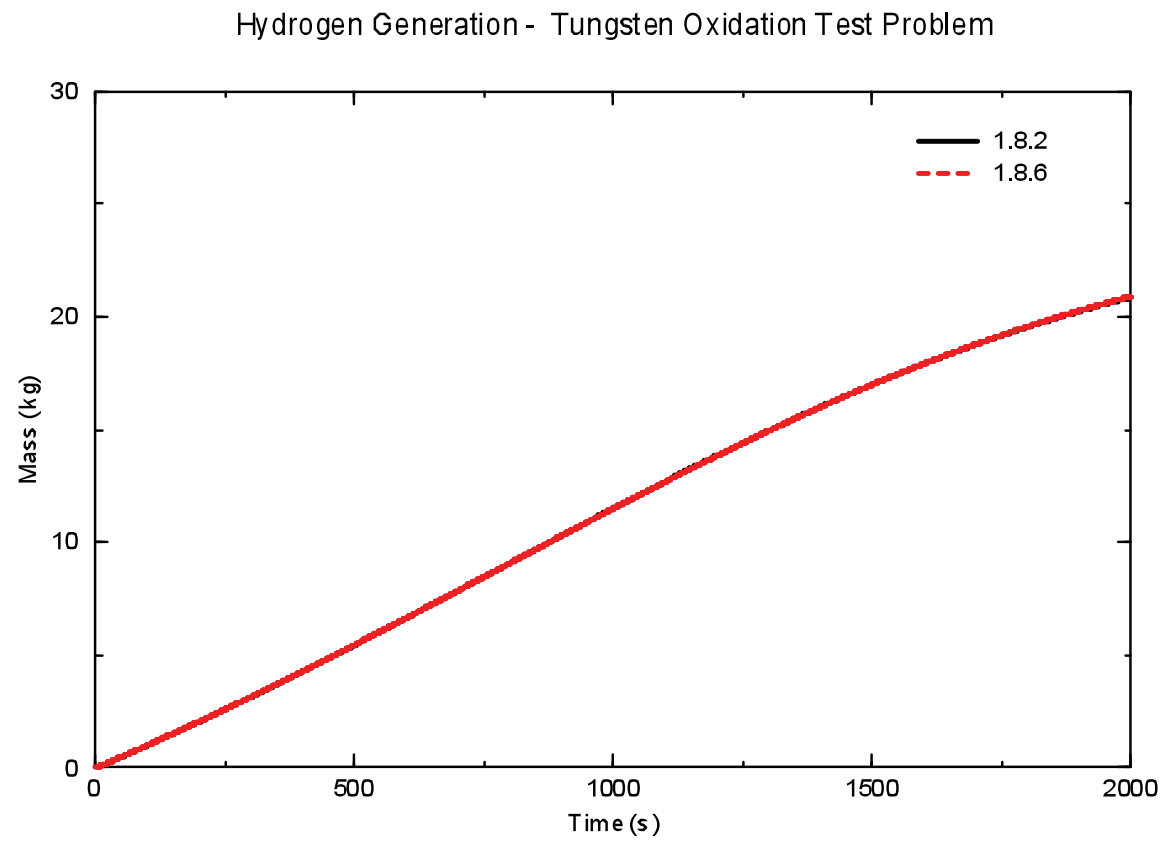

Figure 80. Total hydrogen produced by oxidation with tungsten as PFC.

\subsection{Enclosure Thermal Radiation Heat Transport Model}

A thermal radiation heat transport capability was added to the fusion version of MELCOR 1.8.2 in 1997. This model was added because the existing MELCOR radiation model did not allow for the direct exchange of radiant power between walls of an enclosed structure, or account for the presence of an atmosphere between these components that absorbs and re-radiates this power. The model, model equations, and a test problem to verify that the model was implemented correctly into the MELCOR 1.8.2 code are described in [6]. A listing of the test problem input deck used to verify the model was also included in [6].

\subsubsection{Radiation Test Problem Model Description}

Figure 81 contains a schematic of the radiation test problem, which is an enclosure composed of four walls of different initial temperatures and emissivities, and an absorbing gaseous atmosphere. The enclosure walls are assumed to be $5 \mathrm{~mm}$ thick stainless steel heat structures with a depth of $1 \mathrm{~m}$. The boundary conditions for the back surface of the walls are adiabatic. Heat transfer from the front surface of these walls was only through the net enclosure radiation model. 


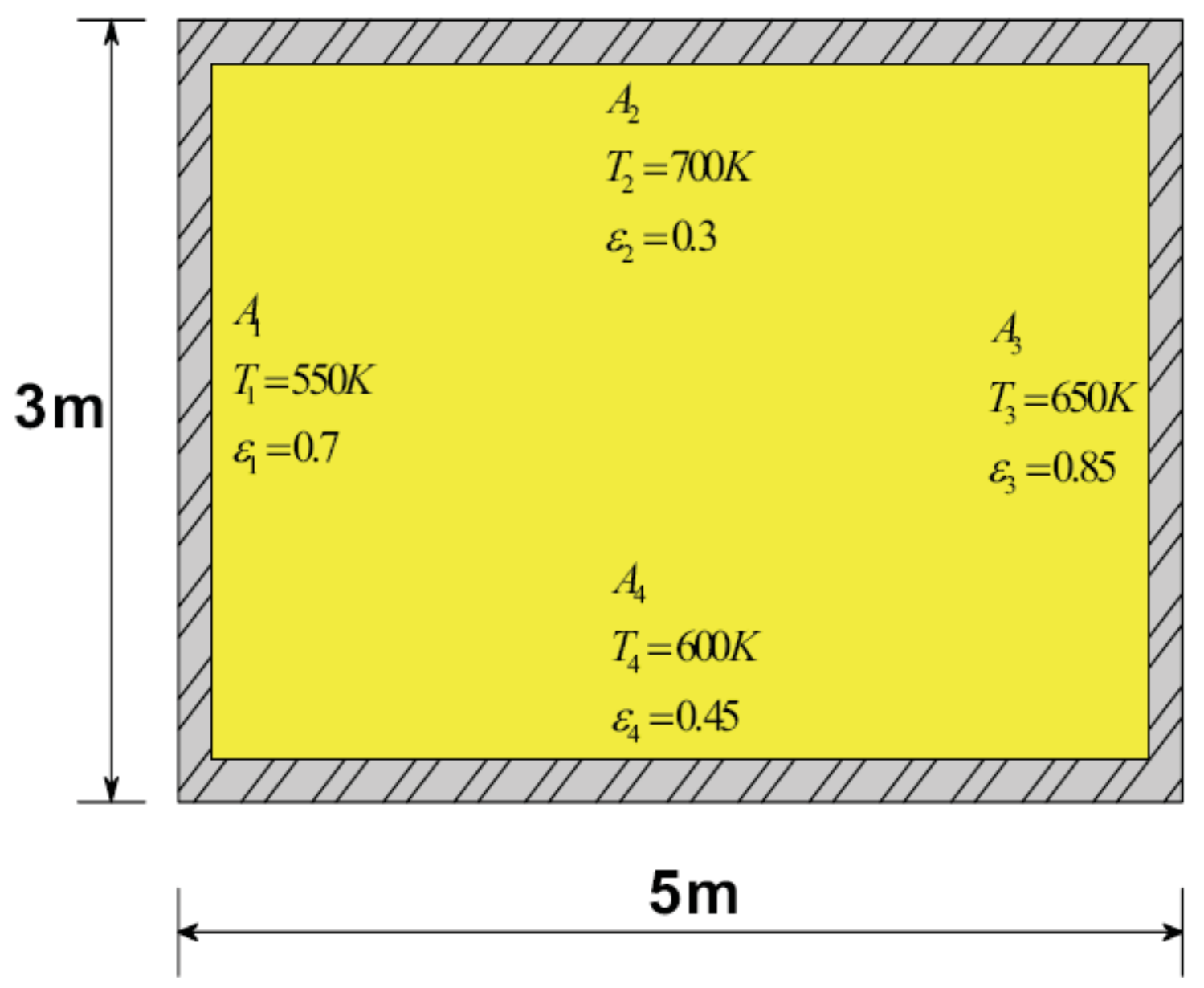

Figure 81. Schematic of the enclosure radiation test problem.

\subsubsection{Radiation Test Problem Results}

Figure 82 contains wall surface and gas temperatures for an absorbing atmosphere enclosure out to a time of 3000 seconds. For the conditions of this enclosure the gas emissivity ranges from 0.18 to 0.22 . The enclosure temperatures show the gas heats up and the wall temperatures converge to about $620 \mathrm{~K}$ by 3000 seconds. This demonstrates that the enclosure net radiation heat transfer model is transferring energy both between the walls and the walls and gas. The temperatures in MELCOR 1.8.6 are exactly the same as for the pedigreed MELCOR 1.8.2. This is what one would expect since the enclosure radiation model and coding have not changed since it was initially put into the fusion version of MELCOR 1.8.2. 


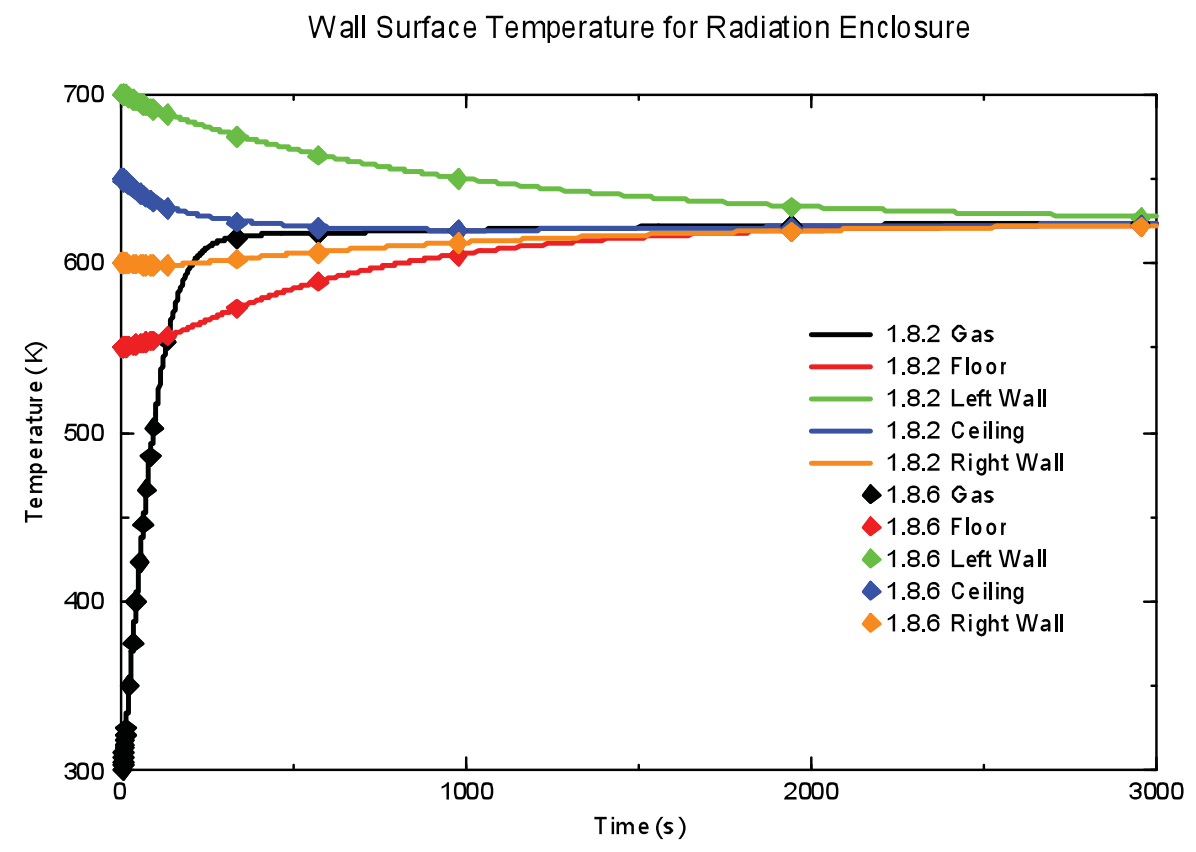

Figure 82. Wall surface and atmosphere temperature in the enclosure radiation test problem.

\section{Conclusions}

A number of additions to MELCOR 1.8.2 for fusion have been ported to MELCOR 1.8.6. Both codes have been compared on a series of test problems, and it has been demonstrated that the fusion modifications work properly in MELCOR 1.8.6 and compare well with results from the pedigreed 1.8.2 code. Though differences between the modified 1.8.2 and 1.8.6 codes sometimes exist, these are generally due to changes in the standard MELCOR code between these versions, with the updates to standard MELCOR 1.8.6 presumably giving better results.

\section{References}

1. B. J. Merrill, et al., Assessment of CONTAIN and MELCOR for Performing LOCA and LOVA Analyses in ITER, EGG-FSP-11386, Idaho National Engineering Laboratory Report, September 1994.

2. R. L. Moore and R.C Martineau, Documentation of New MELCOR Flow Boiling, and Diffusion Coefficient Subroutines, ITER/US/97/TE/SA-6, Idaho National Engineering Laboratory, May 12, 1997.

3. B. J. Merrill and D.L. Hagrman, MELCOR Aerosol Transport Module Modifications for NSSR1, ITER/US/96/TE/SA-03 (INEL-96/0081), Idaho National Engineering Laboratory, March 1996.

4. B. J. Merrill, Initial Modifications to the MELCOR Code, ITER/US/95/TE/SA-18, Idaho National Engineering Laboratory, June 30, 1995.

5. B. J. Merrill, Recent Updates to the MELCOR 1.8.2 Code for ITER Applications, INL/EXT-0712493, Idaho National Laboratory, April 2007. 
6. B.J. Merrill, An Enclosure Thermal Radiation Heat Transport Model for the MELCOR code, ITER/US/97/TE/SA-04, Idaho National Engineering Laboratory, January 31, 1997.

7. R. L. Moore, Pedigree Analysis of the MELCOR 1.8.2 Code to be use for ITER's Report Preliminary on Safety, Idaho National Laboratory Report, INL/EXT-07-12856, June 2007.

8. R. O. Gauntt, et al., MELCOR Computer Code Manuals Vol. 1: Primer and Users' Guide Version 1.8.6, NUREG/CR-6119, Vol. 1, Rev.3, Sandia National Laboratory, September 2005.

9. Generic Site Safety Report (GSSR) Volume VII, Analysis of Reference Events, G 84 RI 6 01-0710 R 1.0 ITER report, 2001.

10. R.L. Moore, Status Report on an ITER ITA on Comparison of MELCOR 1.8.5 Results to MELCOR 1.8.2 Results for a Select Set of Accident Analysis Cases Relevant to ITER FEAT, EDF-5470, Idaho National Laboratory, January 14, 2005. 